\title{
Inventaire de la bibliothèque personnelle de Gérard Bessette
}

\author{
Steven Urquhart \\ Université de Lethbridge
}

Effectué de façon plus ou moins hebdomadaire au cours de l'année qui a suivi le décès de Gérard Bessette en février 2005, l'inventaire de sa bibliothèque personnelle se veut le plus complet possible. Je ne peux toutefois pas en garantir l'exhaustivité, car il est impossible de dire que l'inventaire comprend tous les titres que Bessette ait jamais possédés. En témoignent certaines lacunes évidentes, comme l'absence d'Une saison dans la vie d'Emmanuel alors que tous les autres ouvrages de Marie-Claire Blais publiés jusqu'en 1979 s'y trouvent.

Pour des raisons pratiques, il n'a pas toujours été facile de regrouper tous les ouvrages ayant appartenu à $\mathrm{M}$. Bessette. La plupart se trouvaient au sous-sol, là où il écrivait, mais d'autres — dont parfois les livres les plus précieux, comme les éditions 
de luxe des romans ayant gagné le Prix du Gouverneur Général - se trouvaient dans la bibliothèque de la chambre à coucher. En outre, Mme Bessette, ancienne professeure et bibliothécaire à la faculté de droit de l'Université Queen's, possédait ellemême un nombre de livres impressionnant. Il y avait dans la chambre à coucher, par exemple, une édition luxueuse des œuvres complètes de Freud, qu'elle disait avoir hérité de sa sœur psychiatre, mais que M. Bessette pouvait évidemment lire à loisir.

L'inventaire n'inclut pas par ailleurs les différentes éditions des œuvres de Gérard Bessette lui-même, dont certaines qu'il avait en de multiples exemplaires, ainsi que les traductions de ses ouvrages (dont une du Libraire en tamoul) et différentes éditions de luxe ${ }^{1}$.

1 Not For Every Eye, trad. Glen Shortliffe, Toronto, Macmillan, 1962. Couverture en cuir et une carte de l'éditeur (Macmillan) avec des vœux de Noël et une signature illisible. Éditions reliées de L'Incubation, trad. Glen Shortliffe, Toronto, Macmillan, 1967, et de The Brawl, trad. Marc Lebel and Ronald Sutherland, Montreal, Harvest House, 1976. Édition de luxe de L'Incubation, Montréal, Librairie Déom (coll. "Nouvelle prose"), 1965. Couverture en cuir noir et rouge, dans un étui, avec une page ajoutée après la page-titre où il est inscrit: "Ce livre a mérité pour son auteur un prix du Gouverneur général pour la littérature en 1965”. Une édition reliée de Les Images en Poésie Canadienne-Française, Montréal, Éditions Beauchemin, 1960. Une édition de luxe du Cycle, Montréal, Éditions du Jour, 1971, dans un étui, avec une couverture en cuir vert, les lettres sur la couverture et le bord des pages en couleur or, et une page avant la page-titre où il est inscrit, "Ce livre a valu à son auteur un prix littéraire du Gouverneur général pour l'année 1971", suivi de la signature du Gouverneur général, Roland Mitchener. Une édition reliée (couverture brune, avec lettrage doré), de La Garden-Party de Christophine, Montréal, Québec/Amérique, 1980. Puis finalement, ce véritable objet de collection qu'est un volume relié, couverture en brun avec lettrage doré portant le titre "Gérard Bessette. Le Cycle. Québec/Amérique", mais avec une page de faux-titre correspondant au livre qui suit où il est écrit La GardenParty de Christophine, Montréal, Québec/Amérique, 1980. 
La réalisation de l'inventaire a été soumise à diverses contraintes de temps et de circonstances, dont mon départ de Kingston en juillet 2006 et le déménagement ultérieur de Mme Bessette, ce qui a entraîné la vente de la maison et la dispersion subséquente et définitive de la collection.

Imparfait peut-être, cet inventaire permet toutefois de voir l'immense bagage culturel et littéraire de ce professeur, critique, poète et romancier et donc de mieux comprendre son œuvre. Il devrait aider les futurs chercheurs en donnant une idée des ouvrages que Gérard Bessette avait jugé utile d'avoir sous la main, afin peut-être de les consulter avant de prendre la plume pour écrire.

Abraham, Karl. Psychanalyse et Culture. Paris : Payot, 1966.

Abry, Émile, Charles Audic, et Paul Crouzet. Histoire illustrée de la littérature française. Paris : Didier, 1942.

L'Action universitaire, revue trimestriel. Vol. $15, \mathrm{n}^{\circ} 1$. Octobre 1948. Avec "Analyse d'un poème de Nelligan », p. 62-79. L'auteur est identié comme « Gérard Bessette, Département de français, Université de Saskatchewan ».

-. Vol. 18, no 4. Juillet 1952. Article de Gérard Bessette sur «Bonheur d'occasion », p. 53-74.

-. Vol. 20, no 3. Avril 1954. "Connaît-on Benjamin Constant : Le plus grand roman français du XIXe siècle », p. 15-22, avec la signature « Gérard Bessette, Duquesne University.

ADAM, Antoine. Verlaine. Paris : Hatier, 1953.

Adler, Alfred. Connaissance de l'homme. Paris : Payot, 1949. 
—. Le Tempérament nerveux. Paris : Payot, 1955.

-. Pratique et théorie de la psychologie individuelle comparée. Paris : Payot, 1961.

Alain [Émile Chartier]. Préliminaires à l'esthétique. Paris : Gallimard, 1939.

—. Propos sur l'esthétique. Paris : PUF, 1949.

—. Politique. Paris : PUF, 1952.

AlbAlat, Antoine. L'Art d'écrire enseigné en vingt leçons. Paris : Armand Colin, 1956.

AlbÉRÈS, R. M. L'Aventure intellectuelle du XXe siècle. Panorama des littératures européennes. Paris : Albin Michel, 1959.

—. Bilan littéraire du XXe siècle. Paris : Aubier-Montaigne, 1962.

—. Histoire du roman moderne. Paris : Albin Michel, 1962.

—. Le Roman d'aujourd'hui. Paris : Albin Michel, 1970.

Allard, Jacques. Zola, le chiffre du texte. Montréal : Presses de l’Université du Québec, 1978.

—. Le Roman du Québec. Montréal : Québec/Amérique, 2000.

AlYN, Marc, dir. Poètes du XVIIe siècle. Paris : J'ai lu, 1962.

Anderson, E.W., and W.H. Trethowan. Psychiatry. London: Baillière, Tindall \& Cassell, 1967.

Anoullh, Jean. Beckett. New York: Appleton-Century Crofts, 1969.

Anthologie de la poésie française. Tomes IV et V. Montréal : Bernard Valiquette, s.d.

ANZIEU, Didier. Le Corps de l'œuvre; essais psychoanalytiques sur le travail créateur. Paris : Gallimard, 1981.

Apolinaire. Guillaume. Alcools. Poèmes 1898-1913. Paris : Gallimard, 1920. 
—. Les Onze Mille Verges. Montréal: Quintal Associés, coll. «Éros », 1969.

Aquin, Hubert. Prochain Épisode. Montréal : Le Cercle du Livre de France, 1965. (2)

—. Trou de mémoire. Montréal : Le Cercle du Livre de France, 1968. (2)

—. L'Antiphonaire. Montréal: Le Cercle du Livre de France, 1969.

-.Prochain Épisode. Annoté par Gilles Beaudet. Montréal: Éditions du Renouveau-pédagogique, 1969.

—. Point de fuite. Montréal : Cercle du Livre de France, 1971.

—. Neige noire. Montréal : La Presse, 1974.

—. Blocs érratiques. 1977. Montréal : Quinze, 1982. (2)

Aquinas, Thomas. Elementa philosophiae christianae. Tome II. Québec : L'Action sociale, 1925.

Angers, Pierre. Foi et Littérature. Montréal : Beauchemin, 1959.

Arban, Dominique. Dostoïevski par lui-même. Paris : Seuil, coll. «Écrivains de toujours », 1962.

Arc-Lortie, Jeanne d'. La Poésie nationaliste au Canada français (1606-1867).Québec : Presses de l'Université Laval, 1975.

Archambault, Jacques (dir.). Profile of Quebec. Québec: Quebec Government Communications, 1973.

Archambault, Gilles. Les Pins parasols. Montréal : Quinze, 1976.

—. Parlons de moi. Montréal : Stanké, 1980.

Arendt, Hannah. The Recovery of the Public World. Ed. Melvyn A. Hill. New York : St. Martin's Press, 1979.

Aron, Raymond. La Lutte des classes. Paris : Gallimard, 1964. 
Asimov, Isaac. Le Corps. 1963. Verviers : Marabout Université, 1965.

—. Le Cerveau. 1963. Verviers : Marabout Université, 1977. (2)

Association canadienne des éducateurs de langue française. Esquisses du Canada français. Montréal: Fides, 1967.

Atwood, Margaret. Survival. A Thematic Guide to Canadian Literature. Toronto : Anansi Press, 1972.

Aubert de Gaspé, Philippe. Les Anciens Canadiens. 1863. Montréal : Beauchemin, 1960.

Aubert de Gaspé (fils), Philippe. Le Chercheur de trésor ou L'Influence d'un livre. 1837. Québec : Réédition Québec, 1968.

-. Le Chercheur de trésors ou L'Influence d'un livre. 1837. Québec : Réédition Québec, 1969.

Aubier, Catherine. Singe, Zodiac Chinois. 1908. Paris: FranceAmérique, 1982.

Aubry, Claude. Miroirs déformants. Montréal : Fides, 1945.

—. Les Îles du roi Maha-Maha II. Québec, Éditions du Pélican, 1960.

Aubry, Pierre. Nous ne sommes pas des singes. Montréal : Université Libre, 1979.

Audet, Noël. Figures parallèles. Québec, Éditions de l'Arc, 1963. (2)

—. La Parade. Montréal : Québec/Amérique, 1984.

Aycard, Albert, et Jacqueline Franck. Riez avec "La Réalité dépasse la fiction (ter) ». Paris : Gallimard, 1959. 
$\boldsymbol{B}$

Bachelard, Gaston. L'Air et les Songes. Paris : José Corti, 1943.

—. La Poétique de l'espace. 4e édition. Paris : PUF, 1964.

—. La Poétique de la rêverie. 3e édition. Paris : PUF, 1965.

Bagley, Charles. La France d'autrefois et d'aujourd'hui. New York : Appleton-Century-Crofts, 1951.

Baillargeon, Pierre. Les Médisances de Claude Perrin. Montréal : Lucien Parizeau \& Co, 1945.

—. La Neige et le feu. Montréal : Éditions Variétés, 1948.

—. Le Scandale est nécessaire. Montréal : Éditions du Jour, 1962.

—. Madame Homère. Montréal : Éditions du Lys, 1963.

Baillargeon, Samuel, dir. Littérature canadienne-française. Montréal : Fides, 1957. (2)

Baillie, Robert. Des filles de beauté. Montréal : Quinze, 1980.

Balzac, Honoré de.L'Illustre Gaudissart; La Muse du Département. Paris : Calmann-Lévy, 1844.

—. Le Lys dans la vallée. Paris : Belles Éditions, s.d.

—. Les Employés. Paris : Calmann-Lévy, 1839.

—. Le Curé de village. Paris : Nelson, 1931.

—. Un ménage de garçon. Paris : Calmann-Lévy, 1842.

—. La Cousine Bette. Paris : Larousse, 1908.

Banque royale du Canada. Panorama canadien: Centenaire de 1967. Montréal : Banque royale du Canada, 1967.

Barbeau, Marius. Le Rêve de Kamalmouk. Montréal : Fides, coll. « Nénuphar », 1948. 
Barbeau, Victor. Les Français du Canada. Montréal : Publications de l'Académie canadienne-française, 1963.

-. La Face et l'envers. Essais critiques. Montréal : Publications de l'Académie française, 1966.

Barande, Ilse. Sandor ferenczi. Paris : Payot, 1972.

Barnett, Lincoln. The Universe and Dr. Einstein. New York : New American Library, 1952.

Barr, Donald. The How and Why Wonder Book of Primitive Man. New York: Wonder Books/Grosset \& Dunlop, 1961.

Barrère, Jean-Bertrand. La Cure d'amaigrissement du roman. Paris : Albin Michel, 1964.

Barthes, Roland. Sade, Fourier, Loyola. Paris : Seuil, 1971.

Baruk, Henri. Psychoses et Névroses. Paris : PUF, coll. «Que saisje?», 1960.

Basile, Jean. La Jument des mongols. Montréal : Éditions du Jour, 1964.

—. Joli tambour. Montréal : Éditions du Jour, 1966.

—. Le Grand Khan. Montréal : Éditions Estérel, 1967.

—. Les Voyages d'Irkoutsk. Montréal : Hurtubise HMH, 1970.

Bastien, Hermas. Ces écrivains qui nous habitent. Montréal : Beauchemin, 1969.

Baudoin, Louis. La Recherche au Canada français. Montréal : Presses de l'Université de Montréal, 1968.

Baudouin, Charles. Qu'est-ce que la suggestion? Neuchatel : Delachaux \& Niestlé S.A., 1924.

- Le Mythe du moderne et propos connexes. Genève : Éditions Mont-Blanc, 1946.

—. Psychanalyse du symbole religieux. Paris: Arthème Fayard, 1957. 
-. L'Âme enfantine et la psychanalyse. Neuchatel : Delachaux et Niestlé, 1964.

Beaucaire, Maurice, et Pierre Vincent. Pour apprendre à jouer aux échecs. Paris : S. Bornemann, 1932.

Beauchemin, Nérée. Nérée Beauchemin. Textes choisis et présentés par Clément Marchand. Montréal: Fides, coll. « Classiques canadiens », 1957.

Beauchemin, Yves. Le Matou. Montréal: Québec/Amérique, 1981.

Beaudry, Marguerite. Debout dans le soleil. Montréal : Quinze, 1977.

Beaulieu, Germain. Nos immortels. Montréal : Éditions Albert Lévesque, 1931.

Beaulieu, Michel. Pour chanter dans les chaînes. Montréal : Éditions québécoises, 1964.

-. Je tourne en rond mais c'est autour de toi. Montréal : Éditions du Jour, 1969.

—. Sylvie Stone. Montréal : Éditions du Jour, 1974.

—. La Représentation. Montréal : Éditions du Jour, 1972. (2)

Beaulieu, Maurice. Il fait clair de glaise. Montréal : Éditions d'Orphée, 1948.

Beaulieu, Victor-Lévy. Mémoires d'outre-tonneau. Montréal : Éditions Estérel, 1968.

—. La Nuitte de Malcomm Hudd. Montréal : Éditions du Jour, 1969.

—. Race de monde! Montréal : Éditions du Jour, 1969.

—. Jos Connaissant. Montréal : Éditions du Jour, 1970. (2)

—. Jos Connaissant. 1970. Montréal: VLB, 1978.

—. Pour saluer Victor Hugo. Montréal : Éditions du Jour, 1971. 
—. Les Grands-pères. Montréal : Éditions du Jour, 1971.

—. Un rêve québécois. Montréal : Éditions du Jour, 1972.

—. Jack Kérouac. Montréal : Éditions du Jour, 1972.

—. Oh Miami Miami Miami. Montréal : Éditions du Jour, 1973.

—. Don Quichotte de la Démanche. Montréal : L’Aurore, 1974.

—. En attendant Trudot. Montréal : L'Aurore, 1974.

—. Blanche forcée. Montréal: VLB, 1976. (2)

- N'évoque plus que le désenchantement de ta ténèbre, mon si pauvre Abel : Lamentation. Montréal: VLB, 1976.

- Ma Corriveau suivi de La Sorcellerie en finale sexuée. Montréal: VLB, 1976.

—. Sagamo Job J : cantique. Montréal: VLB, 1977.

—. Cérémonial pour l'assassinat d'un ministre. Montréal: VLB, 1978.

-. Monsieur Melville 2. Lorsque souffle Moby Dick. Montréal: VLB Éditeur, 1978.

-. Monsieur Melville 3. L'après Moby Dick ou la souveraine poésie. Montréal: VLB, 1978.

—. La Tête de monsieur Ferron ou les Chians. Montréal : VLB, 1979.

—. Una. Roman. Illustré par deux petites filles. Montréal: VLB, 1980.

-. Satan Belhumeur. Montréal: VLB, 1981.

—. Discours de Sam. Montréal: VLB, 1983.

-. Entre la sainteté et le terrorisme. Montréal: VLB Éditeur, 1984.

—, dir. Quand les écrivains québécois jouent le jeu. Montréal : Éditions du Jour, 1970. 
Beaudoin, Jean Gibea. Guerre de Sang (ou le Juif). Montréal : Éditions du Lys, 1964.

Beaumarchais, Pierre-Augustin Caron de. Le Barbier de Séville. Paris : Éditions de la bibliothèque mondiale, 1954.

Beauvoir, Simone de. L'Invitée. Paris : Gallimard, 1943.

—. Le Sang des autres. Paris : Gallimard, 1945.

-. Le Deuxième Sexe. Tome I: Les faits et les mythes. Paris: Gallimard, 1949.

-. Le Deuxième Sexe.Tome II. L'Expérience vécue. Paris: Gallimard, 1949.

—. Mémoires d'une jeune fille rangée. Paris : Gallimard, 1958.

—. La Force de l'âge. Paris : Gallimard, 1960.

—. La Force des choses. Paris : Gallimard, 1963.

—. Une mort très douce. Paris : Gallimard, 1964.

—. La Vieillesse. Paris : Gallimard, 1970.

-. La Cérémonie des adieux, suivi de Entretiens avec J.-P. Sartre : août-septembre 1974. Paris : Gallimard, 1981.

Beckett, Samuel. Molloy. Paris : Éditions de Minuit, 1951.

—. Malone meurt. Paris : Éditions de Minuit, 1951.

-. Nouvelles et textes pour un rien. Paris : Éditions de Minuit, 1955.

—. Comment c'est. Paris : Éditions de Minuit, 1961.

—. Oh les beaux jours. Paris : Éditions de Minuit, 1963.

—. Têtes-mortes. Paris : Éditions de Minuit, 1967.

Bédard, Roger-J.L'Essor économique du Québec. Montréal : Beauchemin, 1969.

Bédouin, Jean-Louis. André Breton. Paris : Seghers, 1960. 
Beetz, Jean et al.La Crise de l'enseignement au Canada francais. Urgence d'une réforme. Montréal : Éditions du Jour, 1961.

Bégin, Luc-A. Le Firmament trop cru. Montréal : Éditions Aquila, 1971.

Bégon, Elisabeth. Élisabeth Bégon. Textes choisis, présentés et annotés par Céline Dupré. Montréal : Fides, coll. «Classiques canadiens », 1960.

Béguin, Albert. L'Âme romantique et le rêve. Paris : José Corti, 1963.

Bélair, Michel. Michel Tremblay. Québec : Presses de l'Université du Québec, 1972.

- Le Nouveau théatre québécois. Montréal : Éditions Léméac, 1973.

Bélanger, Bagriana et Irène Thériault-Beaudin. Ma voix seule entend ta voix. Ottawa : Éditions du Vermillon, 1984.

Bélanger, Marcel. Pierre de cécité. Montréal : Éditions ATYS, 1962.

Belleau, André. Le Romancier fictif. Sillery: Presses de l'Université du Québec, 1980.

Bellefeuille, Pierre de, Alain Pontaut et al. La Bataille du livre au Québec: Oui à la culture française, non au colonialisme cuturel. Montréal : Leméac, 1972.

Bellow, Saul. Humboldt's Gift. NYC : Avon Books, 1976.

Benda, Julien. $\mathrm{Du}$ poétique selon l'humanité, non selon les poètes. Paris : Éditions des Trois Collines, 1946.

Benoît, Jacques. Jos Carbone. Montréal : Éditions du Jour, 1967.

—. Les Voleurs. Montréal : Éditions du Jour, 1969.

—. Patience et firlipon. Montréal : Éditions du Jour, 1970. 
-. Les Princes. Montréal : Éditions du Jour, 1973.

-. Gisèle et le serpent. Québec : Libre Expression, 1981.

Benoît, Réal. La Saison des artichauts, suivi de Mes voisins. Montréal : Le Cercle du Livre de France, 1968.

-. Quelqu'un pour m'écouter. Montréal : Le Cercle du Livre de France, 1964.

Ber, André. La Cage aux fauves. Montréal : Librairie Déom, 1981.

Béraud, Jean. Études sur le parler français au Canada. Québec: Presses de l'Université Laval, 1955.

-. 350 ans de théâtre au Canada français. Montréal : Le Cercle du Livre, 1958.

Bergerac, Cyrano de. L'Autre Monde ou les États et empires de la lune et du soleil. Montréal : Le Cercle du Livre de France, 1960.

Bergeron, Henri-Paul. Le Frère André de la congrégation de Sainte Croix. Montréal : Oratoire St. Joseph, 4e édition, 1988.

Bergeron, Léandre. Petit manuel d'histoire du Québec. Montréal : Éditions québécoises, 1970.

-. The History of Quebec. A Patriot's Handbook. Trad. Baila Markus. Toronto : New Canada Publications, 1971.

Bergeron, Marcel. Psychologie du premier âge. Paris : PUF, 1966.

Bergler, Ed. La Névrose de base. Paris : Payot, 1963.

Bergson, Henri. L'Évolution créatrice. Paris : PUF, 1946.

Bernard, André. La Législation électorale au Québec 1790-1967. Montréal : Éditions Sainte-Marie, 1969.

-. La Politique au Canada et au Québec. Montréal : Presses de l’Université du Québec, 1977.

Bernard, Marc. Zola par lui-même. Paris : Seuil, 1952. 
Berne-Joffroy, André. Valéry. Paris : Gallimard, 1960.

Bernier, Hector. Au large de l'écueil. Québec: Librairie de l'Événement : 1912.

Bernier, Jovette. Non Monsieur. Montréal : Le Cercle du Livre de France, 1969.

Bersani, Jacques, Michel Autrard, Jacques Lecarme, et Bruno Vercier. La Littérature en France. Depuis 1945. Paris/Montréal : Bordas, 1970.

Bersianik, Louky. L'Euguélionne. Montréal : La Presse, 1976.

Bertin, Celia. Marie Bonaparte : A Life. New York : Harcourt Brace Jovanovich, 1982.

Bettelheim, Bruno. A Home for the Heart. New York: Bantam Books, 1975.

Bessis, Pierre et Hubert Jaoui. Qu'est-ce que la créativité ? Paris : Dunod, 1972.

Berthiaume, André. La Fugue. Montreal : Le Cercle du Livre de France, 1966.

Bessette, Arsène. Le Débutant. St. Jean: Le Canada français, 1914.

—. Le Débutant. Montréal : Cahier du Québec/Hurtubise HMH, 1977.

Bethléem, Louis. Romans à lire et romans à proscrire. Paris : Franciscus, 1908.

Bettelheim, Bruno. Psychanalyse des contes de fées. Trad. Théo Carlier. Paris : Robert Laffont, 1976.

Billy, André. Apollinaire. Paris : Pierre Seghers, 1956.

Blackburn, Marthe, Marie-Claire Blais, Odette Gagnon, Luce Guilbeault, Pol Pelletier, et France Théoret. La Nef des Sorcières. Montréal : Quinze, 1976. 
Blain, Maurice. Approximations. Montréal : Hurtubise HMH, 1967.

Blais, Jacques. Présence d'Alain Grandbois: Avec quatorze poèmes parus de 1956 à 1969. Québec: Presses de l'Université Laval, 1974.

-. De l'ordre et de l'aventure. Québec: Presses de l'Université Laval, 1975.

Blais, Marie-Claire. La Belle bête. 1959. Montréal : Le Cercle du Livre de France, 1968.

—.Mad Shadows. Trans. Merloyd Lawrence. Toronto: McClelland \& Stewart, 1960.

—. Tête blanche. Québec : Institut littéraire du Québec, 1960.

—. Pays voilés. Québec : Garneau Éditeur, 1963.

—. L'Insoumise. Montréal : Éditions du Jour, 1966.

-. Pays voilés - existences. Montréal : Éditions de l’Homme, 1967.

—. David Sterne. Montréal : Éditions du Jour, 1967.

—. L'Exécution. Montréal : Éditions du Jour, 1968.

-. Manuscrit [sic] de Pauline Archange. Montréal : Éditions du Jour, 1968.

—. Vivre! Vivre ! Montréal : Éditions du Jour, 1969. (2)

—. Les Apparences. Montréal : Éditions du Jour, 1970.

—. Le Loup. Montréal : Éditions du Jour, 1972.

—. Un Joualonais sa joualonie. Montréal : Éditions du Jour, 1973.

- Fièvre et autres textes dramatiques. Montréal : Éditions du Jour, 1974.

—. Une Liaison parisienne. Montréal : Stanké/Quinze, 1975.

—. Les Nuits de l'Underground. Montréal : Stanké, 1978. 
—. Le Sourd dans la ville. Montréal : Stanké, 1979.

Blanchard, Raoul. Le Canada français, province de Québec. Montréal : Librairie Arthème Fayard, 1960.

Blouin, Michèle. Du Saint-Laurent au Nil. Montréal: Le Préambule, 1980.

Boileau, Nicolas. Art Poétique. Paris : Bordas, 1963.

Boisdeffre, Pierre de. Où va le roman ? Paris: Éditions mondiales, 1962.

Bonaparte, Marie. Psychanalyse et Biologie. Paris : PUF, 1952.

-. Edgar Poe. Sa vie - son œuvre, étude analytique. 3 Vol. Paris : PUF, 1958.

Bonenfant, J.-C.et al.Réflexions sur la politique au Québec. Montréal : Éditions Sainte-Marie, 1962.

Bonenfant, Joseph. Repère. Montréal: Hurtubise HMH, 1979.Borduas, Paul-Émile.Refus global \& projections libérantes. Montréal : Parti pris, 1977.

Bosco, Monique. Les Infusions. Montréal : Hurtubise HMH, 1965.

—. La Femme de Loth. Montréal : Éditions Robert Laffont, 1970.

—. Jéricho. Montréal : Hurtubise HMH, coll. «Sur parole », 1971.

Bosquet, Alain. Pierre Emmanuel. Paris: Pierre Seghers, coll. «Poètes d'aujourd'hui », 1959.

Bosquet, Alain. La Poésie canadienne. Montréal: Éditions Seghers/Hurtubise HMH, 1962.

Bouchard, Denis. Une lecture d'Anne Hébert. Montréal : Hurtubise HMH, 1977.

Boucher, Jean-Pierre. Jacques Ferron au pays des amélanchiers. Montréal : Presses de l'Université de Montréal, 1973.

-. Instantanés de la condition québécoise. Montréal : Hurtubise HMH, 1977. 
Boucher, Yvon. L'Ouroboros. Montréal: Grandes Éditions du Québec, 1973.

—. L'Obscenant. Montréal : Le Cercle du Livre de France, 1974.

Boucher de Boucherville, Georges. Une de perdue, deux de trouvées.1849-1851. Montréal : Hurtubise HMH, 1973.

Bouissac, Paul. Les Demoiselles. Paris : Éditions de Minuit, 1970.

Boulenger, L'Abbé A. Manuel d'apologétique. 7e édition. Lyon : Librairie catholique Emmanuel Vitte, 1934.

Bourgault, Pierre. Écrits polémiques 1960-1981: 1. La Politique. Montréal : VLB, 1982.

Bourgeoys, Marguerite. Marguerite Bourgeoys. Textes choisis et présentés par Hélène Bernier. Montréal: Fides, coll. «Classiques canadiens », 1958.

Bourget, Paul. Un drame dans le monde. Paris : Plon, 1921.

—. Le Disciple. Paris : Librairie Arthème Fayard, 1946.

Bourneuf, Roland. Saint-Denys Garneau et ses lectures européennes. Québec : Presses de l'Université Laval, 1969.

Bouthillette, Jean. Le Canadien francais et son double. Montréal : L'Hexagone, 1972.

Bouyoucas, Pan. Une bataille d'Amérique. Montréal: Quinze, 1976.

Boyers, Robert. Ronald Laing et l'antipsychiatrie. Paris : Payot, 1971.

Brassard, André. "Il était une fois dans l'est» de Michel Tremblay. Montréal : L'Aurore, 1974.

Brault, Jacques. Alain Grandbois. Montréal : L'Hexagone, coll. «Poètes d'aujourd'hui », 1968.

—. Chemin faisant. Montréal : La Presse, 1975.

—. Agonie. Montréal : Boréal Express. 1984. 
Brazeau, Raymond J.An Outline of Contemporary French Canadian Literature. Toronto : Forum House, 1972.

Brébeuf, Jean de. Brébeuf. Textes choisis et annotés par René Latourelle. Montréal : Fides, coll. "Classiques canadiens", 1958.

Bree, Germaine et Margaret Guiton. The French Novel: from Gide to Camus. New York: Harbinger, 1962.

Breton, André. Manifestes du surréalisme. Paris: Jean-Jacques Prévert, 1963.

Brien, Roger. Faust aux enfers. Montréal : Éditions du Totem, 1936.

Brochu, André, et Gilles Marcotte. La littérature et le reste. Montréal : Quinze, 1980.

Brochu, André. Privilèges de l'Ombre. Montréal : L'Hexagone, 1961.

—. Délit contre délit. Montréal: Les Presses de l'A.G.E.U.M., 1965.

—. L'Instance critique : 1961 - 1973. Montréal : Leméac, 1974.

-. L'Évasion tragique: Essai sur les romans d'André Langevin. Montréal : Hurtubise HMH, 1985.

Brodeur, Hélène. Chronique du Nouvel Ontario: La Quête d'Alexandre. Montréal : Quinze, 1981.

Brodin, Pierre. Présence contemporaine. Tomes II et III. Paris : Éditions Debresse, 1952.

Brontë, Emily. Wuthering Heights. NYC : The Modern Library, 1950.

-. The Complete Poems of Emily Bronte. Ed. Philip Henderson. London: Folio-Society, 1951.

Brossard, Jacques. Le Métamorfaux. Montréal : Hurtubise HMH, 1974. 
—. Le Sang du souvenir. Montréal : La Presse, 1976.

Brossard, Nicole. Sold-out : étreinte/illustration. Montréal: Éditions du Jour, 1973.

—. L'Amèr ou Le chapitre effrité. Montréal : Quinze, 1977.

Bruchesi, Jean. Histoire du Canada. Montréal: Beauchemin, 1959. (2)

Bruhat, Jean. Marx/Engels. Paris : Union générale, 1971.

Brulotte, Gaétan. L'Emprise. Montréal : Éditions de l’Homme. 1979.

Brunet, Berthelot. Histoire de la littérature canadiennefrancaise. Montréal : L'Arbre, 1946. (2)

Brunet, Jacques. Albert Laberge: sa vie et son œuvre. Ottawa: Éditions de l'Université d'Ottawa, 1969.

Brunet, Michel. Québec Canada anglais: deux itinéraires un affrontement. Montréal : Hurtubise HMH, 1969.

Bugnet, Georges. Siraf : étranges révélations. Montréal. Éditions du Totem, 1934.

—. La Forêt. Montréal : Éditions du Totem, 1935.

—. Voix de la Solitude. Montréal : Éditions du Totem, 1938.

Buies, Arthur. La Lanterne. Éd. Marcel-A. Gagnon. Montréal : Édition de l'Homme, 1964.

- Arthur Buies. Textes présentés et annotés par Léopold Lamontagne. Montréal: Fides, coll. "Classiques canadiens», 1959. (2)

Buliard, Roger. Inuk - Au dos de la terre. Paris : Éditions SaintGermain, 1949.

Bureau, René. Toué, tais-toué. Montréal : Éditions du Jour, 1968.

Burgess, Anthony. Un agent qui vous veut du bien. Trad. Michel Deutsch. Paris : Denoël, 1969. 
Burney, Pierre. Les Langues internationales. Paris: PUF, coll. «Que sais-je?», 1962.

Butor, Michel. Répertoire. Paris : Éditions de Minuit, 1960.

—. Répertoire II. Paris : Éditions de minuit, 1964.

—. Essais sur les modernes. Paris : Gallimard, 1964.

Buytendijk, F. L'Homme et l'Animal. Trad. Renée Laureillard. Paris : Gallimard, 1965.

Byron, Lord. The Poetical Works of Lord Byron. Oxford: Oxford University Press, 1945.

C

Cabiac, Pierre. Feuilles d'érable et fleurs de lys. Anthologie de la poésie canadienne-française. Paris : Éditions de la Diaspora française, 1965.

Cadieux, Pauline. La Lampe dans la fenêtre. Montréal : Libre expression, 1976.

Caillois, Roger. L'Homme et le Sacré. Paris : Gallimard, 1950.

Caldwell, Erskine. Trouble in July. 1940. New York: [Duell, Sloane \& Pearce], 1947.

Callaghan, Barry. As Close As We Came. Toronto : Exile Editions, 1982.

Callaghan, Morley. More Joy in Heaven. 1937. Toronto: McClelland \& Stewart, 1960.

Callaghan, Morley. Telle est ma bien-aimée. Trad. Michelle Tisseyre. Montréal : Cercle du Livre de France, 1974.

Calvet, Jean. Morceaux choisis des auteurs français $d u X^{e} a u$ XXe siècle. Paris : J. de Gigord Éditeur, 1928. 
-. Les Types universels dans les littératures étrangères. Paris: Lanore, 1932.

-. Manuel illustré d'histoire de la littérature française. Paris : J. de Gigord Éditeur, 1934.

Canadian Literature. № 8. Spring 1961. Numéro spécial sur Malcolm Lowry. Article de G. Bessette, "Un grand poète", p. 57-59, qui porte sur Mémoire sans Jours, de Rina Lasnier.

Campbell, R. L'Existentialisme. Paris : Foucher, 1946.

Camus, Albert. La Chute. Paris : Gallimard-Folio, 1956.

—. Noces, suivi de L'Été. Paris : Gallimard, 1959.

Caravel, Jean-Baudoin. La Chirurgie esthétique. Nancy: Henri Veyrier, 1981.

Carbonell, Reyes. Poesias en aire y tierra. Madrid : Laurel, 1951.

Carco, Françis. L'Équipe. Paris : Albin Michel, 1925.

—. Les Innocents. Paris : Albin Michel, 1952.

—. Jésus-La-Caille. Paris : Calmann-Lévy, 1963.

Cardinal, Marie. Les Mots pour le dire. Paris : Grasset-Fasquelle, 1975.

Carles, Jules. Les Origines de la vie. Paris : PUF, coll. «Que saisje? », 1954.

Caron, Louis. L'Emmitouflé. Paris : Robert Laffont, 1977.

—. L'Emmitouflé. 1977. Paris : Seuil, 1982.

—. Les Fils de la liberté. Le Canard de bois. Montréal : Boréal Express, 1981.

Carrel, Alexis. L'Homme, cet inconnu. Paris : Plon, 1935.

Carrier, Roch. Jolis deuils. Montréal : Éditions du Jour, 1964.

—. La Guerre, yes sir! Montréal : Éditions du Jour, 1968. 
—. Il est par là, le soleil. Montréal : Éditions du Jour, 1970.

- Floralie, Where are you? Trans. Sheila Fischman. Toronto: Anansi, 1971.

—. Le Deux-millième Étage. Montréal : Éditions du Jour, 1973.

—. Le Jardin des délices. Montréal : La Presse, 1975.

—. Il n'y a pas de pays sans grand-père. Montréal : Stanké, 1977.

—. De l'amour dans la ferraille. Montréal : Stanké, 1984.

Carrouges, Michel. André Breton et les données fondamentales du surréalisme. Paris : Gallimard, 1950.

Cartier, George. Le Poisson péché : roman. Montréal : Le Cercle du Livre de France, 1964.

Casgrain, l'abbé $\mathrm{H}$ [enri-Raymond]. Les Pionniers canadiens et le tableau de la rivière Ouelle: Légendes. Montréal : Beauchemin et fils, 1895.

Castex, P., et P. Surer. Manuel des études littéraires françaises. XIX ${ }^{e}$ siècle. Paris : Hachette, 1950.

—. Manuel des études littéraires françaises. Tome VI : XXe siècle. Paris : Hachette, 1953.

Catalogue des manuscrits. Montréal : Bibliothèque nationale du Québec, 1978.

Cathelin, Jean, et Gabrielle Gray. Révolution au Canada. Paris : Les Presses du Mail, 1963.

Caullery, Maurice. Les Étapes de la biologie. Paris: PUF, coll. «Que sais-je?», 1954.

Céline, Louis-Ferdinand. Mort à crédit. Paris : Gallimard, 1952.

-. Ballets sans musique, sans personne, sans rien. Paris: Gallimard, 1952.

—. Guignol's Band. Paris : Gallimard, 1952. 
—. Voyage au bout de la nuit. Paris : Gallimard, 1957.

—. D'un château l'autre. Paris : Gallimard, 1957.

Cellier, Léon. Gérard de Nerval. L'homme et l'œuvre. Paris : Hatier Boivin, 1956.

Cendrars, Blaise. Moravagine. 1926. Paris: Bernard Grasset, 1956.

—. L'Homme foudroyé. Paris : Denoël, 1945.

Cerbelaud-Salagnac, Georges. Les Coureurs de brousse. Montréal : Fides, 1957.

Cervantes, Miguel de.Don Quichotte I. Paris : Gallimard-Folio, 1988.

Cestre, Charles. La Littérature américaine. Paris : Armand Colin, 1948.

Chaigne, Louis. Vies et ouvres d'écrivains. Paris: Fernand Lanone, 1954.

Chainé, Yolande. Au seuil de l'enfer. Montréal : Le Cercle du Livre de France, 1961.

Chaloult, René. Mémoires politiques. Montréal : Éditions du Jour, 1969.

Chamberland, Paul. Genèses. Montréal: Les Presses de l'A.G.E.U.M., 1962.

—. L'Afficheur hurle. Montréal : Parti pris, 1964.

—. Terre Québec. Montréal : Librairie Déom, 1964.

—. L'Inavouable. Montreal : Parti pris, 1967. (2)

—.Éclats de la pierre noire d'où rejaillit ma vie. Montréal : Danielle Laliberté, 1971.

Champlain, Samuel de. Champlain. Textes choisis et présentés par Marcel Trudel. Montréal: Fides, coll. «Classiques canadiens », 1956. 
Chansonniers 60. Paris : Éditions Pierre Horay, 1960.

Chapais, Thomas. Thomas Chapais. Textes choisis et présentés par Jean-Charles Bonenfant. Montréal: Fides, coll. «Classiques canadiens », 1957.

Chapman, William. William Chapman. Textes présentés et annotés par Jean Ménard. Montréal. Fides, coll. «Classiques canadiens », 1968.

Chaput, Marcel. J'ai choisi de me battre. Montréal : Club du livre du Québec, 1964.

—. J'ai choisi de me battre. Montréal : Club du Livre du Québec, 1965.

Charbonneau, Robert. Ils possèderont la terre. Montréal : Hurtubise HMH, 1941.

—. Aucune créature. Montréal : Beauchemin, 1961.

Charbonneau, Jean. Des influences françaises au Canada. Tome II. Montréal : Beauchemin, 1918.

Charbonnier, Gabrielle. Le Maniement psychanalytique de l'image : méthode Guillerey. Paris : Éditions ESF, 1970.

Charbonnier, Georges. Entretiens avec Claude Lévi-Strauss. Paris : Union générale, 1961.

Chardin, Pierre Teilhard de. Le Phénomène humain. Paris : Seuil, 1955.

Charest, Gilles.Le Livre des sacres et blasphèmes québécois. Montréal : L’Aurore, 1974.

-. Sacrés sacres et blasphèmes québécois. Montréal : Québec/Amérique, 1980.

Charlevoix, Pierre-François-Xavier de.Charlevoix (16821761). Textes choisis et présentés par Léon Pouliot. Montréal : Fides, coll. «Classiques canadiens », 1959. 
Chateaubriand, René de.Atala. René. Paris: Librairie Gründ, 1938.

Châtillon, Pierre. La Mort rousse. Montréal : Éditions du Jour, 1974.

Chauchard, Paul. Sociétés animales, société humaine. Paris : PUF, coll. «Que sais-je? », 1963.

Chauveau, Pierre-Joseph-Olivier. Charles Guérin: Roman de mœurs canadiennes. 1852. Montréal: Compagnie de la publication canadienne, 1900.

—. Charles Guérin. 1852. Montréal : M.A. Guérin Éditeur, 1973.

-. Pierre-Joseph-Olivier Chauveau. Textes choisis et présentés par André Labarrère-Paulé. Montréal: Fides, coll. « Classiques canadiens », 1962.

Le Chien d'Or. № 4. November 1974. Article de Leonard W. Sugden: "Gérard Bessette's Le Libraire as Seen Through Its Resemblances to Camus' L'Étranger", pp. 16-18.

Choquette, Adrienne. La Nuit ne dort pas. 1954. Notre-Damedes-Laurentides : Presses laurentiennes, 1979.

—. Laure Clouet. Québec : Institut littéraire de Québec, 1961.

-. Laure Clouet. 1961. Notre-Dame-des-Laurentides: Presses laurentiennes, 1980.

-.Je m'appelle Pax. Québec: Presses laurentiennes, 1974. Préface de Robert Choquette.

-. Le Temps des villages. Notre-Dame-des-Laurentides : Presses laurentiennes, 1975.

-. Confidences d'écrivains canadiens-français. Notre-Dame-desLaurentides : Presses laurentiennes, 1976.

-. La Coupe vide. Notre-Dame-des-Laurentides: Presses laurentiennes, 1978. 
-. Adrienne Choquette lue par Suzanne Paradis. Notre-Damedes Laurentides : Presses laurentiennes, 1978.

Choquette, Gilbert. L'apprentissage. Montréal: Beauchemin, 1966.

—. La Défaillance. Montréal : Beauchemin, 1969.

Choquette, Robert. Suite marine. Montréal: Les Sociétés d'édition et de librairie Paul Péladeau, 1953.

- Robert Choquette. Textes choisis et présentés par André Melançon. Montréal : Fides, coll. "Classiques canadiens", 1959.

Choquette, Robert, Luther Dittmer, et Réjean Robidoux. Mélanges de civilisation canadienne-française offerts au professeur Paul Wyczynski. Ottawa: Éditions de l'Université d'Ottawa, 1977.

Christiane F. ,Moi, Chistiane F,.13 ans, droguée, prostituée. Témoignages recueillis par Kai Hermann et Horst Rieck. Trad. Léa Marcou. Paris : Lacombe, 1981.

Christie, Agatha. Le Meurtre de Roger Ackroyd. Paris : Libairie Champs Elysées, 1927.

Christie, Agatha. Mysterious Affair at Styles. 1920. London: Pan, 1956.

—. The Mystery of the Blue Train. 1928. New York: Pocket Books, 1969.

—. The Mysterious Mr. Quin. 1930. New York: Dell, 1968.

-. Murder in the Calais Coach / Murder on the Orient Express. 1934. New York: Pocket Books, 1969.

—. Murder in Retrospect. 1943. New York: Dell, 1970.

—. Mrs McGinty's Dead. 1952. London: Fontana-Collins, 1974.

—. Dead Man's Folly. New York: Pocket Books, 1956. 
—. The Pale Horse. New York : Pocket Books, 1961.

Cixous, Hélène. Dedans. Paris : Grasset, 1969.

Clari, Jean-Claude. Les Grandes Filles. Montréal : Éditions du Jour, 1968.

Clancier, Anne. Psychanalyse et critique littéraire. Toulouse: Éditeur Edouard Privat, 1973.

Claudel, Paul. Art poétique. Paris : Mercure, 1919.

—. Réflexion sur la poésie. Paris : Gallimard, 1963.

Clavel, Bernard. Harricana : le royaume du nord. Paris : Albin Michel, 1983.

Clébert, Jean-Paul. Paris insolite : roman. Paris : Denoël, 1952.

Cleland, John. Fanny Hill. The Memoirs of a Woman of Pleasure. Toronto: Swan, 1964.

Cloutier, Cécile. Cannelles et Craies. Paris : Jean Grassin Editeur, 1969.

—. Mains de sable. Québec : Éditions de L'Arc, 1960. (2)

—. Câblogrammes. Paris : Chambelland, 1972.

Cloutier, Eugène. Les Témoins. Montréal : Le Cercle du Livre de France, 1953.

—. Les Inutiles. Montréal : Le Cercle du Livre de France, 1956.

Cocke, Emmanuel. L'Emmanuscrit de la mère morte. Montréal : Éditions du Jour, 1972.

-. Sexe pour sang. Montréal : Guérin, coll. «Le cadavre exquis », 1974.

Cogswell, Fred, trans. 100 Poems of Modern Quebec. Fredericton, N.B. : Fiddlehead Poetry Books, 1970. (2)

-. 100 Poems of Modern Quebec. Frederiction, N.B. : Fiddlehead Poetry Books, 1971. 
Collectif. L'Homme à la recherche de ses origines: De la mythologie à la théorie de l'évolution. Paris: Éditions du Centenaire, 1979.

Collet, Paulette. L'Hiver dans le roman canadien-français. Québec : Presses de l'Université Laval, 1975.

Colombier, Pierre du. Histoire de l'art. Paris : Librairie Arthème Fayard, 1942.

Comeau, Robert. Économie québécoise. Montréal : Les Cahiers de l’Université du Québec, 1969.

Conan Doyle, Arthur. The Adventures of Sherlock Homes. 1892. London : John Murray, 1962.

—. The Case Book of Sherlock Homes. 1927. New York : Pocket Books, 1950.

Conan, Laure. Angéline de Montbrun. 1884. Montréal : Fides, coll. « Nénuphar », 1950. (2)

—. Angéline de Montbrun. 1884. Montréal : Fides, 1967.

—. L'Oublié. 1900. Montréal : Beauchemin, 1947.

—. L'Obscure Souffrance. 1919. Préface de Thomas Chapais. Québec : L'Action sociale, 1924.

-. Laure Conan. Textes choisis et présentés par Micheline Dumont. Montréal: Fides, coll. "Classiques canadiens», 1959. (2)

Constant, Benjamin. Adolphe. 1816. Paris : Édition Simon, 1935.

—. Adolphe, suivi de Cécile. 1816. Paris : Gallimard et Librairie générale, 1958.

Constantineau, Gilles. Simples poèmes et ballades. Montréal : L'Hexagone, 1960.

Contantin-Weyer, Maurice. Un homme se penche sur son passé. Paris : Rieder, 1928. 
Cormeau, Nelly. Physiologie du roman. Paris : A.G. Nizet, 1966.

Corneille, Pierre. Le Cid. 1636. Paris : J. de Gigord, 1927.

—. Théâtre choisi. Ed. Maurice Rat. Paris : Garnier, 1950.

—. Théâtre choisi. Tome 1. Paris : Lutetia, Nelson Éditeurs, s. d.

Cortazar, Julio. Rayuela. Buenos Aires : Editiorial Sudamericana, 1977.

Corti, E.C. Comte. Vie, mort et résurrection d'Herculanum et de Pompéi. Trad. Henri Daussy. Paris : Plon, 1955.

Costisella, Joseph. L'Esprit révolutionnaire dans la littérature canadienne-française. Montréal : Beauchemin, 1968.

Cotnam, Jacques. Essai de bibliographie chronologique des écrits d'André Gide. Imprimerie Durand : 1961.

—. Poètes du Québec. Montréal : Fides, 1969.

Cousture, Arlette. 1985. Les Filles de Caleb, tome 1 : Le chant du coq. Paris : France Loisirs, 1993.

Cowley, Malcolm, ed. The Indispensable Faulkner. New York: Book Society, 1950.

Craig, Gerald, ed. Lord Durham's Report. Toronto : McClelland \& Stewart, 1966.

Crawford, Bartholow, Alexander C. Kern, and Morriss H. Needleman. American Literature. New York: Barnes and Noble, 1955.

Crébillon, fils. Le Sopha I. Paris : Nilsson, 1906.

Crémazie, Octave. OEuvres compètes d'Octave Crémazie. Montréal : Institut canadien de Québec, Beauchemin et fils, 1896.

-. Crémazie. Texte établi et annoté par Michel Dassonville. Montréal : Fides, coll. « Classiques canadiens », 1956. 
-. OEuvres I : Poésie. Ottawa : Éditions de l'Université d'Ottawa, 1972.

-. CEuvres II : Prose. Ottawa : Éditions de l'Université d'Ottawa, 1976.

Crick, Bernard. George Orwell, une vie. Trad. Jean Clem. Paris : Balland, 1982.

Cuisenier, André. Jules Romain et les hommes de bonne volonté. Paris : Flammarion, 1954.

D

Daco, Pierre. Les Triomphes de la psychanalyse. Verviers : Gérard \& Cie, 1965.

Dadoun, Roger. Géza Roheim. Paris : Payot, 1972.

Dagenais, Pierre. Contes de la pluie et du beau temps. Montréal : Le Cercle du Livre de France, 1953.

Dagenais, Gérard. Pour un Québec français. Montréal : Éditions du Jour, 1973.

Dana, Jacqueline. La Constellation familiale. Paris: Robert Laffont, 1978.

Dantin, Louis. Poètes de l'Amérique française. Montréal: Éditions du Mercure, 1928.

-. Gloses critiques. Montréal : Albert Lévesque, 1931.

-. Gloses critiques (deuxième série). Montréal: Albert Lévesque, 1935.

-. Poèmes d'outre-tombe. Trois-Rivières: Éditions du Bien public, 1962.

-. Les Sentiments d'un père affectueux. Trois-Rivières : Éditions du Bien public, 1963. 
-. Louis Dantin. Textes choisis et présentés par Yves Garon. Montréal : Fides, coll. «Classiques canadiens », 1968

-. Les Enfances de Fanny. Montréal: Le Cercle du Livre de France, 1969.

D’Arles, Henri [Henri Beaudé]. Estampes. Montréal : Bibliothèque de l'Action française, 1926.

Davies, Robertson. The Manticore. Toronto: MacMillan, 1972.

Day, Philip Stephen. Le Miroir allégorique de Céline. Paris: Klincksieck, 1974.

Dechambre, Edmond. Les Chiens. Paris : PUF, coll. «Que saisje? », 1952.

Deffontaines, Pierre. L'Homme et l'hiver au Canada. Paris : Gallimard, 1957.

Deforges, Régine. La Bicyclette bleue. Paris : Éditions Rmasay, 1981.

Delamare-Deboutteville, Claude. La Vie dans les grottes. Paris : PUF, coll. « Que sais-je?», 1971.

Delbos, Victor. Figures et doctrines de philosophes. Paris : Plon, 1918.

—. La Philosophie française. Paris : Plon, 1919.

Deleuze, Gilles, et Félix Guattari. L'Anti-OEdipe. Paris : Minuit, 1972.

Demers, Louis-Philippe. Sherbrooke. Sherbrooke: Gauvin \& Frère Ltée, 1969.

Denham, Paul, ed. The Evolution of Canadian Literature in English 1945-1970. Toronto: Holt, Rinehart \& Winston of Canada, 1973.

Denham, Paul, and Mary Jane Edwards. Canadian Literature in the '70s. Toronto : Holt, Rinehard and Winston, 1980. 
Desaulniers, Gonzalve. Les Bois qui chantent. Montréal : Beauchemin, 1930.

Desbarats, Peter. A Canadian in Search of a Country. Toronto : McClelland \& Stewart, 1976.

Desbiens, Jean-Paul (pseudo. Le Frère Untel). Les Insolences $d u$ frère Untel. Montréal : Éditions de l'Homme, 1960.

—. Sous le soleil de la pitié. Montréal : Éditions du Jour, 1965.

Des Car, Guy. La Maudite. Paris : J’ai lu, 1954.

Deschamps, Marcel, et Deny Tremblay. Dossier en théâtre québécois: bibliographie.Jonquière: Cégep de Jonquière, 1972.

Desjardins, Denis. Des bleus et des bosses. Montréal : Québec/Amérique, 1983.

Desjardins, Marcelle.Mon cœur chargé à blanc. Québec: Éditions de l'Arc, 1963.

Desmarchais, Rex. L'Initiatrice. Montréal : Albert Lévesque, 1932.

Desmond, Robert. The Libertine. California: Collectors Publications, 1972.

Desrochers, Alfred. À l'ombre de l'Orford. 1929. Montréal : Librairie de l'Action canadienne-française, 1930.

—. Paragraphes. Montréal : Albert Lévesque, 1931.

-. Le Retour de Titus. Ottawa: Éditions de l'Université d'Ottawa, 1963. (2)

—. Élégie pour l'épouse en-allée. Montréal : Parti pris, 1967.

Desrochers, Clémence. Le Monde sont drôles. Montréal : Parti pris, 1966. 
Desrosiers, Richard, et Denis Héroux. Le Travailleur québécois et le syndicalisme. Québec: Presses de l'Université du Québec, 1973.

Desrosiers, Léo-Paul. Nord-Sud. Montréal : Fides, 1943.

—. L'Ampoule d'or. Paris : Gallimard, 1951.

-. Les Engagés du grand portage. Montréal: Fides, coll. « Nénuphar », 1958.

Deutsch, Hélène. La Psychologie des femmes. Enfance et adolescence. Tome I. Paris : PUF, 1962.

-. La Psychologie des femmes. Enfance et adolescence. Tome II. Paris : PUF, 1964.

-. Problèmes de l'adolescence. La formation de groupes. Paris : Payot, 1967.

—. La Psychanalyse des névroses et autres essais. Paris: Payot, 1970.

Devaux, Pierre.Automates, automatisme, automation. Paris : PUF, coll. « Que sais-je?», 1960.

Diderot, Denis. Est-il bon ? Est-il méchant? 1781, publié 1834. Éd. Marcel Arland. Paris : Mondiale, 1955.

—. La Religieuse. 1796. Paris: Gallimard-Librairie Générale française, 1966.

Dionne, René, dir. Anthologie de la littérature québécoise: la Patrie littéraire 1760-1895. Vol. 1. Montréal: La Presse, 1978.

-. Propos sur la littérature outaouaise et franco-ontarienne II. Ottawa : La Société des écrivains canadiens, 1979.

Dolto, Françoise. Le Cas Dominique. Paris : Seuil, 1971.

—. L'Évangile au risque de la psychanalyse. Paris: Jean-Pierre Delarge, 1977. 
Dorchain, Auguste, éd. Les Cent Meilleurs Poèmes de la langue française. Paris : Payot, 1940.

Doré, Marc. Le Billard sur la neige. Montréal : Éditions du Jour, 1970.

Dormann, Geneviève. Le Roman de Sophie Trébuchet. Paris: Albin Michel, 1982.

Dos Passos, John. U.S.A.: The 42nd Parallel. New York : The Modern Library, 1930.

-. Manhattan Transfer. New York: Penguin, 1946.

Dostaler, Yves. Les Infortunes du roman dans le Québec du XIXe siècle. Montréal : Hurtubise HMH, 1977.

Dostoïevski, Fyodor. L'Idiot. Trad. Albert Mausset. Paris : Gallimard, 1939.

—. Les Frères Karamazov I et II. Paris : Gallimard, 1952.

- Le Joueur suivi de Les nuits blanches. Trad. Nina HalpérineKaminsky. Paris : Plon, s.d.

—. L'Éternel Mari. Édité par Henri Troyat. Paris : Bibliothèque mondiale, 1956.

Dostoyevsky, Fyodor. The Brothers Karamazov. Trans. Constance Garnett. New York: New American Library, 1957.

-. The Brothers Karamazov. Trans. David Magarshack : Harmondsworth: Penguin, 1959.

-. The Possessed. Trans. Constance Garnett. New York: The Modern Library, 1959.

Doubrovsky, Serge. Pourquoi la nouvelle critique. Paris : Mercure de France, 1966.

Doutre, Joseph. Les Fiancés de 1812. Montréal : RééditionQuébec, 1973. 
Dracoulidès, N.N. Psychanalyse de l'artiste et de son œuvre. Genève : Éditions du Mont-Blanc, 1952.

Drolet, Antonio. Bibliographie du roman canadien-français 19001950. Québec : Presses de l'Université Laval, 1955.

Druon, Maurice. Les Grandes Familles. Paris: René Julliard, 1948.

Dubé, Marcel. Florence. Québec: Institut littéraire de Québec, 1960.

—. Un simple soldat, version nouvelle. Montréal : Éditions de l'Homme, 1967.

.- Bilan. Montréal : Leméac, 1968.

—. Textes et Documents. Montréal : Leméac, 1973.

Dubuc, Carl. Les Doléances du notaire Poupart. Montréal : Éditions du Jour, 1961.

Ducassé, Pierre. Les Grandes Philosophies. Paris : PUF, coll. « Que sais-je? », 1950.

Ducharme, Réjean. L'Avalée des avalées. Paris : Gallimard, 1966.

—. Le Nez qui voque. Paris : Gallimard, 1967.

—. L'Océantume. Paris : Gallimard, 1968.

—. La Fille de Christophe Colomb. Paris : Gallimard, 1969.

—. L'Hiver de force. Paris : Gallimard, 1973.

—. Les Enfantômes. Paris : Gallimard, 1976.

Duguay, Raoul Yaugud. Lapokalipsô. Montréal : Éditions du Jour, 1971.

Duhamel, Roger.Letttres à une Provinciale. Montréal : Beauchemin, 1962.

—. Le Roman des Bonaparte. Montréal : Éditions du Jour, 1969.

Dumas, Alexandre. Kean. Paris : Gallimard, 1954. 
Dumont, Fernand, et Jean-Charles Falardeau. Littérature et société canadiennes-françaises. Québec: Presses de l'Université Laval, 1964.

Dandurand, Albert. Littérature canadienne-française. Montréal : Imprimerie populaire limitée, 1935

Duplessis-Batik, Jacqueline. L'Artisan et son œuvre. St-Eustache : Messier et Perron, 1980.

Dupré, Yves. Chélée ou la passion selon Sainte-Catherine. Montréal : Éditions du Jour, 1974.

Dupuy, Pierre. André Laurence. Paris : Librairie Plon, 1930.

Duquette, Jean-Pierre. Germaine Guèvremont: une route, une maison. Montréal : Presses de l'Université de Montréal, 1973.

Durand, Gilbert. L'Imagination symbolique. Paris : PUF, 1964.

Durant, Will. The Story of Philosophy. New York : Washington Square Press, 1961.

Durham, John George Lambton, Earl of. Le Rapport Durham. Document 1. Trad. Denis Bertrand et Albert Desbiens. Éd. Denis Bertrand et André Lavallée. Montréal : Éditions SainteMarie, 1969.

Dürrenmatt, Friedrich. La Panne. Trad. Armel Guerne. Paris : Albin Michel, 1958.

Durrell, Lawrence. Justine. Paris : Buchet-Chastel, 1959.

$\boldsymbol{E}$

L'École canadienne. Vol. 33, no 2. Octobre 1957. Article de G. Bessette, "L'unanimisme dans les romans de Malraux", p. 80-88. 
École littéraire de Montréal, L'. Les Soirées du Château de Ramezay. Montréal : Eusèbe Senécal et Co., 1900.

-. L'École littéraire de Montréal. Procès-verbaux, correspondance et autres documents inédits. Réunis, classés et annotés par Réginald Hamel. Université de Montréal, 1974 (version non définitive, 25 exemplaires distribués aux spécialistes).

Écrits du Canada français, 1982. Numéro spécial entièrement consacré à Louis Dantin.

Edwards, Mary Jane, ed., The Evolution of Canadian Literature in English : Beginnings to 1867. Toronto: Holt, Rinehart \& Winston of Canada, 1973.

Ehrenzweig, Anton. L'Ordre caché de l'art. Essai sur la psychologie de l'imagination artistique. Trad. Francine Lacoue-Labarthe et Claire Nancy. Paris : Gallimard, 1967.

Einstein, Albert, et Leopold Infeld. L'Évolution des idées en physique. Trad. Maurice Solovine. Paris : Payot, 1963.

Eliade, Mircea. Mythes, rêves et mystères. Paris : Gallimard, 1957.

-. Le Sacré et le Profane. 1957. Paris : Gallimard, 1965.

Élie, Robert. La Fin des songes. Montréal : Beauchemin, 1950.

—, dir. L'École laïque. Montréal : Éditions du Jour, 1961.

Eliott, George. Middlemarch.A Study of Provincial Life. New York : A.L. Burt Co., s.d.

—. The Kissing Man. Toronto: Macmillan, 1962.

Ellenberger, Henri F. Les Mouvements de libération mythiques et autres essais sur l'histoire de la psychiatrie. Montréal : Quinze, 1978.

Émond, Maurice. Yves Thériault et le combat de l'homme. Montréal : Hurtubise HMH, 1973. 
Erikson, Erik. Enfance et société. Neuchatel: Delachaux et Niestlé, 1966.

Escarpit, Robert. Sociologie de la littérature. Paris : PUF, 1958.

—. L'Humour. Paris : PUF, coll. «Que sais-je?», 1960.

Eschyle. Théâtre complet. Trad. Émile Chambry. Paris : GarnierFlammarion, 1964.

Éthier-Blais, Jean. Signets II. Montréal : Le Cercle du Livre de France, 1967.

—. Mater Europa. Montréal : Le Cercle du Livre de France, 1968.

—. Signets III. Montréal : Le Cercle du Livre de France, 1973.

-. Le Manteau de Rubén Darío. Montréal : Hurtubise HMH, 1974.

—. Dictionnaire de moi-même. Montréal : La Presse, 1976.

—. Les Pays étrangers. Montréal : Leméac, 1982.

-, dir. Colloque Nelligan. Poésie rêvée, poésie vécue. Montréal : Le Cercle du Livre de France, 1969.

Etiemble. Parlez-vous franglais ? Paris : Gallimard, 1964.

Euripide. Théâtre complet. Tome I. Paris : Garnier-Flammarion, 1965.

Evans, Fallon. The Trouble with Turlow. New York: Doubleday, 1961.

Evans, Richard. Entretiens avec C.G. Jung. Paris : Payot, 1970.

Eysenck, H. J. Fact and Fiction in Psychology. Harmondsworth: Penguin, 1965. 
$\boldsymbol{F}$

Fabi, Thérèse. Le Monde perturbé des jeunes dans l'œuvre de Marie-Claire Blais. Montréal : Éditions agence d'Arc, 1973.

Faguet, Émile. Dix-huitième siècle. Études littéraires. Paris : Boivin et Cie, 1890.

—. Dix-septième siècle. Études littéraires. Paris : Boivin et Cie, 1890.

Faille, Armand. Contes et Nouvelles. Montréal: Agence de distribution populaire, 1969.

Falardeau, Jean-Charles. L'Essor des Sciences sociales au Canada français. Québec: Ministère des Affaires culturelles, 1964.

-. Notre société et son roman. Montréal : Hurtubise HMH, coll. «Sciences de l'Homme et Humanisme », nº 1, 1967.

-. Imaginaire social et littérature. Montréal : Hurtubise HMH, 1974.

Farley, Paul-Emile, et Gustave Lamarche. Histoire du Canada. Montréal : Librairie des Clercs de St-Viateur, 1937.

Farrow, E. Pickworth. Psycho-Analyse Yourself. New York: Lancer Books, 1953.

Faulkner, William. The Sound and the Fury and As I Lay Dying. New York: Modern Library, 1946.

—. Knights Gambit. New York: Signet, 1950.

-. Le Bruit et la Fureur. Trad. Maurice-Edgar Coindreau. Paris : Gallimard, 1972.

Ferenczi, Sandor. Thalassa. Psychanalyse des origines de la vie sexuelle. Paris : Payot, 1962.

-. Psychanalyse I. CEuvres complètes - Tome I: 1908-1912. Paris : Payot, 1968. 
—. Psychanalyse II. OEuvres complètes II - Tome II : 1913-1919. Paris : Payot, 1970.

Ferland, Jean-Baptiste-Antoine. M. J.-B.-A. Ferland. Textes choisis et présentés par Thomas M. Charland. Montréal: Fides, coll. « Classiques canadiens », 1959.

Fernandez, Dominique. L'Échec de Pavese. Paris : Grasset, 1967.

—. L'Arbre jusqu'aux racines. Paris : Bernard Grasset, 1972.

Ferron, Jacques. La Barbe de François Hertel. Montréal : Éditions d'Orphée, 1956.

-. Tante Élise ou le prix de l'amour. Montréal : Éditions d'Orphée, 1956.

—. Le Licou. Montréal : Éditions d’Orphée, 1958.

—. Les Grands Soleils. Montréal : Éditions d’Orphée, 1958.

—. Cotnoir. Montréal : Éditions d’Orphée, 1962.

—. Cotnoir. 1962. Montréal : Éditions du Jour, 1970.

—. La Tête du roi. Montréal : Les Presses de l’A.G.E.U.M., 1963.

—. Contes anglais et autres. Montréal : Éditions d’Orphée, 1964.

—. La Nuit. Montréal : Parti pris, 1965.

—. Papa Boss. Montréal : Parti pris, 1966.

—. La Charrette. Montréal : Hurtubise HMH, 1968.

—. Contes. Montréal : Hurtubise HMH, 1968.

-. Théâtre I: Les Grands soleils, Tante Élise et Le Don Juan chrétien. Montréal : Librairie Déom, 1968.

—. Historiettes. Montréal : Éditions du Jour, 1969.

—. Le Ciel de Québec. Montréal : Éditions du Jour, 1969.

—. Le Salut de l'Irlande. Montréal : Éditions du Jour, 1970.

—. L'Amélanchier. Montréal : Éditions du Jour, 1970. (2) 
—. Les Roses sauvages. Montréal : Éditions du Jour, 1971.

—. Le Saint-Élias. Montréal : Éditions du Jour, 1972.

-. La Chaise du maréchal ferrant. Montréal : Éditions du Jour, 1972.

—. Les Confitures de coings. Montréal : Parti pris, 1972.

—. Les Confitures de coings. Montréal : Parti pris, 1977.

—. Du fond de mon arrière-cuisine. Montréal : Éditions du Jour, 1973.

—. Escarmouches : la longue passe. Tome 1. Montréal : Leméac, 1975.

-. Rosaire précédé de L'Exécution de Maski. Montréal : VLB, 1981.

Ferron, Madeleine. Cour de sucre. Montréal : Hurtubise HMH, 1966.

—. La Fin des loups-garous. Montréal : Hurtubise HMH, 1966.

—. Sur le chemin Craig. Montréal : Stanké, 1983.

Filiatrault, Jacques, dir. Petite Anthologie du Noroît. Montréal : Éditions du Noroît, 1986.

Filiatrault, Jean. Terres stériles. Québec: Institut littéraire de Québec, 1953.

—. Chaînes. Montréal : Le Cercle du Livre de France, 1955.

-. Le Refuge impossible. Montréal: Le Cercle du Livre de France, 1957.

-. L'Argent est odeur de nuit. Montréal : Le Cercle du Livre de France, 1961.

Filion, Gérard. Les Confidences d'un commissaire d'écoles. Montréal : Éditions de l'Homme, 1960. 
Flaubert, Gustave. Madame Bovary. Paris : CharpentierFasquelle, 1909.

—. L'Éducation sentimentale. Paris : Bibliothèque mondiale, 1955.

—. Bouvard et Pécuchet. Paris : Librairie Gründ, 1939.

—. Trois contes. Paris : Librairie Gründ, 1956.

Fontainas, André. Histoire de la peinture française au XIXe et au XXe siècle (1801-1920). Paris : Mercure de France, 1922.

Fontaine. Nathalie. "Maudits Français! ». Montréal : Éditions de l'Homme, 1964.

Foucault, Michel. Histoire de la folie. Paris: Union générale d'éditions, 1961.

Foucault, Michel, et al. Théorie d'ensemble. Paris : Seuil, 1968.

Foulquié, Paul. Existentialisme. Paris : PUF, coll. «Que sais-je?», 1953.

Fournier, Alain. Le Grand Meaulnes. 1913. Paris: Émile-Paul Frères, 1963.

Fournier, Jules. Mon encrier. Montréal : Fides, 1965.

-. Jules Fournier. Textes choisis et présentés par Adrien Thério. Montréal : Fides, coll. « Classiques canadiens », 1957.

Francoeur, Louis, et Philippe Panneton. 1924. À la manière de..., 4e éd. Montréal : Éditions Variétés, 1942.

Fréchette, Louis. La Légende d'un peuple. 1887. Québec: C. Darveau, 1890.

—. Originaux et détraqués, douze types québécois. 1892. Montréal : Beauchemin, 1943.

-. Fréchette. Texte établi et annoté par Michel Dassonville. Montréal : Fides, coll. «Classiques canadiens », 1959. 
-. Mémoires intimes. Texte établi par George A. Klinck. Préface de Michel Dassonville. Montréal : Fides, coll. "Nénuphar», 1961.

—. Originaux et détraqués. 1892. Présenté par Jean-Claude Germain. Montréal : Éditions du Jour, 1972.

—. Contes de Jos Violon. Éd. Victor Lévy-Beaulieu. Montréal : L'Aurore, 1974.

—. Félix Poutré. [1871.] Montréal : Leméac, 1974.

Fréchette, Louis-Honoré et al. Contes canadiens. Illustrés par Henri Julien. Montréal : Beauchemin, 1919.

Freeman, Lucy. Fight Against Fears. New York: Pocket Books, 1951. (2)

Frégault, Guy. François Bigot, administrateur français. Montréal : Les Études de l'Institut d'histoire de l'Amérique française, 1948. (2)

—. Chroniques des années perdues. Montréal : Leméac, 1976.

Frère Untel. The Impertinences of Brother Anonymous. Trans. Miriam Chapin. Montréal : Harvest House, 1962.

Fretigny, Roger, et André Virel. L'Imagerie mentale. Introduction à l'onirothérapie. Lausanne : Éditions du MontBlanc, 1968.

Freud, Sigmund. Le Mot d'esprit et ses rapports avec l'inconscient. Trad. Marie Bonaparte et M. Nathan. Paris : Gallimard, 1930.

-. Essais de psychanalyse appliquée. Trad. Marie Bonaparte et F. Marly. Paris : Gallimard, 1933.

-. Leonardo DaVinci : A Study in Psychosexuality. Trans. A. A. Brill. New York : Random House/Vintage Books, 1947.

-. Moïse et le monothéisme. Trad. Anne Berman. Paris : Gallimard, 1948. 
-. Délire et rêves dans la «Gradiva» de Jensen. Trad. Marie Bonaparte. Paris : Gallimard, 1949.

—. Introduction à la psychanalyse. Trad. S. Jankélévitch. Paris : Payot, 1950.

—. De la technique psychanalytique. Trad. Anne Berman. Paris : PUF, 1953.

-. Cinq psychanalyses. Trad. Marie Bonaparte et R. Loewenstein. Paris : PUF, 1954.

-. Civilisation and its Discontents. Trans. James Strachey. New York : W.W. Norton \& Co., 1961.

-. Introduction à la psychanalyse. Trad. S. Jankélévitch. Paris : Payot, 1962.

-. Trois essais sur la théorie de la sexualité. Trad. B. ReverchonJouve. Paris : Gallimard, 1962.

-. Psychologie collective et analyse du moi suivi de Cinq leçons sur la psychanalyse. Trad. S. Jankélévitch et Yves Le Lay. Paris : Payot, 1962.

—.Essais de psychanalyse. Trad. S. Jankélévitch. Paris : Payot, 1963.

-. Abrégé de psychanalyse. Trad. Anne Berman. Paris: PUF, 1964.

—. Inhibition, symptôme et angoisse. Trad. Michel Tort. Paris : PUF, 1965.

—. Totem et Tabou. Trad. S. Jankélévitch. Paris : Payot, 1965.

—. Psychopathologie de la vie quotidienne. Paris : Payot, 1967.

-. Métapsychologie. Trad. Jean Laplanche et J.-B. Pontalis. Paris : Gallimard, 1968.

—. La Vie sexuelle. Trad. Jean Laplanche. Paris : PUF, 1969. 
—. Malaise dans la civilisation. Trad. Ch et J. Odier. Paris : PUF 1971.

-. Névrose, psychose et perversion. Trad. Jean Laplanche. Paris : PUF, 1973.

-. The Interpretation of Dreams. Trans. James Strachey. New York : Penguin Books, 1977.

Freud, Sigmund, et Joseph Breuer. Études sur l'hystérie. Trad. Anne Berman. Paris : PUF, 1956.

Freud, Anna. Le Moi et les mécanismes de défense. Trad. Anne Berman. Paris : PUF, 1964.

Friday, Nancy. My Mother/ My Self. The Daughter's Search for Identity. New York: Dell, 1978.

Froissart, Jean. Les Chroniqueurs français, Froissart, Joinville, Commines. OEuvres choisies. Paris : La Renaissance du Livre, 1929.

Fromentin, Eugène. Les Maîtres d'autrefois: Belgique, Hollande. Paris, 1876.

Frontenac, Louis de Buade. Frontenac. Textes choisis et annotés par Lilianne et Guy Frégault. Montréal: Fides, coll. « Classiques canadiens », 1956.

Fromm, Erich. Marx's Concept of Man. New York: Frederick Ungar Publishing Co., 1964.

Frye, Northrop. The Modern Century. Toronto: Oxford University Press, 1967.

Funck-Brentano, Frantz. L'Ancien Régime. Paris : Fayard, 1936.

Fussini-Doddoli, Myriam. Le Rêve éveillé dirigé. Paris : Édition ESF, 1970.

Frydman, Daniel. Et vous trouverez le sommeil. Paris : Encre Éditions, 1980. 
$\boldsymbol{G}$

Gaboury, Placide. Louis Dantin et la critique d'identification. Montréal : Hurtubise HMH, 1973.

Gagné, Marc. Les Visages de Gabrielle Roy. Montréal : Beauchemin, 1973.

Gagnon, Alain. Poèmes de l'homme non-né. Montréal : Le Cercle du Livre de France, 1975.

Gagnon, Alfonse. Une lune de trop. Montréal : Éditions du Jour, 1964.

—.Intensité : poèmes et parodies. Montréal : Éditions du Jour, 1964.

Gagnon, Daniel. La Fille à marier. Montréal : Leméac, 1985.

Gagnon, Ernest. L'Homme d'ici. Quebec: Institut littéraire du Québec, 1952.

—. L'Homme d'ici suivi de Visage d'intelligence. Montréal : Hurtubise HMH, 1963.

Gagnon. Jean-Louis. La Mort d'un nègre suivi de La Fin des haricots. Montréal : Éditions du Jour, 1961.

Gagnon, Marcel-A. La Vie orageuse d'Olivar Asselin. Tome 1. Montréal : Éditions de l'Homme, 1962.

-. La vie orageuse d'Olivar Asselin. Tome 2. Montréal : Éditions de l'Homme, 1962.

-. Jean-Charles Harvey, précurseur de la Révolution tranquille. Montréal : Beauchemin, 1970.

Gagnon. Maurice. Le Chasseur d'ombres. Montréal : Le Cercle du Livre de France, 1959.

Gamow, George. Biography of the Earth. 1941. New York: New American Library, 1948. 
—. The Creation of the Universe. 1952. New York: New American Library, 1957.

Garneau, Michel. Sur le matelas. Montréal : L’Aurore, 1974.

Garneau, François-Xavier. Histoire $d u$ Canada depuis sa découverte jusqu'à nos jours. Tome 1. 6e édition. Paris : Librairie Félix Alcan, 1920.

- Histoire du Canada depuis sa découverte jusqu'à nos jours. Tome 2. 5e édition. Paris : Libairie Félix Alcan, 1920.

- François-Xavier Garneau. Textes choisis et présentés par Arsène Lauzière. Montréal : Fides, coll. Classiques canadiens, 1965.

Gaudreau, Jean. De l'échec scolaire à l'échec de l'école: les sacrifiés. Montréal : Québec/ Amérique, 1980.

Gauvin, Lise. Parti pris littéraire. Montréal: Presses de l’Université de Montréal, 1975.

Gauvreau, Jean-Marie. Artisans du Québec. Trois Rivières: Éditions du Bien public, 1940.

Gay, Paul. Notre littérature: guide littéraire du Canada français. Montréal : Hurtubise HMH, 1969.

- Notre Roman. Panorama littéraire du Canada français I. Montréal : Hurtubise HMH, 1973.

-. Notre poésie. Panorama littéraire du Canada français II. Montréal : Hurtubise HMH, 1974.

Gazounaud. Mission négative. Montréal: Guérin, coll. «Le cadavre exquis », 1974.

Geets, Claude. Mélanie Klein. Paris: Éditions universitaires, 1971.

Gélinas, Gratien. Tit-coq. Montréal : Beauchemin, 1950.

—. Bousille et les justes. Québec: Institut littéraire de Québec, 1960. 
Gélinas, Michelle. Léo-Paul Desrosiers ou le récit ambigu. Montréal : Presses de l'Université de Montréal, 1973.

Gélinas, Pierre. Les Vivants, les morts et les autres. Montréal : Le Cercle du Livre de France, 1959.

—. L'Or des Indes. Montréal : Le Cercle du Livre de France, 1962.

Gendron, Lionel. La Sexualité. Montréal : Éditions de l'Homme, 1968.

—. Vivre 100 ans. Montréal : Lionel Gendron, 1974.

Gendron, Marc. Louise ou la nouvelle Julie. Montréal : Québec/Amérique, 1981.

Genet, Jean. OEuvres complètes. Paris : Gallimard, 1951.

Genevoix, Maurice. Canada. Paris : Flammarion, 1945.

Genuist, Monique. La Création romanesque chez Gabrielle Roy. Montréal : Le Cercle du Livre de France, 1966.

Genuist, Paul. Marie-Anna Roy, une voix solitaire. St-Boniface : Éditions des Plaines, 1992.

Geoffrion, Louis-Philippe. Zigzag autour de nos parlers : simples notes. Séries I, II, III. Québec : Chez l'auteur, 1925.

Gérin-Lajoie, Antoine.Jean Rivard, le défricheur. 1864. Montréal : Beauchemin, 1913.

Germain, Jean-Claude. Les Tourtereaux ou la vieillesse frappée à l'aube. Montréal : L'Aurore, 1974.

Gérols, Jacqueline. Le Roman québécois en France. Montréal: Hurtubise HMH, 1984.

Gershman, Herbert S., et Kernan B. Whitworth, Jr., éd. Anthologie des préfaces de romans français du XIXe siècle. Paris : Julliard, 1964.

Ghislaine, Rey, éd. Anthologie du roman haïtien de 1859 à 1946. Sherbrooke : Éditions Naaman, 1978. 
Gibault, François. Céline. Tome 2. 1932-1944 : Délires et persécutions. Paris : Mercure de France, 1985.

Gide, André. Journal 1939-1949. Souvenirs. Paris : Gallimard, coll. «Bibliothèque de la Pléiade », 1954.

Gignac, Rodrigue. Toua - poèmes. Québec: Éditions de l’hôte, 1960.

Giguère, Diane. Le Temps des jeux. Montréal : Le Cercle du Livre de France, 1961.

-. L'Eau est profonde. Montréal : Le Cercle du Livre de France, 1965.

Giguère, Roland. L'Âge de la parole. Montréal: L'Hexagone, 1965.

—. Pouvoir du noir. Montréal : Ministère des affaires culturelles, [1966?].

Gilford, Barry, et Lawrence Lee. Les Vies parallèles de Jack Kerouac. Trad. Brice Matthieussent. Paris: Henri Veyrier, 1979.

Gill, Charles. Le Cap Éternité. Montréal : Éditions du Devoir, 1919.

-. Correspondance. Réunie, classée et annotée par Réginald Hamel. Montréal : Parti pris, 1969. (2)

Girard, Claude. Ernest Jones, sa vie, son ouvre. Paris: Petite Bibliothèque Payot, 1972.

Girard, Rodolphe. Marie Calumet. 1904. Montréal : Fides, coll. « Nénuphar», 1973.

Giraud, Marcel. Histoire du Canada. Paris : PUF, coll. «Que saisje?», 1950.

Girott, Haim G. Between Parent and Child : New Solutions to Old Problems. New York: Macmillan, 1965. 
Girourard, Marot. La Ville inhumaine. Montréal: Parti pris, 1964.

Giroux, Maurice. Essai politique sur la crise des deux nations canadiennes. Montréal : Éditions Sainte-Marie, 1967.

Giroux, André. Le Gouffre a toujours soif. Québec: eQuébec, 1959.

Glassco, John, ed. The Poetry of French Canada in Translation. Toronto: Oxford University Press, 1970.

Giroux, Robert. Les Bengalis d'Arthur de Bussières. Sherbrooke : Éditions Cosmos, 1975.

Gobeil, Jules. Le Publicain. Montréal: Le Cercle du Livre de France, 1958.

Gobin, Pierre. «Les Enfants terribles » de Jean Cocteau. Paris : Hachette, coll. « Lire aujourd'hui », 1974.

Gobin, Pierre. Le Fou et ses doubles: Figures de la dramaturgie québécoise. Montréal : Presses de l'Université de Montréal, 1978. (2)

Godbout, Jacques. C'est la chaude loi des hommes. Montréal : L'Hexagone, 1960.

—. L'Aquarium. Paris : Seuil, 1962. (2)

—. Le Couteau sur la table. Paris : Seuil, 1965. (2)

-. Le Mouvement du 8 avril. Montréal : Mouvement laïque de langue française, coll. « MLF », n 1, 1966.

—. Salut Galarneau. Paris : Seuil, 1967. (2)

—. D’Amour P.Q. Paris : Seuil, 1972.

—. Le Réformiste, texte tranquille. Montréal : Quinze, 1975.

—. L'Ile au dragon. Paris : Seuil, 1976.

—. Les Têtes à Papineau. Paris : Seuil, 1981. 
Godfrey, Dave. The New Ancestors. Toronto: New Press, 1973.

Godin, Gérard. Les Cantouques. Montréal : Parti pris, 1967.

Godin, Jean-Cléo, et Laurent Mailhot. Le Théâtre québécois. Montréal : Hurtubise HMH, 1970.

Godin, Marcel. La Cruauté des faibles. Montréal : Éditions du Jour, 1961.

—. Ce maudit soleil, roman. Paris : Robert Laffont, 1965.

Goethe. Faust et le second Faust. Trad. Gérard de Nerval. Paris : Librairie Garnier Frères, 1950.

Goldmann, Lucien. Le Dieu caché. Paris : Gallimard, 1959.

-. Pour une sociologie du roman. Paris : Gallimard, 1964.

-. Structures mentales et création culturelle. Paris: Union générale d'édition, 1970.

Goodall, Jane Van Lawick. Les Chimpanzés et moi. Trad. Robert Latour. Paris : Stock, 1971.

Goulet, Robert. The Violent Season. New York: New American Library, 1961.

Goustard, Michel. Les Singes anthropoïdes. Paris: PUF, coll. «Que sais-je?», 1970.

Graham, Angus. Napoléon Tremblay. Montréal : Tremblay, 1945.

Grandbois, Alain. Rivages de l'homme, poèmes. Québec: (s.é.), 1948.

—. L'Étoile pourpre. Montréal : L'Hexagone, 1957.

-.Né à Québec: Louis Jolliet; récit. Montréal: Fides, coll. « Nénuphar », 1962.

—. Poèmes. Montréal : Éditions de l’Hexagone, 1963.

-. Avant le chaos, suivi de quatre nouvelles inédites. Montréal : Hurtubise HMH, 1964. 
- Alain Grandbois. Textes choisis et présentés par Jacques Brault. Montréal : Fides, coll. « Classiques canadiens », 1967. (2)

-.Visages du monde: images et souvenirs de l'entre deux guerres. Montréal : Hurtubise HMH, 1971.

Grandpré, Pierre de.Marie Louise des champs: roman. Montréal : Fides, 1948.

- La Passion des justes. Montréal: Le Cercle du Livre de France, 1966.

-. Dix ans de vie littéraire au Canada français. Montréal: Beauchemin, 1966.

Grandpré, Pierre de, dir. Histoire de la littérature française du Québec. Tome 1. Montréal : Beauchemin, 1967.

-. Histoire de la littérature française du Québec. Tome 2. Montréal : Beauchemin, 1968.

-. Histoire de la littérature française du Québec. Tome 3. Montréal : Beauchemin, 1969.

-. Histoire de la littérature française du Québec. Tome 4. Montréal : Beauchemin, 1969.

Grant, Elliot. French Poetry of the Nineteenth Century. New York: Macmillan, 1962.

Gray, Clayton. Le Vieux Montréal. Montréal : Éditions du Jour, 1964.

Grebanier, Bernard D. N. The Essentials of English Literature. 1948. Vol 1. New York: Barron's Educational Series, 1955.

Greer, Germaine. The Female Eunuch. 1970. London: Granada, 1981.

Greenberg, Harvey R., M.D. The Movies on Your Mind. New York: Saturday Review Press, 1975. 
Grignon, Edmond. En guettant les loups. Montréal : Beauchemin, 1930.

Grignon, Claude-Henri. Un homme et son péché. 1933. Montréal : Éditions du Vieux Chêne, 1941.

-. Un homme et son péché. 1933. Montréal : Centre Éducatif et culturel, 1965.

-. Le Déserteur et autres récits de la terre. Montréal : Éditions du Vieux chêne, 1940.

Grisé, Yolande. Pour se faire un nom. Montréal : Fides, 1982.

Grollman, Earl. A., ed. Explaining Death to Children. Boston: Beacon, 1969.

Grosskurth, Phyllis. Canadian writers and their works: Gabrielle Roy. Toronto : Forum House, 1972.

Groult, Benoîte. Ainsi soit-elle. Paris : Bernard Grasset, 1975.

Groulx, Lionel. Les Rapaillages. Vieilles choses vieilles gens. 1916. Montréal : Librairie Granger Frères, 1943.

- (pseudo. Alonié de Lestres). L'Appel de la race. 1922. Montréal : Librairie Granger Frères, 1943.

-. L'Appel de la race. 1922. Montréal : Fides, 1956. Préface de Bruno Lafleur.

-. Au Cap Blomidon. Montréal : Librairie Granger Frères, 1932.

—. Au Cap Blomidon. 1932. Montréal : Librairie Granger Frères, 1943.

-. L'Enseignement francais au Canada : Les écoles des minorités. Vol 2. Montréal : Librairie Granger Frères, 1935/1935.

—. Directives. Montréal : Éditions du Zodiaque : Librairie Déom frère, 1937.

-. Lionel Groulx. Textes choisis et présentés par Benoît Lacroix. Montréal : Fides, coll. « Classiques canadiens », 1967. 
—. Mes Mémoires 1878-1920. Tome I. Montréal : Fides, 1970.

—. Mes Mémoires 1920-1928. Tome II. Montréal : Fides, 1971.

—. Notre maître, le passé. Tome II. Montréal : Stanké, 1977.

—. Notre maître, le passé. Tome III. Montréal : Stanké, 1978.

Grunberger, B. Le Narcissisme. Essais de psychanalyse. Paris : Payot, 1975.

Guay, Jean-Pierre. Lorsque notre littérature était jeune: Entretiens avec Pierre Tisseyre. Montréal: Pierre Tisseyre, 1983.

Guay, Jacques. Les Gudulades. Montréal : Éditions bleu et or, 1961. (Caricatures)

Guèvremont, Germaine. En pleine terre. Montréal : Fides, 1942.

—. Le Survenant. Paris : Plon, 1945.

—. Marie-Didace. Montréal : Fides, coll. du « Nénuphar », 1947.

Guillemin, Henri. Notions de littératures étrangères envisagées dans leurs rapports avec la littérature française. Paris: J. de Gigord, 1937.

Guimont, Marie Saint-Jacques. À la limite des choses. Montréal : Éditions Beauchemin, 1957.

Guiomar, Michel. Inconscient et imaginaire dans Le Grand Meaulnes. Paris : José Corti, 1964.

Guitard, Agnès. Les Corps communicants. Montréal : Québec/Amérique, 1981.

Gurik, Robert. Spirales. Montréal : Holt, Reinhart \& Winston, 1966.

Guyénot, Émile. L'Origine des espèces. Paris: PUF, coll. «Que sais-je? », 1951.

Guyon, Bernard. Péguy. Paris : Hatier, 1960. 
Guyot, Lucien. Histoire de la flore terrestre. Paris: PUF, coll. «Que sais-je?», 1969.

Guyot, Lucien, et Pierre Gibassier. Les Noms des animaux terrestres. Paris : PUF, coll. « Que sais-je?», 1968.

\section{$\boldsymbol{H}$}

Hadfield, J. A. L'Enfance et l'adolescence. Paris : Payot, 1968.

Hadley, Anita, et Jacqueline van Campen. Gens de chez nous. Toronto : Irwin, 1985.

Hamel, Louis-Paul. Poèmes. Montréal : Litho Presses Inc., 1966. (2)

—.Poèmes, premier recueil. Montréal: Imprimerie Michaud, 1958.

Hamel, Réginald. Cahier bibliographique des lettres québécoises, janvier, février, mars 1968. Montréal : Presses de l'Université de Montréal, 1968.

—. Gaétane de Montreuil. Montréal : L’Aurore, 1976.

Hamelin, Jean. Le Renouveau du théâtre au Canada français. Montréal : Éditions du Jour, 1961.

—. Nouvelles singulières. Montréal : Hurtubise HMH, 1964.

-. Le Théâtre au Canada français. Québec: Ministère des Affaires culturelles, 1964.

—. Le Canada français : son évolution historique. Trois Rivières : Boréal Express, 1966-1967.

Hamm, Jean-Jacques. Lisborg les bains; pièce en trois actes et vingt-six tableaux. Bordeaux : Maison des jeunes, 1969.

—. Griffes. Paris : La Pensée universelle, 1985. 
Harris, Marvin. Cannibals and Kings. The Origins of Cultures. New York: First Vintage, 1978.

Hartley, Anthony, ed. The Penguin Books of French Verse, vol. 3: $19^{\text {th }}$ century. Harmondsworth: Penguin, 1957.

Harvey, Jean-Charles. L'Homme qui va. 1929. Montréal : Éditions de l'Homme, 1967.

—. Les Demi-civilisés. 1934. Montréal : Éditions de l'Homme, 1962.

Hasek, Jaroslave. The Good Soldier Schweik. New York: New American Library, 1963.

Hatch, Alden. Le Miracle de la montagne: l'histoire de frère André et de l'oratoire Saint-Joseph à Montréal. Trad. Jean de Madre. Paris : Librairie Arthème Fayard, 1959.

Hawthorne, Nathaniel. Scarlet Letter. 1850. New York : Award Books, n.d.

Hayne, David M., et Marcel Tirol. Bibliographie critique du roman canadien-français, 1837-1900. Toronto: Toronto University Press, 1968.

Hébert, Anne. Les Songes en équilibre. Montréal : Éditions de l'Arbre, 1942.

—. Le Torrent. Montréal : Beauchemin, 1950.

—. Le Torrent. 1950. Montréal : Hurtubise HMH, 1976.

—. Le Tombeau des rois. Québec: Institut littéraire de Québec, 1953.

—. Les Chambres de bois. Paris : Seuil, 1958.

—. Poèmes. Paris : Seuil, 1960.

-. Le Temps sauvage, La Mercière assassinée, Les Invités au procès. Montréal : Hurtubise HMH, 1967.

—. Kamouraska. Paris : Seuil, 1970. 
—. Les Enfants du sabbat. Paris : Seuil, 1975.

—. Les Fous de Bassan. Paris : Seuil, 1982.

Hébert, Jacques. Trois jours en prison. Montréal : Le Club du Livre du Québec, 1965.

—. Les Écoeurants. Montréal : Éditions du Jour, 1966.

—. Bla bla bla du bout du monde. Montréal : Éditions du Jour, 1971. (2)

—. Voyager en pays tropical. Montréal : Boréal Express, 1984.

Hébert, Louis-Philippe. La Manufacture de machines. Montréal : Quinze, 1976.

Hébert, Maurice. De livres en livres. Montréal : Éditions du Mercure, 1929.

—. D'un livre à l'autre. Montréal : Albert Lévesque, 1932.

-. Les Lettres au Canada français, première série. Montréal : Albert Lévesque, 1936.

Hébert, Marie-Francine. Slurch (suite érotique). Montréal : La Barre du jour, 1970.

Hegel. Esthétique. Textes choisis par Claude Khodoss. Paris : PUF, 1959.

Held, René R. Psychothérapie et psychanalyse. Paris: Payot, 1968.

Hémon, Louis. Maria Chapdelaine. 1916. Montréal : Fides, coll. « Nénuphar», 1924.

—. Maria Chapdelaine. 1916. Paris : Bernard Grasset, 1924.

—. Colin Maillard. 1924. Montréal : Éditions du Jour, 1972.

—. Monsieur Ripois et la Némésis. Paris : Bernard Grasset, 1950.

Hénault, Gilles. Sémaphore suivi de Voyage au pays de mémoire.

Montréal : L’Hexagone, 1962. 
Hertel, François. Mondes chimériques. Montréal : Société des Éditions Pascal, 1944.

—.Journal d'Anatole Laplante. Montréal: Serge Brousseau, 1947.

-. Journal philosophique et littéraire. Paris: Éditions de la Diaspora française, 1961.

—. Poèmes européens. Paris : Éditions de la Diaspora française, 1961.

—. Le Beau Risque. Montréal : Fides, 1961. (sans couverture)

—. Méditations théologiques 1952-1962. Paris: Éditions de la Diaspora française, 1963. (2)

—. Anthologie 1934-64. Paris : Éditions de la Diaspora française, 1964.

—. La Morte. Paris : Éditions de la Diaspora française, 1965.

—.Vers une sagesse. Paris : Éditions de la Diaspora française, 1966.

—. Jérémie et Barabbas; Nouvelles. Montréal : Éditions du Jour, 1966.

—. Louis Préfontaine, autobiographie approximative. Montréal : Éditions du Jour, 1967.

-. Cent ans d'injustice? Un beau rêve: le Canada. Montréal : Éditions du Jour, 1967.

—. Du métalangage. Paris : Éditions de la Diaspora française, 1968.

—. Divagations sur le langage. Paris : Éditions de la diaspora française, 1969.

-. Souvenirs, historiettes, réflexions. Paris: Éditions de la Diaspora francaise, 1972.

—. Souvenirs et impressions. Montréal : Stanké, 1977. 
-. Souvenirs et impressions du premier âge, du deuxième âge et du troisième âge. Montréal : Stanké, 1977.

Hesnard, A. L'Univers morbide de la faute. Paris : PUF, 1949.

—. Manuel de sexologie. Paris : Payot, 1959.

—. Les Phobies et la névrose phobique. Paris : Payot, 1961.

Hiebert, Paul. Sarah Binks. Toronto: McClelland \& Stewart, 1967.

Hillesum, Etty. An Interrupted Life. The Diaries of Etty Hillesum 1941-1943. Ed. J.G. Gaarlandt. New York: Washington Square Press, 1985.

Hoeniger, F.D. "Review Article: A French Canadian Picaro ». Queen's Quarterly.Vol. 69, no 2. Summer 1962: s.p. [tiré à part. SurNot For Every Eye, la traduction du Libraire par Glen Shortliffe.]

Hoffmann. Ernest. Contes fantastiques. Paris: Nouvel Office d'Édition, 1963.

Hoffman, Frederick. Samuel Beckett. The Man and His Works. Toronto : Forum House, 1969.

Hollander, Xaviera. Madam'. Paris : Jean-Claude Lattès, 1972.

Homer. L'Odyssée. Trad. Victor Bérard. Paris : Livre de Poche, 1960.

Hoopes, Ned E. and Richard Peck, ed. Edge of Awareness. 25 Contemporary Essays. New York: Dell, 1969.

Horic, Alain. Blessure au flanc du ciel. Montréal : L'Hexagone, 1962.

Horney, Karen. New Ways in Psychoanalysis. New York: Norton Library, 1939.

-. Les Voies nouvelles de la psychanalyse. Trad. Jean Pans. Paris : L’Arche, 1951. 
Hoskisson, J. Bradley. Loneliness : An Explanation, a Cure. New York: Citadel Press, 1965.

Hoyle, Fred. The Nature of the Universe. New York: New American Library, 1955.

Huard, Roger. Huard deux farces, théâtre à demi. Montréal : Éditions Agora, (s.d.).

—. Pile. Québec : Éditions de l’Arc, 1984.

Hubbard. R.H. Scolarship in Canada 1967. Toronto: University of Toronto Press, 1968.

Hudon, Normand. Parlez-moi d'humour. Montréal : Éditions du Jour, 1965.

Hugo, Victor. Ruy Blas. Paris : Bordas, 1963.

-. Morceaux choisis de Victor Hugo. Tome 1. Le Poète. Santiago de Chile : Éditions de la Librairie française, s.d.

-. AEuvres choisies illustrées. Éd. Léopold-Lacour. Poésie et drames en vers. Paris : Bibliothèque Larousse, s.d.

Hunt, Morton M. The Natural History of Love. New York: Grove Press, 1959.

Huxley, Aldous. Point Counter Point. New York: Modern Library, 1928.

—. Time Must Have a Stop. New York: Berkley Publishing Corp, 1944.

-. Les Portes de la perception. Trad. Jules Castier. Monaco: Éditions du Rocher, 1954.

—. Marina Di Vezza. Trad. Julia Bastin. Paris : Plon, 1957.

—. Île. Trad. Mathilde Treger. Paris : Plon, 1962.

Huxley, Julian. Man in the Modern World. New York: New American Library, 1944. 
Ibsen, Henrik. Hedda Gabler and Three Other Plays: The Pillars of Society, The Wild Duck, Little Eyolf. Trans. Michael Meyer. New York: Doubleday, 1961.

Isaacs, Susan. Les Premières Années de l'enfant. Trad. Robert Eggimann. Paris : Delachaux et Niestlé S.A., 1955.

Jacques, Michel. Roseaux ensevelis. Arthabaska: Le pont invisible, 1963.

Jagot, Paul-C. Le Pouvoir de la volonté sur soi-même, sur les autres, sur le destin. Paris : Dangles, 1943.

Jakobson, Roman. Essais de linguistique générale. Trad. Nicolas Ruwet. Paris : Éditions de Minuit, 1963.

—. Huit questions de poétique. Paris : Seuil, 1977.

James, Henry. Daisy Miller and Other Stories. New York: Airmont, 1969.

James, William. Psychology. Greenwich, Conn.: Fawcett, 1963.

Jankélévitch, Vladimir.L'Ironie ou la bonne conscience. 2e édition. Paris : PUF, 1950.

—. Le Pur et l'Impur. Paris : Flammarion, 1960.

Janov, Arthur. Le Cri primal. Trad. Jeanne Etoré et France Daunic. Paris : Flammarion, 1975.

-. L'Amour et l'Enfant. Trad. Anne Rabinovitch. Paris: Flammarion, 1977.

Janvier, Ludovic. Une parole exigeante. Le nouveau roman. Paris : Éditions de Minuit, 1964. (2) 
Jasmin, Claude. Délivrez-nous du mal. Montréal : Éditions À la page, 1961.

一. Éthel et le terroriste. Montréal : Librairie Déom, 1964.

-. Et puis tout est silence. Montréal: Éditions de l'Homme, 1965.

—. Pleure pas, Germaine. Montréal : Parti pris, 1965.

—. Les Couurs empaillés. Montréal : Parti pris, 1967.

-. Rimbaud, mon beau salaud. Montréal: Éditions du Jour, 1969.

—. Tuez le veau gras. Montréal : Leméac, 1970.

-. Jasmin par Jasmin. Montréal : Claude Langevin, 1970. (2)

—. L'Outaragasipi. Montréal : L’Actuelle, 1971.

—. La Petite Patrie. Montréal : La Presse, 1972.

-. Pointe-Calumet : Boogie-Woogie. Montréal : La Presse, 1973.

—. Feu à volonté. Montréal : Leméac, 1976.

-. Le Loup de Brunswick City. Montréal : Leméac, 1976.

—. Revoir Éthel. Montréal : Stanké, 1976.

—. La Sablière. Montréal : Leméac, 1979.

Jean, Georges. Le Roman. Paris : Seuil, 1971.

Jean-Charles. Vingt cancres après. Paris : Presses de la Cité, 1966.

Jenkins, T.A., éd. La Chanson de Roland. Boston : D.C. Heath \& Company, 1924.

Jones, Ernest. The Life and Works of Sigmund Freud. Vol 2. Years of Maturity 1901-1919. New York : Basic Books, 1955.

-. The Life and Works of Sigmund Freud. Vol. 3. The Last Phase. New York : Basic Books, 1957. 
Jones, D.G. Butterfly on Rock. A Study of Themes and Images in Canadian Literature. Toronto: University of Toronto Press, 1970.

Joyce, James. Ulysse. Trad. Auguste Morel. Paris : Gallimard / Le Livre de Poche, 1948. (2)

Joyce. James. A Portrait of the Artist as a Young Man. New York: Viking Press, 1965.

-. The Essential James Joyce. Ed. Harry Levin. Harmondsworth: Penguin, 1974.

Juéry, René, dir.Manie Tobie, femme du Manitoba. SaintBoniface : Éditions des Plaines, 1979.

Jung. C.G. Conflits de l'âme enfantine. Trad. L. Devos et Olga Raesvky. Paris : Aubier, 1936.

—. L'Homme à la découverte de son âme. Paris : Payot, 1962.

-. L'Âme et la vie. Trad. Roland Cahen et Yves Le Lay. Paris : Buchet/Chastel, 1963.

—. Psychologie de l'inconscient. Genève : Librairie Georg \& Cie, 1963.

—. Essai d'exploration de l'inconscient. Paris : Gonthier Laffont, 1964.

-. Man and His Symbols. Trans. Roland Cahen. New York: Dell, 1968.

Jung, C. G., et Ch. Kerényi. Introduction à l'essence de la mythologie. Trad. H.E. del Medico. Paris : Payot, 1953.

$\boldsymbol{K}$

Kafka, Franz. La Colonie pénitentiaire. Trad. Alexandre Vialatte.

Paris : Gallimard-« Le Livre de poche », 1948. 
-. Selected Short Stories of Franz Kafka. Trans. Willa and Edwin Muir. Ed. Philip Rahv. New York: The Modern Library, 1952.

—. La Métamorphose. Trad. Alexandre Vialatte. Gallimard-« Le Livre de Poche », 1955.

—. Le Procès. Trad. Alexandre Vialatte. Paris : Gallimard, 1957.

—. Le Château. Trad. Alexandre Vialatte. Paris : Gallimard-Folio, 1965.

Kant, Immanuel. Critique of Pure Reason. Part I, Vol 1. Trans. J.M.D. Meiklejohn. New York: P.F. Collier and Son, 1900.

Karel, David.André Biéler ou le choc des cultures. Québec: Presses de l'Université Laval, 2005.

Kas. Kas. Paris : Calmann-Lévy, 1970.

Kattan, Naïm, dir. Les Juifs et la communauté française. Montréal : Éditions du Jour, coll. «Idées du jour », 1965.

-. Le Réel et le Théâtral. Montréal: Hurtubise HMH, coll. « Constantes », 1970.

—. Adieu Babylone. Montréal : La Presse, 1975.

—. Les Contes de grand-mère. Montréal : Bergeron, 1982.

Kavanaugh, Robert. E. Facing Death. New York: Penguin, 1974.

Kazantzakis, Nikos. The Last Temptation of Christ. Trans. P.A. Bien. Montreal: Bantam Books, 1960.

Keats, John. Poems of Keats. Ed. Edwin Markham. New York: Cooperative Publication Society, 1910.

Keller, Helen. The Story of My Life. 1902. Ed. Eleanor Roosevelt. New York: Doubleday, 1961.

Keller, Joseph. Something Happened. New York: Alfred A. Knopf, 1974.

Kent, William. London for Everyman. London: J.M. Dent \& Sons, 1971. 
Kerouac, Jack. Sur la route. Trad. Jacques Houbard. Paris : Gallimard, 1960.

—. Le Vagabond solitaire. Trad. Jean Autret. Paris : Gallimard, 1969.

Kidd, Flora. Meeting at Midnight. Toronto: Harlequin Books, 1981.

Kierkegaard, Soeren. Le Journal du séducteur. Trad. F. et O. Prior et M.H. Guignot. Paris : Gallimard, 1943.

Klein, A.M. The Second Scroll. Toronto: McClelland \& Stewart, 1951.

Klein, Mélanie. Narrative of a Child Analysis. New York: Dell, 1955.

-. Essais de psychanalyse (1921-1945). Trad. Marguerite Derrida. Paris : Payot, 1967.

-. Envie et gratitude, et autres essais. Trad. Victor Smirnoff. Paris : Gallimard, 1968.

-. Psychanalyse d'un enfant. Trad. Mireille Davidovici. Paris : Claude Tchou, 1973.

Klein, Mélanie, Susan Isaacs, Paula Heimann, et Joan Riviere. Développements de la psychanalyse. Trad. Willy Baranger. Paris : PUF, 1966.

Klimov, Alexis. Soljenitsyne, la science et la dignité de l'homme. Montréal : Guy Maheux, 1978.

Klinck, Georges A. Louis Fréchette, prosateur. Lévi : Le quotidien limité, 1955.

Koestler, Arthur et Cynthia. L'Étranger du square. Trad. MarieFrance de Paloméra. Paris : Calmann-Lévy, 1984.

Kofman, Sarah. L'Enfance de l'art. Paris : Payot, 1970.

Kohler, Wolfgang. Psychologie de la forme. Paris: Gallimard, 1964. 
Kovel, Joel. A Complete Guide to Therapy. From Psychoanalysis to Behaviour Modification. New York: Panthcon Books, 1976.

Kretschmer, Ernest. Paranoïa et sensibilité. Paris : PUF, 1963.

Kushner, Éva. Patrice de La Tour du Pin. Paris: Seghers, coll. « Poètes d'aujourd'hui », 1961.

—. Saint-Denys Garneau. Paris : Pierre Seghers. Coll. "Poètes d'aujourd'hui », 1967.

—. Mauriac. Paris : Desclée de Brouwer, 1972.

\section{$\boldsymbol{L}$}

Labarrère-Paule, André. Les Instituteurs laïques au Canada français 1836-1900. Québec. Presses de l'Université Laval, 1965.

Laberge, Albert. La Scouine. Montréal : L’Actuelle, 1972. (2)

-. La Scouine. (photocopie)

-. Peintres et écrivains d'hier et d'aujourd'hui. Montréal: Édition Privée, 1938.

—. La Fin du voyage. Montréal : Édition Privée, 1948.

Laberge, Marie. Halte. Québec : Éditions de l’Arc, 1965. (2)

Laborit, Henri. L'Homme et la Ville. Paris : Flammarion, 1971.

La Bruyère. Les Caractères. 1688. Paris : Garnier-Flammarion, 1965.

—. Les Caractères. 1688. Paris : Nelson Éditeurs, s.d.

Lacan, Jacques. Écrits I. Paris : Seuil, 1966.

Lacassagne, Jean, et Pierre Devaux. L'Argot du milieu. Paris : Albin Michel, 1948.

Lacasse, Lise. Au défaut de la cuirasse. Montréal : Quinze, 1977. 
Lacassin, Francis. Pour un 9e art: la bande dessinée. Paris: Union Générale d'Éditions, 1971.

Lacey, Robert. Majesty: Elizabeth II and the House of Windsor. New York: Avon, 1977.

Lachance, Micheline. Le Frère André. Montréal: Éditions de l'Homme, 1980.

Lacombe, Patrice. La Terre paternelle. 1846. Québec: Imprimerie A. Coté, 1877.

Lacôte, René, et Georges Haldas. Tristan Tzara. Paris : Seghers, 1952.

Laclos, Choderlos de. Les Liaisons dangereuses. Paris : S.E.P.E (Bibliothèque de Lecture de Paris), s.d.

Lacretelle, Jacques de.Silbermann suivi de Le Retour de Silbermann. Paris : Gallimard, 1946. (2).

LaFayette, Madame de. 1678. La Princesse de Clèves. Paris: Gallimard et Libraire Générale française, 1958.

—. La Princesse de Clèves. 1678. Paris : Livre de Poche, 1958.

Laffont, Robert. Robert Laffont éditeur. Uun homme et son métier. Paris : Robert Laffont, 1974.

La Fontaine. Fables. Ed. Pierre Clarac. Paris : Librairie Générale Française, 1972.

-. Les Fables de La Fontaine. Ed. Jean Giraudoux. Paris: Gallimard-Librairie Générale Française, 1964.

Lafrance, Yvon, dir.Philosophie et littérature. Montréal: Bellarmin, 1979.

Laforte, Conrad. La Chanson folklorique et les écrivains du dixneuvième siècle en France et au Québec. Montréal : Hurtubise HMH, coll. « Cahiers du Québec », 1973.

Lagarde, André, et Laurent Michard. Moyen Âge. Tome I. Paris : Bordas, 1962. 
—. XVIIe siècle. Tome III. Paris : Bordas, 1962.

—. XVIIIe siècle. Tome IV. Paris : Bordas, 1962.

—. XIXe siècle. Tome V. Paris : Bordas, 1962.

—. XXe siècle. Tome VI. Paris : Bordas, 1962.

Lahner, Stephan. Discover Yourself. Greenwich, Conn.: Fawcett, 1963.

Lahontan, Louis Armand de Lom d 'Arce.Un outre-mer au XVIIe siècle. Voyages au Canada du Baron de La Hontan. Éd. François Nion. Paris : Librairie Plon, 1900.

Laliberté, Alfred. Mes souvenirs. Montréal : Éditions du Boréal Express, 1978.

Lalou, René. Histoire de la littérature française contemporaine (1870 à nos jours). Paris : PUF, 1947.

—. Les Étapes de la poésie française. Paris : PUF, coll. «Que saisje? », 1947.

Lamartine, Alfonse de. Méditations poétiques. Ed. Jean des Cognets. Paris : Librairie Garnier Frères, 1925.

Lamb, Harold. Theodora and the Emperor. The Drama of Justinian. London: Robert Hale, 1953.

Lamirande, Claire de. Aldébaran ou la fleur. Montréal : Éditions du Jour, 1968.

—. La Baguette magique. Montréal : Éditions du Jour, 1971.

—. Signé de biais. Montréal : Quinze, 1976.

Lamontagne, Léopold. Arthur Buies, homme de lettres. Québec : Presses de l'Université Laval, 1957.

-.Kingston: son héritage français. Vanier: Éditions L'Interligne, 1995.

Lanctôt, Gustave. Histoire du Canada. Des origines au Régime royal. Montréal : Beauchemin, 1962. 
-. Histoire du Canada. Du Régime royal au Traité d'Utrecht 1663-1713. Montréal : Beauchemin, 1963.

-. Histoire du Canada. Du Traité d'Utrecht au Traité de Paris 1713-1763. Montréal : Beauchemin, 1964.

—. Filles de joie ou filles du roi. Montréal: Éditions du Jour, 1964.

Landon, Margaret. Never Dies the Dream. Garden City, N.Y.: Doubleday, 1949.

Langevin, André. Évadé de la nuit. Montréal : Le Cercle du Livre de France, 1951.

—. Poussière sur la ville. Montréal : Le Cercle du Livre de France, 1953.

—. Poussière sur la ville. 1953. Montréal : Éditions du renouveau pédagogique, 1969.

—. Le Temps des hommes. Montréal: Le Cercle du Livre de France, 1956.

—. L'Élan d'Amérique. Montréal : Le Cercle du Livre de France, 1972.

-. Une chaîne dans le parc. Montréal: Le Cercle du Livre de France, 1974.

Langlois, Gilbert. Le Domaine Casaubon. Montréal : L’Actuelle, 1971.

Languirand, Jacques. Les Grands Départs. Montréal : Le Cercle du Livre de France, 1958.

-. Les Insolites, Les violons de l'automne. Montréal: Le Cercle du Livre de France, 1962.

—. Tout compte fait. Montréal : Éditions de Noël, 1963.

—. Klondyke. Montréal : Le Cercle du Livre de France, 1971. 
Lanoux, Armand. Quand la mer se retire. Paris : René Julliard, 1963.

Lanson, G., et P. Tuffrau. Manuel illustré d'histoire de la littérature française. Paris : Hachette, 1931.

-. Histoire de la littérature française. Remaniée et complétée pour la période 1850-1950 par Paul Tuffrau. Paris : Hachette, 1951.

Lanson, Gustave. Corneille. Paris : Hachette, 1946.

Lanzmann, Jacques. Mémoire d'un amnésique. Paris : Gallimard, 1978.

Laplanche, Jean. Hölderlin et la question du père. Paris: PUF, 1969.

Lapointe, Gatien. Ode au Saint-Laurent précédé de J'appartiens à la terre. Montréal : Éditions du Jour, 1963.

—. Le Premier Mot. Montréal : Éditions du Jour, 1967.

Lapointe, Paul-Marie. Pour les âmes. Montréal : L'Hexagone, 1964.

—. Le Réel absolu; poèmes 1948-1965. Montréal : L’Hexagone, 1971.

LaPierre, Laurier L., dir. Québec : hier et aujourd'hui. Toronto : Macmillan Company, 1967.

Larbaud, Valéry. Fermina Márquez. Paris : Gallimard, 1926.

Laroche, Maximilien. Marcel Dubé. Montréal : Fides, coll. «Écrivains canadiens d'aujourd'hui », 1970.

- Le Miracle et la métamorphose: Essai sur la littérature du Québec et d'Haïti.Montréal : Éditions du Jour, 1970.

Larocque, Pierre-A. Ruines. Montréal : Éditions du Jour, 1974.

La Rocque, Gilbert. Le Nombril. Montréal : Québec/Amérique, 1970. (3) 
—. Le Nombril. Montréal : Éditions du Jour, 1970. (2)

—. Corridors. Montréal : Éditions du Jour, 1971.

—. Après la boue. Montréal : Éditions du Jour, 1972.

—. Après la boue. 1972. Montréal : Québec/Amérique, 1981. (3)

—. Le Refuge. Montréal: VLB, 1979. (3)

—. Les Masques. Montréal : Québec/Amérique, 1980. (3)

—. Le Passager. Montréal : Éditions du Jour, 1984.

Larouche, Georges. Ébauche d'un cri. Jonquière: Éditions du Réveil, 1947.

- La Voix saguenayenne ou le chemin de la délivrance. Jonquière : Éditions du Réveil, 1949.

—. Élans d'amour. (S.l.) : Coll. Boréale, 1951.

—. Val-Menaud. (s.l.) : Coll. Boréale no 4, 1952.

Larson, Christian. Échouerie. Montréal : Beauchemin, 1963.

Larue, Monique. La Cohorte fictive. Montréal : L’Étincelle, 1979.

—. Les Faux Fuyants. Montréal : Québec/Amérique, 1982.

Lasalle-Leduc, Annette. La Vie musicale au Canada français. Québec : Ministère des Affaires culturelles, 1964.

Lasnier, Louis. La Magie de Charles Amand. Montréal : Québec/Amérique, 1980.

Lasnier, Rina. Miroirs sans jours. Montréal : Éditions de l'Atelier, 1960.

—. L'Arbre blanc. Montréal : L'Hexagone, 1966.

-. Rina Lasnier. Textes choisis et présentés par Jean Marcel. Montréal : Fides, coll. « Classiques canadiens », 1964. (2)

Latreille, André et al.Le Canada français aujourd'hui et demain. Paris : Librairie Arthème Fayard, 1961. 
Laurence, Margaret. The Stone Angel. Toronto: McClelland \& Stewart, 1968.

Laurendeau, Jean. Canadiens français dans tes brumes. Québec: Éditions de l'Arc, 1962.

Laurendeau, André. Voyages au pays de l'enfance. Montréal : Beauchemin, 1960.

—. La Crise de la conscription. Montréal : Éditions du Jour, 1962.

—. Une vie d'enfer. Montréal : Hurtubise HMH, 1965.

Laurendeau, André, et A. Davidson Dunton. Rapport de la Commission royale d'enquête sur le bilinguisme et le biculturalisme: Livre I. Les langues officielles. Ottawa: Imprimeur de la Reine, 1969.

Laurin, Camille. Ma traversée du Québec. Montréal : Éditions du Jour, 1970.

Laurion, Gaston. L'Orchidée-sœur. Montréal : Éditions Aquila, 1972.

Lautréamont [Isidore Ducasse]. CEuvres complètes du Comte de Lautréamont. Ed. Philippe Soupault. Paris : Au Sans Pareil, 1927.

La Varende, Jean de. Flaubert par lui-même. Paris : Seuil, coll. «Écrivains de toujours », 1962.

Lawrence, D. H. L'Amant de Lady Chatterley. Trad. F. RogerCornaz. Paris : Gallimard, 1932.

Lazure, Jacques. La Jeunesse du Québec en révolution. Montréal : Presses de l'Université du Québec, 1970.

Leacock, Stephen. Arcadian Adventure with the Idle Rich. Toronto: McClelland \& Stewart, 1959.

Lebel, Andrée. La Corriveau. Montréal : Libre Expression, 1981.

Le Bel, Michel, et Jean-Marcel Paquette. Le Québec par ses textes littéraires, 1934-76. Montréal : France-Québec, 1979. 
Lebel, Maurice. D'Octave Crémazie à Alain Grandbois: études littéraires. Québec : Éditions de l'Action, 1963.

LeBlanc, Emery. Les Acadiens. Montréal : Éditions de l'Homme, 1963.

LeBlanc, Léopold, dir.Écrits de la Nouvelle-France. Vol. 1. Montréal : La Presse, 1978.

Le Bourhis, Jean-Paul. L'Exil intérieur. Montréal: Québec/ Amérique, 1979.

Le Carré, John. The Spy Who Came in from the Cold. London: Pan, 1964.

Leclaire, Serge. Psychanalyser : un essai sur l'ordre de l'inconscient et la pratique de la lettre. Paris : Seuil, 1968.

Leclerc, Gilles. Journal d'un inquisiteur. Montréal : Éditions de l'Aube, 1960.

Leclerc, Rita.Germaine Guèvremont. Montréal : Fides, coll. «Écrivains canadiens d'aujourd'hui », 1963.

Leclerc, Félix. Pieds nus dans l'aube. Montréal : Fides, 1946.

—. L'Auberge des morts subites. Montréal : Beauchemin, 1964.

-. Carcajou ou le diable des bois. Montréal : Éditions du Jour, 1973.

—. Chansons pour tes yeux. Montréal : Fides, 1980.

Lederer, William J., and Eugene Burdick. The Ugly American. 1958. Grenwich, Conn.: Fawcett, 1966.

Lefebvre, Henri. Le Marxisme. Paris : PUF, coll. «Que sais-je? », 1960.

—. La Vie quotidienne dans le monde moderne. Paris : Gallimard, 1968.

Lefèbvre, Mgr Marcel. Un évêque parle.Écrits et allocutions, 1963-1974. Montréal : Éd. Dominique Martin Morin, 1974. 
Le Franc, Marie. La Rivière solitaire. Montréal: Fides, coll. « Nénuphar », 1957. Préface de Léo-Paul Desrosiers.

Le Galliot, Jean. Psychanalyse et langages littéraires. Théorie et pratique. Paris : Fernand Nathan, 1977.

Legault, Rolland. La Rançon de la Cognée. Montréal : Éditions Lumen, 1945.

Léger, Pierre. Le Pays au destin nu suivi de Journal pour Patrice. Montréal : Beauchemin, 1963.

Le Grand, Albert. Anne Hébert. De l'exil au royaume. Conférence J.-A. de Sève. Montréal : Presses de l'Université de Montréal, 1966-1967.

Lejeune, Paul. Paul Lejeune, s.j. 1591-1664. Textes choisis et présentés par Léon Pouliot. Montréal: Fides, coll. «Classiques canadiens », 1957.

Lemay, Michèle. L'Affaire. Montréal : Éditions de l'Aurore, 1974.

Lemay, Pamphile. Le Pèlerin de Sainte-Anne; roman de mours. Montréal : Granger Frères \& Tours, 1930.

—. Picounoc le maudit. Montréal : Hurtubise HMH, 1972.

Lemelin, Roger. Au pied de la pente douce. Montréal : Éditions de l'Arbre, 1944.

—. Au pied de la pente douce. 1944. Montréal : La Presse, 1975.

- Fantaisies sur les péchés capitaux. Montréal : Beauchemin, 1949.

—. Les Plouffe. Québec : Institut littéraire de Québec, 1954.

- That town below. Trans. Samuel Butnam. Toronto : McClelland and Stewart, 1961.

—. Inédits de Roger Lemelin. Montréal : La Barre du Jour, mai 1971. 
Lemieux, Pierre. Nelligan et Françoise. Montréal: Fondation littéraire Fleur de Lys, 2004.

Lemoine, Roger.Joseph Marmette, sa vie, son cuvre. Québec: Presses de l'Université Laval, 1968.

-. L'Amérique et les poètes français de la Renaissance. Ottawa : Éditions de l'Université d'Ottawa, 1972.

Lemoine, Wilfrid. Les Anges dans la ville suivi de L'Ange gardien, l'ange de solitude. Montréal : Éditions d'Orphée, 1959.

Lénine, Vladimir. Deux tactiques de la social-démocratie dans la révolution démocratique. Pékin: Éditions en Langues étrangères, 1966.

Lépine, Pierre. Les Virus. Paris : PUF, « Que sais-je? », 1973.

Leroux, Gaston. L'Épouse du soleil. Verviers (Belgique): Marabout, 1978.

Le Senne, René. Traité de caractérologie. Paris : PUF, 1949.

Letellier, Marie. On n'est pas des trous-de-cul. Montréal : Parti pris, 1971.

Létourneau, Louis-Philippe. Dîner à la croque au sel. Québec: Éditions Micheline, 1977.

Létourneau, Henri. Raconte. Winnipeg: Éditions Bois-brûlés, 1978.

Lettres québécoises. № 11. Septembre 1978. Avec une entrevue de G. Bessette par Réjean Robidoux.

-. No 38. Été 1985. Avec une photo de G. Bessette sur la couverture, une entrevue de Gérard Bessette par Agnès Whitfield, et un compte rendu de Réjean Robidoux du livre Les Dires d'Omer Marin (p. 45).

Lever, Yves. Cinéma et société québécoise. Montréal : Éditions du Jour, 1972. 
Lévesque, René.Attendez que je me rappelle. Montréal: Québec/Amérique, 1986.

—. La Solution: Le programme du Parti québécois. Montréal : Éditions du Jour, 1970.

Lévesque, Richard. Les Yeux d'orage. Rivière-du-loup : Castelriand, 1978.

—. Le Vieux du bas-du-fleuve. Rivière-du-loup: Castelriand, 1979.

Lévi-Strauss, Claude. Race et histoire. Genève : Gonthier, 1961.

Lévy, Bernard Henri. La Barbarie à visage humain. Paris: Grasset, 1977.

Lewin, Louis. Phantastica: drogues psychédéliques, stupéfiants, narcotiques, excitants, hallucinogènes. Paris : Payot, 1970.

Lewis, Oscar. La Vida. New York: Vintage-Random House, 1966.

Lewis, Sinclair. Main Street. New York: New American Library, 1961.

Leyrac, Monique. Mon enfance à Rosemont. Montréal : Primeur, 1983.

Liaison. No 10. Déc. 1947. Montréal. Avec «Hymne à l'esprit alcoolique, par Gérard Bessette », p. 594-596.

Liaison. № 24. Avril 1949. Montréal. «Entretien nocturne, par Gérard Bessette », p. 198-199. Poème, avec un vers rajouté à la main par l'auteur.

Littérature canadienne-française. Conférences J.A.de Sève. 110. Montréal : PUM, 1969.

Lichtman, Richard. An Outline of Marxism. Toronto: Forum House, 1970.

Limoges, Thérèse. La Prostitution à Montréal. Montréal : Éditions de l'Homme, 1967. 
Linteau, Paul-André, René Durocher, et Jean-Claude Robert. Histoire du Québeccontemporain. De la confédération à la crise (1867-1929). Montréal : Boréal Express, 1979.

Lochhead, Douglas. Bibliographie des bibliographies canadiennes. Toronto : University of Toronto Press, 1972.

Loeffler-Delachaux, Marguerite. Le Symbolisme des contes de fées. Paris : L'Arche, 1949.

Lombroso, Gina. L'Âme de la femme. Trad. François Le Hénaff. Paris : Payot, 1937.

Loranger, Françoise. Mathieu. Montréal : Le Cercle du Livre de France, 1949.

-. Une maison un jour. Montréal : Le Cercle du Livre de France, 1965.

—. Medium saignant. Montréal : Leméac, 1970.

Lorenz, Konrad. L'Agression. Une histoire naturelle du mal. Trad. Vilma Fritsch. Paris : Flammarion, 1969.

Lord, Denis. La Violence des forts. Montréal : Éditions du Lys, 1964.

Lowry, Malcolm. Under the Volcano. 1947. Harmondsworth : Penguin, 1962.

Lozeau, Albert. Albert Lozeau. Textes choisis et présentés par Yves de Margerie. Montréal: Fides, coll. «Classiques canadiens », 1958.

Luche, René. Les Banques. Paris : Foucher, 1951.

Ludlum, Robert. The Rhinemann Exchange. 1974. New York: Dell, 1977.

—. The Gemini Contenders. 1976. New York : Dell, 1977.

-. Le Cercle bleu des Matarèse. Tomes 1 \& 2.1979. Trad. Michel Courtois-Fourcy. Paris: Robert Laffont (et Le Livre de Poche), 1983. 
Lukacs, Georges. La Théorie du roman. Trad. Jean Clairevoye. Berlin-Spandau : Gonthier, 1963.

Luna, A. R. The Working Brain: Introduction to Neurapsychology. Trans. Basil Haigh. London: Penguin Books, 1973.

Lyall, Gavin. Midnight Plus One. 1965. New York: Dell, 1966.

M

Maccabée Iqbal, Françoise. Hubert Aquin, romancier. Québec: Presses de l'Université Laval, coll. «Vie des Lettres québécoises », 1978.

MacDonald, John D. A Deadly Shade of Gold. Greenwich, Conn.: Fawcett : 1965.

Machiavelli, Niccolo. The Prince. Trans. Luigi Ricci. New York: New American Library, 1952.

Mackenzie, Katherine. Fleurs sauvages du Québec. Montréal : Éditions du Jour, 1973.

Maheux-Forcier, Louise. Amadou. Montréal : Le Cercle du Livre de France, 1963.

—. L'Île joyeuse. Montréal : Le Cercle du Livre de France, 1964.

—. Une forêt pour Zoé. Montréal : Le Cercle du Livre de France, 1969.

Mailhot, Laurent. Albert Camus ou l'imagination du désert. Montréal : Presses de l'Université de Montréal, 1973.

—. La Littérature québécoise. Paris : PUF, coll. "Que sais-je?», 1974.

Mailhot, Michèle. Le Fou de la reine. Montréal : Éditions du Jour, 1969. 
Maillet, Antonine. Pointe-aux-coques. 1958. Montréal : Leméac, 1972.

—. La Sagouine. Montréal : Leméac, 1971.

—. Don L'Orignal. Montréal : Leméac, 1972.

—. Gapi et Sullivan. Montréal : Leméac, 1973.

—. Mariaagélas. Montréal : Leméac, 1973.

—. Pélagie-la-Charrette. Montréal : Leméac, 1976.

—. Les Cordes-de-bois. Montréal : Leméac, 1977.

—. Les Crasseux. Montréal : Holt, Rinehart et Winston, 1978.

Maillet, Andrée. Les Remparts de Québec. Montréal : Éditions du Jour, 1964.

—. Élémentaires 1954-1964. Montréal : Déom, 1964.

-. Le Paradigme de l'idole. Montréal: Amérique française, 1964.

Mailloux, Alexis. Le Manuel des parents chrétiens. Montréal : VLB éditeur, 1977.

Mailly, Claudy. Le Cortège. Montréal : Beauchemin, 1966.

Maisonneuve, Jean. La Dynamique des groupes. 1968. Paris: PUF. Coll. « Que sais-je? », 1970.

Major, André. Le Cabochon. Montréal : Parti pris, 1964.

—. La Chair de poule. 2e édition. Montréal : Parti pris, 1965.

—. Félix-Antoine Savard. Montréal : Fides, 1968.

-. Le Vent du diable. Montréal: Éditions du Jour, coll. « Romanciers du Jour », 1968.

—. L'Épouvantail. Montréal : Éditions du Jour, 1974.

—. L'Épidémie. Montréal : Éditions du Jour, 1975.

—. Les Rescapés. Montréal : Quinze, 1976. (2) 
Major, Jean-Louis. Saint-Exupéry, l'écriture et la pensée. Ottawa : Éditions de l'Université d'Ottawa, 1968.

-. Anne Hébert et le miracle de la parole. Montréal : Presses de l'Université de Montréal, 1976.

Malenfant, Paul Chanel. Forges froides. Montréal : Quinze, 1977.

Malet, A., et J. Isaac. Révolution empire. Première moitié du XIXe siècle. Paris : Hachette, 1924.

Malet, Léo. 120, rue de la gare. Paris : Bel-Air, 1965.

Mallarmé, Stéphane. Divagations. Genève: Éditions du MontBlanc, 1943.

—. Poésies. Ed. E. Noulet. Mexico : Quetzal, 1944.

—. Poésies. Éd. Jean-Paul Sartre. Paris : Gallimard, 1952.

-. OEuvres complètes. Ed. Henri Mondor et G. Jean-Aubry. Paris : Gallimard, coll. « Bibliothèque de la Pléiade », 1961.

-. Pour un tombeau d'Anatole. Éd. Jean-Pierre Richard. Paris : Seuil, 1961.

Mallet-Joris, Françoise. L'Empire céleste. Paris : René Julliard, 1958. (2)

Malmberg, Bertil. La Phonétique. Paris : PUF, coll. «Que sais-je? $», 1960$.

Malraux, André. Les Conquérants. Paris : Bernard Grasset, 1928.

—. La Voix royale. 1930. Paris : J. Ferenczi \& Fils, coll. « Le Livre moderne illustré », 1934. Illustrations de Claude-René Martin.

-.Man's Fate (La Condition humain). Trans. Haakon M. hevalier. New York: Random House, 1934.

—. Le Temps du mépris. Paris : Gallimard, 1935.

—. L'Espoir. Paris : Gallimard, 1937. 
—. La Condition humaine. Paris : Gallimard, 1946.

-. Romans. Paris: Gallimard, coll. «Bibliothèque de la Pléiade », 1947.

Malrieu, Philippe. La Construction de l'imaginaire. Bruxelles : Charles Dessart, 1967.

Malson, Lucien. Les Enfants sauvages. Paris : Union générale, 1964.

Manceaux, Michèle. Grand reportage. Paris : Seuil, 1980.

Mannoni, Octave. Clefs pour l'Imaginaire ou L'Autre Scène. Paris : Seuil, 1969.

Marceau, Alain. À la pointe des yeux. Montréal : L'Hexagone, 1958.

Marcel, Gabriel. Le Mystère de l'être. I. Réflexions et Mystère. II. Foi et réalité. Paris : Aubier-Montaigne, 1951.

Marcel, Jean. Jacques Ferron malgré lui. Montréal : Édition du Jour, coll. « Littérature du jour », 1970.

—. Le Joual de Troie. Montréal : Éditions du Jour, 1973.

Marchand, Olivier. Par détresse et tendresse. Poèmes 1963-1965. Montréal : Éditions de l'Hexagone, 1971.

Marchand, Clément. Les Soirs rouges. Trois-Rivières : Éditions du Bien public, 1947.

Marcotte, Gilles. Le Poids de Dieu. Paris : Flammarion, 1962.

-. Une littérature qui se fait. Montréal : Hurtubise $\mathrm{HMH}$, coll. «Constantes », vol. 2, 1962.

-. Le Temps des poètes : description critique de la poésie actuelle au Canada français. Montréal : Hurtubise HMH, 1969.

—. Un voyage. Montréal : Hurtubise HMH, 1973.

—. Le Roman à l'imparfait. Montréal : La Presse, 1976. 
Marion, Séraphin. Nos trois premiers romans canadiensfrançais. Québec : Cap Diamant, 1943.

-. Les Lettres canadiennes d'autrefois. Tome 6. Ottawa : Éditions de l'Université d'Ottawa, 1949.

Marissel, André. Samuel Beckett. Paris : Éditions universitaires, 1963.

Marivaux, Pierre Carlet de. La Vie de Marianne. Ed. Frédéric Deloffre. Paris : Éditions Garnier Frères, 1963.

Marsolais, Gilles. Le Cinéma canadien. Montréal : Éditions du Jour, coll. «Idées du Jour », 1968.

Mason, Stephen F. A History of the Sciences. New York: Collier, 1967.

Martel, Émile. L'Ombre et le Silence. Montréal : Éditions du Jour, 1974.

—. Les Gants jetés. Montréal : Quinze, 1977.

Martin, Claire. Avec ou sans amour. Montréal : Le Cercle du Livre de France, 1958.

—. Doux amer. Paris : Robert Laffont, 1960.

- Quand j'aurai payé ton visage. Montréal : Le Cercle du Livre de France, 1962.

-.Dans un gant de fer, autobiographie: la joue gauche. Montréal : Le Cercle du Livre de France, 1965.

-. Dans un gant de fer: la joue droite. Montréal : Le Cercle du Livre de France, 1966.

—. Les Morts. Montréal : Le Cercle du Livre de France, 1970.

-. Je n'étais qu'espoir. Montréal : Le Cercle du Livre de France, 1972.

Martin, David. G. Introduction to Psychotherapy. Belmont, CA: Woodsworth, 1971. 
Martin du Gard, Roger. Les Thibault. Quatrième Partie. Paris : Gallimard, 1928.

—. Les Thibault. Tomes I, II, III, IV, V. Paris : Gallimard, 1955.

Martin, Gérard. Tentations. Québec : Librairie Garneau, 1943.

Martin, Gérard, dir. Bulletin bibliographique des écrivains canadiens. Montréal: Société des écrivains canadiens à Montréal, Canada, 1957.

-. Bulletin bibliographique des écrivains canadiens. Montréal : Société des écrivains canadiens à Montréal, Canada, 1958.

-. Bulletin bibliographique des écrivains canadiens. Montréal : Société des écrivains canadiens à Montréal, Canada, 1959.

Martino. P. Parnasse et Symbolisme (1850-1900). Paris : Armand Colin, 1925.

Marx, Karl. Selected Writings in Sociology and Social Philosophy. Ed. T. B. Bottomore and M. Rubel. England: Penguin, 1961.

- Early Writings. Trans. and ed. T.B. Bottomore. New York: McGraw-Hill, 1964. (2)

Marx, Karl, and Friedrich Engels. Marx \& Engels. Basic writings on Politics and Philosophy. Ed. Lewis S. Feuer. Garden City, NY: Doubleday, 1959.

—. Manifeste du Parti communiste. Pékin : Éditions en Langues étrangères, 1966.

-. La Chine. Trad. et préface Roger Dangeville. Paris : Union Générale d'édition, 1973.

Massicotte, E.Z., dir.Anecdotes canadiennes suivies de Mours, coutumes et industries d'autrefois, mots historiques, miettes de l'histoire. Montréal : Beauchemin, 1913.

Massis, Henri. L'Honneur de servir. Paris : Plon, 1937. 
Masson, Jeffrey Moussaieff. Le Réel escamoté, le renoncement de Freud à la théorie de la séduction. Trad. Claude Monod. Paris : Aubier, 1984.

Mathieu, Claude. La Mort exquise. Montréal : Le Cercle du Livre de France, 1965.

Mauguy, Axel. Poésie et société au Québec 1937-1970. Québec: Presses de l'Université Laval, 1972.

Maulnier, Thierry. Introduction à la poésie française. Paris : Gallimard, 1939.

Maupassant, Guy de. Bel-Ami. Paris : Albin Michel, 1962.

—.Mont-Oriol. Paris : Ernest Flammarion, s.d.

Mauriac, François. Le Fleuve de feu. Paris : Grasset, 1923.

Mauriac, Claude. L'Allitérature contemporaine. Artaud, Barthes, Bataille, Beckett...Paris : Albin Michel, 1958.

Maurois, André. Byron. Tome II. Paris : Bernard Grasset, 1930.

Mauron, Charles. Mallarmé par lui-même. Paris: Seuil, coll. « Microcosme - Écrivains de toujours », 1964.

May, Rollo. Existential Psychotherapy. Toronto : CBC / Bryant Press, 1967.

McConnell, G. Robert. Québec raconte... Montréal : Aquila, coll. « Lectures françaises », 1977.

McCormick, Donald. Who's Who in Spy Fiction. London : Sphere Books, 1979.

McCourt. Edward, A. The Canadian West in Fiction. Toronto: Ryerson Press, 1949.

McDougall, William. Social Psychology. 1908. London: Methuen \& Co.,1960.

McFadden, George. Dryden, The Public Writer 1660-1686. Princeton, NJ: Princeton University Press, 1978. 
Melançon, Joseph-Marie. Lucien Rainier, l'homme et l'œuvre. Montréal : Éditions du Lévrier, 1966.

Mélançon, Claude. Charmants voisins. Les oiseaux du Québec. Montréal : Éditions du Jour, 1964.

—. Légendes indiennes du Canada. Montréal : Éditions du Jour, 1967. (2)

—. Nos animaux chez nous. Montréal : Éditions du Jour, 1972.

Memmi, Albert. 1968. L'Homme dominé. Paris : Payot, 1973.

—. Portrait du colonisé. 1968. Paris : Payot, 1973.

—. Juifs et Arabes. Paris : Gallimard, 1974.

Ménard, Jean. L'Oeuvre de Boylesve. Paris : Nizet, 1956.

—. Plages. Montréal : Beauchemin, 1962.

—. Les Myrtes. Montréal : Beauchemin, 1963. (2)

-.Xavier Marmier et le Canada. Québec: Presses de l'Université Laval, 1967.

- La Vie littéraire au Canada français. Ottawa: Éditions de l'Université d'Ottawa, 1971.

Mendel, Gérard. La Révolte contre le père; une introduction à la sociopsychanalyse. Paris : Payot, 1968.

—. La Crise des générations. Paris : Payot, 1969.

Mendel, Gérard, et al. Sociopsychanalyse 3. Paris : Payot, 1973.

Métayer, Maurice. Mémoires d'un esquimau. Moi, Nulyak. Montréal : Éditions du Jour, 1972.

Metayer, Maurice, ed. \& trans. I, Nuligak. The Autobiography of a Canadian Eskimo. Richmond Hill, Ont.: Simon \& Schuster of Canada, Ltd., 1966.

Meyer, Françoise. La Pensée de Bergson. Paris : Bordas, 1948. 
Micha, René. Nathalie Sarraute. Paris : Éditions universitaires, 1966.

Michaud, Guy. Mallarmé, l'homme et l'œuvre. Paris: HatierBoivin, coll. « Connaissance des lettres », 1958.

Michaut, Pierre. Histoire du ballet. Paris : PUF, Coll. «Que saisje? », 1948.

Michelet, Jules. La Sorcière. Paris : Garnier-Flammarion, 1966.

Miesch, Jean. Alain Robbe-Grillet. Paris : Éditions universitaires, 1965.

Migué, Jean-Luc, dir.Le Québec d'aujourd'hui. Regards universitaires. Montréal : Hurtubise HMH, 1971.

Les Mille et Une Nuits. Trad. Antoine Galland. Montréal : Beauchemin, s.d. [1906?]

Les Mille et Une Nuits. Trad. Antoine Galland. Paris : GarnierFlammarion, 1965.

Miller, Henry. Tropic of Cancer. New York: Grove Press, 1961.

Miller, Henry.J'suis pas plus con qu'un autre. Paris: BuchetChastel, 1976.

Miller, Jean Baker, ed. Psychoanalysis and Women. New York: Brunner/Mazel, 1973.

Minville, Esdras, dir. Montréal économique. Montréal : Fides, 1943.

Mishara, Brian L., et Robert G. Riedel. Le Vieillissement. Paris : PUF, 1984.

Moisan, Clément. L'Âge de la littérature canadienne. Montréal : Hurtubise HMH, 1969.

Molière. OEuvres complètes. 6 tomes (dont 2 manquent) Paris : Nelson, s.d.

Mondat, Claire. Poupée. Montréal : Éditions du Jour, 1963. 
Mongeau, Serge. Adieu médecine, Bonjour santé. Montréal : Québec/Amérique, 1982.

Mongeau, Yves. Veines. Montréal : Librairie Déom, 1964.

Monière, Denis. Le Développement des idéologies au Québec, des origines à nos jours. Montréal : Québec/Amérique, 1977.

Monod, Jacques. Le Hasard et la Nécessité. Essai sur la philosophie naturelle de la biologie moderne. Paris: Seuil, 1970.

Montagu, Ashley. L'Hérédité. Verviers: Marabout Université, 1967.

Montalembert, Hugues de. La Lumière assassinée. Paris : Robert Laffont, 1982.

Moodie, Susanna. Roughing it in the Bush. Toronto: McClelland \& Stewart, coll. "New Canadian Library", 1964.

Moody, Raymond A. Jr. Life after Life. Toronto: Bantam, 1977.

Moreau, Pierre. La Critique littéraire en France. Paris : Armand Colin, 1960.

Morice, Louis. Nova; poèmes. Québec : Aspects, 1978.

Morin, Paul. Poèmes de cendre et d'or. Montréal : Éditions du Dauphin, 1922.

-Géronte et son miroir. Montréal: Le Cercle du Livre de France, 1960.

-. OEuvre poétique: Le Paon d'émail, Poèmes de cendre et d'or. Montréal : Fides, coll. « Nénuphar », 1961.

Morris, Desmond. The Naked Ape. Toronto: Bantam, 1967.

—. Le Singe nu. Trad. Jean Rosenthal. Paris : Grasset, 1968.

—. The Human Zoo. Toronto: Clarke, Irwin \& Co, 1969.

—. Le Zoo humain. Trad. Jean Rosenthal. Paris : Grasset, 1970. 
Morris, Desmond and Ramona. Men and Pandas. London: Sphere Books, 1968.

-. Hommes et Singes. Trad. Marie-Alyx Revellat. Paris : Stock, 1967.

Morisset, Gérard. Peintres et tableaux. Québec: Éditions du chevalet, 1937.

Morrissette, Bruce. Les Romans de Robbe-Grillet. Préface de Roland Barthes. Paris : Éditions de Minuit, 1963.

Mornet, Daniel. Histoire des grandes ceuvres de la littérature française. Paris : Larousse, 1925.

-. La Littérature française enseignée par la dissertation. Paris : Larousse, 1936.

—. La Pensée française au XVIIIe siècle. Paris: Armand Colin, 1956.

Mounier, Emmanuel. Introduction aux existentialismes. Paris : Gallimard, 1962.

Motut, Robert, dir. Moissons. Edmonton: Ministère de l’Éducation de l'Alberta, 1979.

Moynier, Bob R. 4000 d'heures d'agonie. Récit recueilli par Pierre Caron. Montréal : Québec/Amérique, 1978.

Mucchielli, Roger. Introduction à la psychologie structurale. Bruxelles : Charles Dessart, 1968.

Mueller, F. L. La Psychologie contemporaine. Paris : Payot, 1963.

Mullahy, Paul. CEdipe. Du mythe au complexe. Trad. Simone Fabre. Paris : Payot, 1951.

Munro, Alice. La Danse des ombres. Trad. Colette Tonge. Montréal : Québec/Amérique, 1979.

-. Pour qui te prends-tu? Trad. Colette Tonge. Montréal: Québec/Amérique, 1981. 
Musset, Alfred de. Comédies et proverbes. Tome 1 et II. Paris : Flammarion, 1928.

—. Poésies nouvelles 1836-1852. Paris : Flammarion, s.d.

$N$

Naaman, Antoine. Guide bibliographique. Montréal : Éditions Cosmos, 1970.

Nacké, Lorraine. Le Passé oublié. Montréal : Fides, 1979. (2)

Nadeau, Maurice. Histoire du surréalisme. Paris : Seuil, 1945.

—. Le Roman français depuis la guerre. Paris : Gallimard, 1963.

Nadeau, Vincent.Marie-Claire Blais: le noir et le tendre. Montréal : Presses de l’Université de Montréal, 1974.

Nadeau, Maurice. L'Homme des tavernes. Montréal : Mouvement laïque de langue française, 1967.

Narrache, Jean [Émile Coderre]. Bonjour, les gars! Montréal : Fernand Pilon, 1948.

Nathan, Robert. Road of Ages. 1935. New York: Alfred A. Knopf, 1935.

Naubert, Yvette. La Dormeuse éveillée. Montréal : Le Cercle du Livre de France, coll. « Nouvelle France », 1965.

-. Contes de la solitude. Tome 1. Montréal : Le Cercle du Livre de France, 1967.

-. Contes de la solitude. Tome 2. Montréal : Le Cercle du Livre de France, 1972.

-. L'Été de la cigale. Montréal : Le Cercle du Livre de France, 1968. 
-. Les Pierrefendre. Montréal: Le Cercle du Livre de France, 1972.

—. Les Pierrefendre. Tome 2. Montréal : Pierre Tisseyre, 1975.

—. Les Pierrefendre. Tome 3. Montréal : Pierre Tisseyre, 1977.

Navarre, Yves. Le Jardin d'acclimatation. Paris : Flammarion, 1980.

Nelligan, Émile. Poésies complètes 1896-1899. Montréal : Fides, coll. « Nénuphar », 1952. (3)

-.31 poèmes autographes, 2 carnets d'hôpital 1938. TroisRivières : Écrits des Forges, 1986.

—. OEuvres complètes I: Poésies complètes 1896-1941. Dir. Réjean Robidoux et Paul Wyczynski. Montréal : Fides, 1991.

—. OEuvres complètes II : Poèmes et textes d'asile : 1900-1941. Éd. Jacques Michon. Montréal : Fides, 1991.

Nerval, Gérard de. Poésies. Paris : Gallimard, 1964.

-. La Main enchantée suivi de Contes et facéties. Paris : Éditions de la Bibliothèque mondiale, s.d.

—. OEuvres choisies. Lausanne: Éditions du Grand-Chêne / H. Kaeser, 1948.

Nathan, Robert. Road of Ages. 1935. New York: Alfred A. Knopf, 1935.

Newland, Constance A. Myself and I. The Explosive Experience of Constance Newland Who Took Twenty-Three Doses of the Dangerous New Mind Drug LSD. New York : New American Library, 1962.

Nion, François de, éd. Un outre-mer au XVIIe siècle. Voyages au Canada du Baron de La Hontan. Paris : Librairie Plon, 1900.

Nisin, Arthur. La Littérature et le lecteur. Paris: Éditions universitaires, 1959. 
Noël, Bernard. Les Premiers Mots. Paris : Flammarion, 1973.

Nord. № 1. Automne 1971. Sillery : Éditions de l'Hôte. Numéro spécial sur Michel Tremblay.

$\boldsymbol{O}$

Oates, Joyce Carol. Amours profanes. Trad. Michel CourtoisFourcy. Montréal : Québec/Amérique, 1982.

O'Leary, Dostaler. Le Roman canadien-français. Montréal : Le Cercle du Livre de France, 1954.

Olivier, Christiane. Les Enfants de Jocaste - L'empreinte de la mère. Paris : Dénoel-Gonthier, 1970.

Ortigues, Marie-Cécile et Edmond. OEdipe africain. Paris : Plon, 1973.

Osborn. Reuben. Marxisme et psychanalyse. Paris : Payot, 1965.

Ouellet, Cyrias. La Vie des sciences au Canada français. Québec : Ministère des Affaires culturelles, 1964.

Ouellet, Fernand. Histoire économique et sociale du Québec, 1760-1850. Montréal : Fides, 1966.

Ouellette, Fernand. Ses anges de sang. Montréal : L'Hexagone, 1955.

—. Dans le sombre. Montréal : L'Hexagone, 1967.

-. Les Actes retrouvés. Montréal: Hurtubise HMH, coll. « Constantes », vol. 24, 1970.

—.Tu regardais intensément Geneviève. Montréal: Quinze, 1978.

Ouvrard, Hélène. La Fleur-de-peau. Montréal : Éditions du Jour, 1965. 
—. Le Corps étranger. Montréal : Éditions du Jour, 1973.

—. La Noyante. Montréal : Québec/Amérique, 1980.

Oüy, Achille. Philosophie. Classe de sciences expérimentales. Paris : Bordas, 1954.

\section{$\boldsymbol{P}$}

Pacey, Desmond. Créative Writing in Canada. 1952. Toronto: Ryerson Press, 2nd edition, 1961.

Packard, Vance. The Hidden Persuaders. 1957. New York: Pocket Books, 1968.

—. The Status Seekers. 1959. Montreal: Pocket Books, 1962.

Pagé, Pierre. Anne Hébert. Montréal: Fides, coll. «Écrivains canadiens d'aujourd'hui », 1965.

Pagnol, Marcel. Topaze. Boston: D. C. Heath and Co., 1936.

Pallascio-Morin, Ernest. Pleins feux sur l'homme. Montréal: Librairie Déom, 1963.

Panneton, Jean. Ringuet. Montréal : Fides, coll. «Écrivains canadiens d'aujourd'hui », 1970.

Paradis, Suzanne. À temps, le bonheur... Poèmes, Beaumont: Chez l'auteure, 1960.

-. La Chasse aux autres. Trois-Rivières: Éditions du Bien public, 1961.

Paré, Yvon. Anna-Belle. Montréal : Éditions du Jour, 1972.

Paré, Paul. L'Improbable Autopsie. Montréal : Quinze, 1977.

Parent, Charles. De givre et de feu. Vence : Studio A4, 1976. 
Parent, Étienne. Étienne Parent. Textes choisis et présentés par Paul-Eugène Gosselin. Montréal : Fides, coll. «Classiques canadiens », 1964.

Parizeau, Alice. Fuir. Montréal : Librairie Déom, 1963.

—. Survivre. Montréal : Le Cercle du Livre de France, 1964.

—. L'Envers de l'enfance. Montréal : La Presse, 1976.

-. Les Lilas fleurissent à Varsovie. Montréal : Pierre Tisseyre, 1981. (2)

—. La Charge des sangliers. Montréal : Pierre Tisseyre, 1982. (2)

—. Côte-des-neiges. Montréal : Pierre Tisseyre, 1983.

—. Ils se sont connus à Lwow. Montréal : Pierre Tisseyre, 1985.

—. L'Amour de Jeanne. Montréal : Pierre Tisseyre, 1986.

—. Une femme. Montréal : Leméac, 1991.

Parker, George, ed. The Evolution of Canadian Literature in English 1914-1945. Toronto: Holt, Rinehart \& Winston of Canada, 1973.

Parrot, Louis, et Jean Marcenac. Paul Éluard. Paris: Pierre Seghers, coll. « Poètes d'aujourd'hui », 1961.

Pascal, Gabrielle. La Quête de l'identité chez André Langevin. Montréal : Aquila, 1976. (2)

—. Le Défi d’Albert Laberge. Montréal : Aquila, coll. « Figures du Québec », 1976. (2)

Pascal, Blaise. Pensées. Paris : Nelson Éditeur, s.d. [1953?]

Patry, André. Visages d'André Malraux. Montréal: L'Hexagone, coll. « Les Voix », 1956.

Patry, Yvan, dir.Le Cinéma québécois: tendances et prolongements. Montréal : Éditions Sainte-Marie, 1968.

Paul-Crouzet, Jeanne. Poésie au Canada. Paris : Didier, 1946. 
Pavel, Thomas. Le Miroir persan. Montréal : Quinze, 1977.

Pavlov, Ivan. Réflexes conditionnels et inhibitions. Genève: Gonthier, 1963.

Pavlovic, Miodrag. Singing at the Whirlpool. Trans. Barry Callaghan. Toronto: Exile Editions, 1983.

Payot, Jules. L'Éducation de la volonté. Paris : PUF, 1942.

Péguy, Charles. Ève - Les Tapisseries. Paris: Gallimard, coll. « NRF », 1946.

—. Ses plus beaux textes. Montréal : Nouvelles éditions du CEP, 1941.

—. Prières. Paris : Gallimard, 1939.

Pellerin, Jean. Le Calepin du diable. Montréal : Éditions du Jour, 1965.

Pelletier, Albert. Égrappages. Montréal : Éditions Albert Lévèsque, 1933.

Pelletier, Gérard. Les Années d'impatience 1950-1960. Montréal : Stanké, 1983.

Perrault, Pierre. Portulan. Montréal : Beauchemin, 1961.

—. Au cœur de la rose. Montréal : Beauchemin, 1964.

Petite Anthologie du Noroît. 2e éd. Montréal : Noroît, 1984.

Petrone.Satiricon. Préface de Jean Dutourd. Paris: Librairie Générale française, 1960.

Peyre, Henri. The Contemporary French Novel. New York: Oxford University Press, 1955.

Peyrefitte, Roger. Les Clés de Saint Pierre. Paris : Flammarion, 1955.

Pia, Pascal. Apollinaire par lui-même. Paris : Seuil, 1960.

Piaget, Jean. Six études de psychologie. Genève : Gonthier, 1964. 
—. Le Structuralisme. Paris : PUF, coll. « Que sais-je? », 1968.

Pichet, Alfonse. Poèmes 1946-1950. Trois-Rivières : Éditions du Bien public, 1966.

Picon, Gaëtan. André Malraux. Paris : Gallimard, 1945.

-. Panorama de la Nouvelle littérature française. Paris: Gallimard, 1949.

—. Malraux par lui-même. Paris: Seuil, coll. «Écrivains de toujours », 1953.

Pieyre de Mandiargues, André. La Marge. Paris : Gallimard, coll. « Folio », 1967.

Pilon, Jean-Guy. Les Cloîtres de l'été. Montréal : L’Hexagone, 1954.

—. L'Homme et le Jour. Montréal : L'Hexagone, 1957. (2)

—. La Mouette et le Large. Montréal : L’Hexagone, 1960.

—. Recours au pays. Montréal : L'Hexagone, 1961.

—. Pour saluer une ville. Paris : Pierre Seghers, 1963. (2)

—. Solanges. Montréal : Les Éditions du Jour, 1966.

-. Comme eau retenue, poèmes 1954-1963. Montréal : L'Hexagone, 1968.

Pingaud, Bernard. Écrivains d'aujourd'hui, 1940-1960. Paris : Grasset, 1960.

Pinget, Robert. Graal Flibuste. Paris : Éditions de Minuit, 1956.

—. Passacaille. Paris : Éditions de Minuit, 1969.

Pinsonneault, Jean-Paul. Les Terres sèches, roman. Montréal : Beauchemin, 1964.

Platon. Protagoras ou les sophistes. Gorgias ou de la rhétorique. Trad. Léon Robin. Paris : 1950.

—. La République. Trad. Émile Chambry. Paris : Gonthier, 1963. 
-. Le Banquet et Phèdre. Trad. Émile Chambry. Paris : GarnierFlammarion, 1964.

—. Apologie de Socrate, Criton, Phédon. Trad. Émile Chambry. Paris : Garnier-Flammarion, 1965.

Poe, Edgar Allan. Les Aventures d'Arthur Gordon Pym. Ed. Pierre Mac Orlan. Paris : Bibliothèque Mondiale, s.d.

-. Histoires extraordinaires. Trad. Charles Baudelaire. Paris : Éditeur R. Simon, 1935.

Poe, Edgar Allan. Tales and Poems of Mystery and Imagination. New York: Pocket Books,1941.

Poincaré, Henri. La Science et l'Hypothèse. Paris : Flammarion, 1943.

Pontaut, Alain. La Tutelle. Montréal : Leméac, 1968.

-.Dictionnaire critique du théâtre québécois. Montréal : Leméac, 1972.

Pornon, Charles, dir. Anthologie (apocryphe) de la poésie française. Paris : Nouvel Office d'édition, 1963.

Pouillon, Jean. Temps et roman. Paris : Gallimard, 1946.

Poulet, Georges. Études sur le temps humain. Paris : Plon, 1949.

—. La Distance intérieure. Paris : Plon, 1952.

—. Les Métamorphoses du cercle. Paris : Plon, 1961.

—. Le Point de départ. Paris : Plon, 1964.

- Les Chemins actuels de la critique. Paris: Union générale d'édition, 1968.

Poulin, Gabrielle. Les Miroirs d'un poète: Images et reflets de Paul Éluard. Bruxelles : Declée de Brouwer; Montréal : Bellarmin, coll. « Essais pour notre temps », 1969.

—. Cogne la caboche. Montréal : Stanké, 1979. 
Poulin, Jacques. Mon cheval pour un royaume. Montréal : Éditions du Jour, 1967.

—. Jimmy. Montréal : Éditions du Jour, 1969.

—. Le Cour de la baleine bleue. Montréal : Éditions du Jour, 1970.

—. Les Grandes Marées. Montréal : Leméac, 1978.

—.Volkswagen Blues. Montréal : Québec/Amérique, 1984.

Pouliot, André. Modo pouliotico. Montréal : Éditions de la file indienne, 1957.

Pouliot, Léon, Robert Lahaise et al. Histoire du Canada. Une expérience tricentenaire. Montréal : Éditions de Sainte-Marie, 1967.

Poupart, Jean-Marie. Angoisse play, roman. Montréal : Éditions du Jour, 1968.

—. Ma tite vache a mal aux pattes, roman. Montréal : Éditions du Jour, 1970.

—. Les Récréants. Montréal : Éditions du Jour, 1972. Essai.

-. Ce n'est pas donné à tout le monde d'avoir une belle mort. Montréal : Éditions du Jour, 1974.

Préfontaine, Yves. Pays sans parole. Montréal: L'Hexagone, 1967.

Prévert, Jacques. Paroles. Paris : Gallimard, 1972.

Prévost, L'abbé. Manon Lescaut. Paris : Librairie Gründ, 1956.

Prévost, Jean. Baudelaire. Paris : Mercure de France, 1964.

Priou, Jules-Marie. Leconte de Lisle. Paris : Seghers, 1966.

Pronovost, André. Les Marins d'eau douce, roman. Montréal: Éditions de la Catalyse, 1975.

Propp, Vladimir. Morphologie du conte. Paris : Seuil, 1970. 
Proulx, J.-B. [Jean-Baptiste]. L'Enfant perdu et retrouvé ou Pierre Cholet. 1887. Montréal : Beauchemin, 1940.

Proust, Marcel. Du côté de chez Swann. Tome I. Paris : Gallimard, 1939. (2)

—. Un amour de Swann. Paris : Gallimard, 1954.

Provencher, Jean. René Lévesque: portrait d'un Québécois. Montréal : La Presse, 1973.

Purlenne, Jean-Baptiste [l'abbé Paul-Marcel Gauthier]. Les Chansons «nettes » de l'abbé Paul-Marcel Gauthier. Montréal, Éditions Purlenne, 1959.

$\boldsymbol{Q}$

Queen's Quarterly. Vol.69, no 2. Summer 1962. "French Canadian Society as Seen by Contemporary Novelists, by Gérard Bessette," p. 177-197.

Les Québécois. "Parti pris». Préface de Jacques Berque. Paris : François Maspero, 1967.Queneau, Raymond.Zazie dans le métro. Paris : Gallimard, 1959.

Queval, Jean. Raymond Queneau. Paris : Seghers. Coll. «Poètes d'aujourd'hui », 1960.

Quillet, Pierre. Bachelard. Paris : Seghers, 1964.

$\boldsymbol{R}$

Racine, Claude. L'Anticléricalisme dans le roman québécois 19401965. Montréal : Hurtubise HMH, 1972. 
Racine, Jean. Théâtre en deux volumes. Tome II. Paris : Edition Lutécia, Nelson Editeur, 1939.

Racine, Luc. Opus 1. Montréal : Éditions du Jour, 1969.

Radwanski, George. Trudeau. Scarborough: Macmillan/NAL, 1978.

Rainier, Lucien [Joseph Melançon].Lucien Rainier. Textes choisis et annotés par Claude Lavergne. Montréal : Fides, coll. « Classiques canadiens », 1961.

Rank, Otto. Don Juan et le double. Paris : Payot, 1932.

—. Le Traumatisme de la naissance. Paris : Payot, 1968.

Rashley, R.E. Rock Painter: Poems.Winnipeg: Turnstone Press, 1978.

Raymond, Marcel. De Baudelaire au surréalisme. Paris: José Corti, 1963.

Reboussin, Marcel. Les Grandes Époques culturelles de la France. New York : The Ronald Press Company, 1951.

Reboux, Paul et Charles Müller. 1908-1913.À la manière de... Paris : Grasset, coll. « Livre de poche », 1964.

Regards sur Israel. September 1980. «Entrevue avec Monsieur Gérard Bessette, écrivain, » pp. 4-5.

Reischauer, Edwin O. Histoire du Japon et des Japonais. Des origines à 1945. Trad. Richard Dubreuil. Paris : Seuil, 1973.

Rémillard, Jean-Robert. Sonnets archaïques pour ceux qui verront l'indépendance,suivis de Complaintes du pays des porteurs d'eau. Montréal : Parti pris, 1966.

Renan, Ernest. Souvenirs d'enfance et de jeunesse. Paris : NelsonCalmann Lévy, 1939.

Renaud, Jacques. Le Cassé, suivi de quelques nouvelles. Montréal : Parti pris, 1964. (2) 
—.En d'autres paysages. Montréal : Parti pris, 1970.

-. Clandestine ou La traduction du couchant. Montréal : Biocreux, 1980.

Renchnick, P. Les orphelins mènent le monde. Genève : Médecine et Hygiène, 1975.

Ricard, François. L'Art de Félix-Antoine Savard dans Menaud, maître-draveur. Montréal : Fides, 1972.

—. Gabrielle Roy. Montréal : Fides, 1975.

Ricardou, Jean. Problèmes du nouveau roman. Paris : Seuil, 1967.

—. Pour une théorie du nouveau roman. Paris : Seuil, 1971.

Richard, Jean-Jules. Neuf jours de haine. Montréal : Éditions de l'Arbre, 1948.

—. Ville rouge - Nouvelles. Montréal : Éditions Tranquille, 1949.

—. Le Feu dans l'amiante. [Montréal?] : Chez l'auteur, 1956.

—. Journal d'un hobo. Montréal : Parti pris, 1965.

- Faites-leur boire le fleuve. Montréal : Le Cercle du Livre de France, 1970.

—. Carré Saint-Louis. Montréal : L'Actuelle, 1971.

Richard, Jean-Pierre. Littérature et sensation: Stendhal, Flaubert. Paris : Seuil, 1954.

Richepin, Jean. La Chanson des gueux. Paris: BibliothèqueCharpentier, 1922.

Richer, Jean. Gérard de Nerval. Paris: Pierre Seghers, coll. « Poètes d'aujourd'hui », 1959.

Richer, Julia. Léo-Paul Desrosiers. Montréal : Fides, coll. «Les écrivains canadiens d'aujourd'hui », 1966.

Richler, Mordecai. A Choice of Enemies. 1957. London: Quartet Books, 1973. 
—. The Street. 1969. London: Panther, 1971.

Rilke, Rainer Maria. Letters to a Young Poet. 1943. Trans. K.W. Maurer. St. James: Winnipeg Printing \& Eng. Co., 1958.

Rimbaud, Arthur. QEuvres complètes. Montréal : Bernard Valiquette, 1938-1946.

—. OEuvres. Paris : Garnier Frères. 1960.

Ringuet [Philippe Panneton]. Trente Arpents. Paris : Flammarion, 1938.

—. Trente Arpents. Montréal : Fides, Coll. « Nénuphar », 1938.

-. L'Héritage et autres contes. Montréal: Éditions Variétés, 1946.

—. Le Poids du jour. Montréal : Éditions Variétés, 1949.

—. Confidences. Montréal : Fides, 1965.

-. Huit conférences, saison artistique, 1953-1954. Montréal : Club musical et littéraire de Montréal, vol. B-4, s.d.

Rioux, Hélène. Yes monsieur. Montréal : La Presse, 1972.

—. Finitude. Montréal : Éditions d’Orphée, 1972.

—. Un sens à ma vie. Montréal : La Presse, 1974.

—. J'elle. Montréal : Stanké, 1978.

—. Une histoire gitane. Montréal : Québec/Amérique, 1982.

Rioux, Marcel. Les Québécois. Paris : Seuil, 1974.

Rivard, Yvon. Mort et naissance de Christophe Ulric. Montréal : La Presse, 1976.

Robbe-Grillet, Alain. Les Gommes. Paris: Éditions de Minuit, 1953.

—. La Jalousie. Paris : Éditions de Minuit, 1957.

—. Dans le labyrinthe. Paris : Éditions de Minuit, 1959. 
—. Pour un nouveau roman. Paris : Gallimard, 1963.

—. L'Immortelle. Paris : Éditions de Minuit, 1963.

—. La Maison de rendez-vous. Paris : Éditions de Minuit, 1965.

-. Projet pour une révolution à New York. Paris : Éditions de Minuit, 1970.

—. Djinn. Un trou rouge entre les pavés disjoints. Paris : Éditions de Minuit, 1981.

Robert, Guy. Broussailles givrées. Montréal : Éditions Goglin, 1959.

-. La Poétique du songe; Introduction à l'œuvre d'Anne Hébert. Montréal : A.G.E.U.M., cahier no 4, 1962.

—. Et le soleil a chaviré. Montréal : Librairie Déom, 1963. (2)

-. Littérature du Québec, tome 1. Montréal : Librairie Déom, 1964.

—. Québec se meurt. Montréal : Electra, 1969.

-. Aspects de la littérature québécoise. Montréal : Beauchemin, 1970.

Robert, Marthe. L'Ancien et le Nouveau: de Don Quichotte à Kafka. Paris : Petite Bibliothèque Payot, 1967.

-. D'CEdipe à Moïse. Freud et la conscience juive. Paris: Calmann-Lévy, 1974.

Robert, Paul. Au fil des années et des mots. 1. Les Semailles. Paris : Robert Laffont, 1979.

Robidoux, Réjean. Roger Martin du Gard et la religion. Paris : Aubier, 1964.

-. "'Les soirées canadiennes' et 'Le foyer canadien' dans le mouvement littéraire québécois de 1860." Revue de l'Université d'Ottawa, octobre 1958. 
—. «Fortune et infortune de l'abbé Casgrain.» Revue de l'Université d'Ottawa. Ottawa, 1965.

—. Le "Traité du Narcisse (théorie du symbole») d'André Gide. Ottawa : Éditions de l'Université d'Ottawa, 1978.

—. Connaissances de Nelligan. Montréal : Fides, 1992.

Robidoux, Réjean, et André Renaud.Le Roman canadienfrançais du vingtième siècle. Ottawa : Éditions de l'Université d'Ottawa, 1966.

Robillard, Edmond. L'Unicorne. Montréal : Le Cercle du Livre de France, 1967.

—. Le Temps d'un peuple... Poèmes. Montréal : Éditions Albertle-Grand, 1980.

Robillard, Claude. Dilettante. Montréal : Albert Lévesque, 1931.

Rochefoucauld, Edmée de la. Paul Valéry. Paris: Éditions universitaires, 1954.

Rohmer, Richard. Separation. Toronto: McClelland \& Stewart, 1976.

Roquebrune. Robert de. Testament de mon enfance. Montréal : Fides, coll. « Nénuphar », 1958.

—. Les Dames Le Marchand. Montréal : Fides, 1964.

-. Quartier Saint-Louis. Montréal : Fides, coll. "Nénuphar», 1966.

—. Cherchant mes souvenirs, 1911-1940. Montréal : Fides, coll. « Nénuphar », 1968.

Romains, Jules. Les Copains. Paris : Gallimard, 1922.

- Les Hommes de bonne volonté. Vol. XVIII : La Douceur de la vie. Paris : Flammarion, 1939.

Ronsard, Pierre de. Poèmes choisis. Paris : Nelson, 1938.

Rosny aîné, J.H. La Guerre du feu. Paris : Nelson, 1951. 
—. La Guerre du feu. Paris : Robert Borel-Rosny, 1977.

—. Eyrimah. Paris : Tallandier, 1977.

—. La Guerre du feu. Paris : Librairie Générale française, 1980.

-. La Guerre du feu et autres romans préhistoriques. Paris: Robert Laffont, coll. « Bouquins », 1985.

Ross, Malcolm, ed.Poets of the Confederation. Toronto: McClelland \& Stewart, 1960.

Rostand, Jean. L'Homme. Paris : Gallimard, 1962.

Roussan, Jacques de. Les Canadiens et nous. Montréal : Éditions de l'Homme, 1964.

Rousseau, Guildo, éd.Préfaces des romans québécois du XIXe siècle. Montréal : Éditions Cosmos, 1970.

Rousseau, Jean-Jacques. Discours sur les sciences et les arts. Paris : Éditions Diderot, 1945.

—. Le Contrat social. Paris : Hatier, 1946.

-. Confessions. Tome I et II. Paris : Gallimard, 1963.

Rousseau, Pierre. De l'atome à l'étoile. Paris : PUF, coll. «Que sais-je? », 1951.

Routhier, Adophe-Basile. Le Centurion: roman des temps messaniques. France: Société St-Augustin, Desclée de Brouwer, 1909.

Roux, Jean-Louis. Bois-brûlés. Montréal : Éditions du Jour, 1968.

Roy, Claude. Aragon. Paris: Seghers, coll. "Poètes d'aujourd'hui », 1960.

-. La Traversée du Pont des Arts. Paris: Gallimard, coll. « Folio », 1979.

Roy, Pierre-Georges. À propos de Crémazie. Québec: Garneau, 1945. 
Roy, Michel. L'Acadie perdue. Montréal: Québec/Amérique, 1978.

Roy, Camille. Nos origines littéraires. Québec: L'Action sociale, 1909.

—. Érables en fleur. Québec : L’Action sociale, 1923.

—. À l'ombre des érables. Québec : L'Action sociale, 1924.

—. Études et croquis. Montréal : Éditions du Mercure, 1928.

—. Romanciers de chez nous. Montréal : Beauchemin, 1932.

-. Morceaux choisis d'auteurs canadiens. 2e éd. Montréal : Beauchemin, 1938.

-. Morceaux choisis d'auteurs canadiens. Montréal : Beauchemin, 1959.

-. Manuel d'histoire de la littérature canadienne de langue française. Montréal : Beauchemin, 1946.

Roy, Gabrielle. Bonheur d'occasion. 2 tomes. Montréal : Société des Éditions Pascal, 1945.

—. Bonheur d'occasion. Paris : Flammarion, 1945.

—. Bonheur d'occasion. 1945. Montréal : Beauchemin, 1965.

—. La Petite Poule d'eau. Montréal : Beauchemin, 1950.

—. Alexandre Chenevert. Montréal : Beauchemin, 1954.

—. Alexandre Chenevert. 1954. Montréal : Beauchemin, 1973.

—. Rue Deschambault. Paris : Flammarion, 1955.

—. La Montagne secrète. Montréal : Beauchemin, 1961.

—. La Route d'Altamont. Montréal : Hurtubise HMH, 1966.

—. La Rivière sans repos. Montréal : Beauchemin, 1970.

—. Cet été qui chantait. Montréal : Éditions françaises, 1972.

—. Un jardin au bout du monde. Montréal : Beauchemin, 1975. 
—. Ces enfants de ma vie. Montréal : Stanké, 1977.

—. Fragiles lumières de la terre. Montréal : Quinze, 1978.

—. Courte-queue. Montréal : Stanké, 1979. (2)

—. La Détresse et l'Enchantement. Montréal : Boréal Express, 1984.

—. De quoi t'ennuies-tu, Evelyne? suivi de Ely! Ely! Ely! 1982. Montréal : Boréal Express, 1984.

Roy, Marie-Anna A. Le Pain de chez nous. Histoire d'une famille manitobaine. Montréal : Éditions du Lévrier, 1954. (2)

—.Valcourt ou La dernière étape. Beauceville: L'Éclaireur, 1958.

- Les Capucins de Toutes-Aides, Manitoba, Canada et leurs dignes confrères. Montréal : Éditions franciscaines, 1967.

-. La Montagne Pembina au temps des colons. Winnipeg : Canadian Publishers, 1970. (2)

—. Le Miroir du passé. Montréal : Québec/Amérique, 1979.

Roy-Hewitson, Lucille. L'Impasse. Sherbrooke : Naaman, 1980.

Rumilly, Robert. Histoire de la province de Québec. Tome VI. «Les Nationaux ». Montréal : Bernard Valiquette, 1943.

Rythmes et Couleurs, Revue internationale de langue française, France. №59. Juillet-août-septembre 1967. Article de François Hertel [Rodolphe Dubé], «Discours aux sourds. Éloge de Bessette », p. 1-12.

$\boldsymbol{S}$

Sade, D.A.F. de. Les Crimes de l'amour. Historiettes, contes et fabliaux. Paris : Sagittaire, 1950. 
-. Aline et Valcour ou Le roman philosophique. Montréal : Éditions du Bélier. Coll. «Aries », 1966.

—. Justine. Montréal : Éditions du Bélier, coll. « Aries », 1966.

—. La Philosophie dans le boudoir. Montréal : Éditions du Bélier, coll. « Aries », 1966.

—. Les Crimes de l'amour. 3 tomes. Montréal : Éditions du Bélier, coll. « Aries », 1967.

Sagard, Gabriel. Gabriel Sagard Théodat. Textes choisis et présentés par Jean-de-la-Croix Rioux. Montréal : Fides, coll. «Classiques canadiens », 1964.

Sainte-Beuve, C.-A. Volupté. Tomes I et II. Paris : La Bibliothèque mondiale, 1954.

Saint-Cyr, Charles. Sous le signe du caribou. Paris : Éditions du Monde moderne, 1926.

Saint-Denys Garneau, Hector de. Poésies complètes. Montréal : Fides, coll. « Nénuphar », 1949.

-. Saint Denys Garneau. Textes choisis et présentés par Benoît Lacroix. Montréal: Fides, coll. "Classiques canadiens", 1956.

Sainte-Marie-Éleuthère, Soeur. La Mère dans le roman canadienfrançais. Québec: Presses de l'Université Laval, coll. «Vie des lettres canadiennes », 1964.

Saint-Evremond. Pages choisies. Paris : La Renaissance du Livre, s.d.

Saint-Exupéry, Antoine de. Vol de Nuit. Paris : Gallimard, 1931.

Saint-Martin, Fernande. La Littérature et le non-verbal. Montréal : Éditions d'Orphée, 1958.

-. Structures de l'espace pictural. Montréal : Hurtubise HMH, coll. «Constantes », 1958. 
Saint-Onge, Paule. Ce qu'il faut de regrets... Montréal : Le Cercle du Livre de France, 1961.

- Le Temps des cerises. Montréal : Centre de psychologie et de pédagogie, 1962.

—. La Maîtresse. Montréal : Le Cercle du Livre de France, 1963.

- La Saison de l'inconfort. Montréal: Le Cercle du Livre de France, 1968.

—. La Vie défigurée. Montréal : La Presse, 1979.

Salinis de, Louis-Antoine, et Bruno-Dominique de Scorbiac. Précis d'histoire de la philosophie. Bruxelles: Société belge de librairie, 1845.

Samain, Albert. Au jardin de l'infante. Paris : Mercure de France, 1957.

Sami Ali, M. De la projection. Une étude psychanalytique. Paris : Payot, 1970.

—. L'Espace imaginaire. Paris : Gallimard, 1974.

Samson, Bruno. L'Amer noir, roman. Montréal : Éditions du Jour, 1973.

Samuels, Mike Sami, et Hal Bennett. Je suis bien dans ma peau grâce à la médecine naturelle. Trad. Jean Sandy. Paris: Tchou, 1977.

San-Antonio. On t'enverra du monde. Paris : Fleuve noir, 1971.

Sand, Georges. Un hiver à Majorque. Paris : Librairie Générale française, 1984.

Sands, Maurice. An Outline of the Modern American Novel. Boston: Student Outlines Co. 1958.

Sarraute, Nathalie. Portrait d'un inconnu. Paris : Union générale d'éditions, 1956.

—. Tropismes. Paris : Éditions de Minuit, 1957. 
—. Le Planétarium. Paris : Gallimard, 1959.

—. Les Fruits d'or. Paris : Gallimard, 1963.

—. Le Silence, suivi de Le Mensonge. Paris : Gallimard, 1967.

—. Entre la vie et la mort. Paris : Gallimard, 1968.

—. Vous les entendez ? Paris : Gallimard, 1972.

Sartre, Jean-Paul. La Nausée. Paris : Gallimard, 1938.

—. La Nausée. 1938. Paris : Gallimard, 1954.

—. Le Mur. Paris : Gallimard, 1939.

-. L'Imaginaire. Psychologie phénoménologique de l'imagination. Paris : Gallimard, 1940.

—. Les Chemins de la liberté II. Le Sursis. Paris : Gallimard, 1945.

-. Les Chemins de la liberté III. La mort dans l'âme. Paris: Gallimard, 1949. (2)

—. Les Chemins de la liberté V. L'Age de raison. Paris : Gallimard, 1945.

—. Baudelaire. Paris : Gallimard, 1947.

—. Baudelaire. 1947. Paris : Gallimard, 1963.

—. Situations I. Paris : Gallimard, 1947.

—. Situations II. Paris : Gallimard, 1948.

—. Situations III. Paris : Gallimard, 1949.

—. Les Mains sales. Paris : Gallimard, 1948.

—. Le Diable et le bon dieu. Paris : Gallimard, 1951.

-. Existentialism and Human Emotions. Trans. Bernard Frechtman and Hazel E. Barnes. New York: Wisdom Libary, 1957.

—. Questions de méthode. Paris : Gallimard, 1960. 
-. Critique de la raison dialectique. Tome I. Paris: Gallimard, 1960.

—. Les Mouches. Éd. F.C. St. Aubyn and R.G. Marshall. New York : Harper \& Row, 1963.

—. Les Mots. Paris : Gallimard, 1964.

-. L'Idiot de la famille. Gustave Flaubert de 1821 à 1857. Vols I et II. Paris : Gallimard, 1971-1972.

Saurel, Pierre [Pierre Daignault]. Le Manchot, vol. 1 : La Mort frappe deux fois. Montréal : Québec/Amérique, 1980.

Savane, Marcel. André Malraux. Paris : Richard-Masse, coll. « Triptyque », 1946.

Savard, Pierre. Jules-Paul Tardivel, la France et les Etats-Unis (1851-1905). Québec : Presses de l'Université Laval, 1967.

Savard, Félix-Antoine.Menaud, maître-draveur. Québec: Librairie Garneau, 1937.

—. Menaud, maître-draveur. Montréal : Fides, 1937.

—. Menaud, maître-draveur. 1937. Montréal : Fides, 1971.

—. Menaud, maître-draveur. Montréal : Fides, 1978.

—. L'Abatis. Montréal : Fides, 1943.

—. La Minuit. Montréal : Fides, coll. « Nénuphar », 1948.

—. Le Barachois. Montréal : Fides, 1959.

—. Journal et souvenirs 1961-62. Tome 1. Montréal : Fides, 1973.

Savard, Marie. Les Coins de l'ove. Québec: Éditions de l'Arc, 1965.

Savary, Charlotte. Isabelle de Frêneuse. Québec: Institut littéraire de Québec, 1950.

Savoie, Renald. À joual sur les mots. Montréal : Éditions du Jour, 1963. 
Schultz-Hencke, H. Analyse des rêves. Paris : Payot, 1954.

Serreau, Geneviève. Histoire $d u$ "nouveau théâtre ». Paris : Gallimard, 1966.

Servais-Maquoi, Mireille. Le Roman de la terre au Québec. Québec : Presses de l'Université Laval, 1974.

Servan-Schreiber, Jean-Jacques. Le Défi américain. Paris : Denoël, 1967.

Shakespeare, William. King Lear. Ed. George Lyman Kittredge. Boston: Ginn and Company, 1940.

-. Othello. Ed. George Lyman Kittredge. Boston: Ginn and Company, 1941.

-. Five Great Tragedies. Introduction by John Masefield. New York: Pocket Books, 1941.

—. Théâtre complet de Shakespeare. Éd. André Gide. Paris : Gallimard, coll. « Bibliothèque de la Pléiade », 1950.

—. OEuvres dramatiques II. Trad. M. Guizot. Paris : Henri Béziat, s.d.

-. The Tempest, Twelfth Night, A Midsummer Night's Dream, As You Like Iit. New York: Pocket Books, 1964.

Shek, Ben-Zion. Social Realism in the French-Canadian Novel. Montréal : Harvest House, 1977.

-.French-Canadian \& Québécois Novels. Toronto : Oxford University Press, 1991.

Shellens, J.-J., et J. Mayer, dir. Encyclopédie universelle 2. Verviers : Marabout Université, 1962.

Shelley, Percy Bysshe. Poems by Shelley. Vols. I et II. Ed. Edward Dowden. New York: The Co-operative Publication Society, $1910 ?$

Sherif, Muzafer, and Hadley Cantril. The Psychology of EgoInvolvements. New York: John Wiley \& Sons, 1947. 
Siegfried, André. Le Canada. Puissance internationale. Paris : Armand Colin, 1939.

Sillamy, Norbert. Dictionnaire de la psychologie. Paris : Larousse, 1965.

Simard, Jean. Mon fils pourtant heureux. Montréal : Le Cercle du Livre de France, 1956.

- Les Sentiers de la nuit. Montréal: Le Cercle du Livre de France, 1959.

—. Répertoires. Montréal : Le Cercle du Livre de France, 1961.

—. Treize récits. Montréal : Hurtubise HMH, coll. «L'arbre », vol 3, 1964.

—. Nouveaux répertoires. Montréal : Hurtubise HMH, 1965.

Simenon, Georges. The Blue Room. Trad. Eileen Ellenbogen. New York : The New American Library, 1964.

—. L'Ami d'enfance de Maigret. Paris : Presses de la Cité, 1968.

—. Maigret et le tueur. Paris : Presses de la cité, 1969.

—. Quand j'étais vieux. Paris : Presses de la cité, 1970.

—. Mémoires intimes. Paris : Presses de la cité, 1981.

Simeon, Richard, ed.Must Canada Fail? Montreal: McGillQueen's Press, 1977.

Simon, P.H. Histoire de la littérature française contemporaine I. Paris : Armand Colin, 1956.

Simon, Claude. Le Vent. Tentative de restitution d'un retable baroque. Paris : Éditions de Minuit, 1957.

—. L'Herbe. Paris : Éditions de Minuit, 1958.

—. La Route des Flandres. Paris : Éditions de Minuit, 1960.

—. Histoire. Paris : Éditions de Minuit, 1967.

—. Histoire. 1967. Paris : Gallimard, coll. « Folio », 1973. 
—. La Bataille de Pharsale. Paris : Éditions de Minuit, 1969.

—. Les Corps conducteurs. Paris : Éditions de Minuit, 1971.

—. Les Géorgiques. Paris : Éditions de Minuit, 1981.

Simonin, Albert. Touchez pas au grisbi. Paris : Gallimard, 1953.

Simpson, George Gaylord. The Meaning of Evolution. New York: The New American Library, 1951.

Sirois, Antoine. Montréal dans le roman canadien. Montréal : Marcel Didier, 1968.

Smart, Patricia. Hubert Aquin, agent double. Montréal : Presses de l’Université de Montréal, 1973.

—. Écrire dans la maison du père. Montréal : Québec/Amérique, 1988.

Smirnoff, Victor. La Psychanalyse de l'enfant. Paris : PUF, 1966.

Smith, A.J.M., ed. Masks of Fiction: Canadian Critics on Canadian Prose. Toronto: McClelland \& Stewart, 1961. (2)

Smith, André. L'Univers romanesque de Jacques Godbout. Montréal : Aquila, coll. «Figures du Québec », 1976. (2)

Smith, Donald. Gilles Vigneault, conteur et poète. Montréal : Québec/Amérique, 1984.

—. L'Écrivain devant son œuvre. Montréal : Québec/Amérique, 1984.

Smollett, Tobias George. The Expedition of Humphrey Clinker. New York: Rinehart \& Co. 1950.

Solomon, Michael. Magadan. Montréal : Chateau Books, 1971.

Sontag, Susan. L'OEuvre parle. Trad. Guy Durand. Paris : Seuil, 1968.

Sorel, Pierre. OEil pour œil. Montréal : Québec/Amérique, 1981. 
Soupault, Philippe.Alfred de Musset. Paris: Seghers, coll. «Poètes d'aujourd'hui », 1957.

—. Lautréamont. Paris : Seghers, coll. "Poètes d'aujourd'hui », 1960.

Spettigue, Douglas 0. Many Mansions. Ottawa : University of Ottawa Press, 1976.

Spitz, René A. De la naissance à la parole. La première année de la vie. Trad. Liliane Flourney. Paris : PUF, 1968.

Starobinski, Jean. L'OEil vivant. Paris : Gallimard, 1961.

Stein, Conrad. La Mort d'CEdipe. Paris : Denoël/Gonthier, 1977.

Steinbeck, John. The Grapes of Wrath. 1939. New York: Viking Press, 1960.

—. The Pearl. 1945. New York : Bantam, 1983.

Stéphane, André. L'Univers contestationnaire ou les nouveaux chrétiens. Étude psychanalytique. Paris : Payot, 1964.

Stewart, Pierre. L'Amour d'une autre. Montréal : Pierre Tisseyre, 1975.

Stratford, Philip, éd. Stories from Quebec. Toronto : Van Nostrand and Reinhold, 1974.

Sullivan, J.W.N. The Limitations of Science. 1933. New York: New American Library, 1949.

Sutherland, Ronald. Second Image: Comparative Studies in Quebec/Canadian literature. Toronto: New Press, 1971.

-. Where do the MacDonalds Bury Their Dead. Don Mills, ON: General Publishing, 1976.

-. The New Hero: Essays in Comparative Quebec/Canadian Literature. Toronto: Macmillan, 1977.

—.Un héros nouveau. Trad. Jacques de Roussan. Montréal: Pierre Tisseyre, 1979. 
Swenson, Eric, ed. Famous French Short Stories. Montreal: Pocket Books, 1947.

Sylvestre, Guy. Sondages. Montréal : Beauchemin, 1945.

—. Impressions de théâtre. Ottawa : Le Droit, 1950.

-. Anthologie de la poésie canadienne-française. Montréal: Beauchemin, 1963.

-. Panorama des lettres canadiennes-françaises. Québec: Ministère des affaires culturelles, 1964. (2)

Sylvestre, Guy, dir. Structures sociales $d u$ Canada français. Québec/Toronto: Presses de l'Université Laval \& University of Toronto Press, 1966.

Sylvestre, Guy, et $\mathrm{H}$. Gordon Green. Un siècle de littérature canadienne. Montréal : Hurtubise HMH, 1967.

Szucsany, Désirée. Le Violon. Montréal: Québec/Amérique, 1981.

\section{$T$}

Taché, Jean-Charles. Les Soirées canadiennes. Trois légendes de mon pays.Québec, 1861.

- Les Soirées canadiennes. Trois légendes de mon pays. Montréal : P.-J. Delisle, 1882.

Taine, H. La Fontaine et ses fables. 1860. Paris : Hachette, 1952.

Tajan, Alfred, et René Volard. Le Troisième Père : Symbolisme et dynamique de la rééducation. Paris : Payot, 1973.

Tard, Louis-Martin. Vingt ans de théâtre au nouveau monde. Histoire d'une compagnie théâtrale canadienne. Montréal: Éditions du Jour, 1971. 
Tardif, Thérèse. La Vie quotidienne, roman. Montréal : Chez l'auteure (L'imprimerie Saint-Joseph), 1951.

Taubman, Robert. The Penguin Book of Modern European Short Stories. Harmondsworth : Penguin, [1969].

Taylor Bradford, Barbara. Les Voix du cœur. Trad. Michel Ganstel. Paris : Pierre Belfond, 1983.

Tétreau, Jean. Le Moraliste impénitent. Paris: Éditions de la Diaspora française, 1965.

—. Les Nomades. Montréal : Éditions du Jour, 1967.

-. Volupté de l'amour et de la mort; histoires fantastiques. Montréal : Éditions du Jour, 1968.

—. Treize histoires en noir et blanc. Montréal : Éditions du Jour, 1970.

Thackeray, W. M. The History of Henry Esmond Esquire. London and New York: J. M. Dent \& Sons Ltd. and E.P. Dutton \& Co., 1931.

Thériault, Marie José.Pourtant le sud...; poème. Montréal : Hurtubise HMH, 1972.

—. La Cérémonie; contes. Montréal : La Presse, 1978.

—. Lettera amorosa. Montréal : Hurtubise HMH, 1978.

Thériault, Yves. Contes pour un homme seul. Montréal : Éditions de l'Arbre, 1944.

-. Contes pour un homme seul. Montréal : Hurtubise HMH, coll. « L'Arbre », 1965.

—. La Fille laide. Montréal : Beauchemin, 1950. (2)

—. La Fille laide. 1950. Montréal : Éditions de l'Homme, 1962.

—. La Fille laide. 1950. Montréal : Éditions de l’Homme, 1965. (2) 
—. Le Dompteur d'ours. Montréal : Le Cercle du Livre de France, 1951.

—. Le Dompteur d'ours. 1951. Montréal : Éditions de l'Homme, 1965.

—. Les Vendeurs du temple. Québec: Institut littéraire de Québec, 1951.

-. Les Vendeurs du temple. 1951. Montréal: Éditions de l'Homme, 1964.

—. Aaron. Paris : Bernard Grasset, 1957.

-. Agaguk. Québec: Bernard Grasset-Institut littéraire de Québec, 1958.

—. Agaguk. 1958. Montréal : Éditions de l’Homme, 1961.

—. Agaguk. 1958. Montréal : L’Actuelle, 1971.

—. Agaguk. 1958. Montréal : Quinze, 1981.

—. Roi de la Côte Nord. Montréal : Éditions de l'Homme, 1960.

- Les Commettants de Caridad. Québec: Institut littéraire de Québec, 1961.

—. Amour au goût de mer. Montréal : Beauchemin, 1961.

—. Le Vendeur d'étoiles et autres contes. Montréal : Fides, 1961.

—. Séjour à Moscou. Montréal : Fides, 1961.

—.Cul-de-sac. Québec : Institut littéraire de Québec, 1961.

—. Cul-de-sac. Québec : Le Club des livres à succès, 1961.

—. Cul-de-sac. 1961. Montréal : Éditions de l’Homme, 1968.

—. Si la bombe m'était contée. Montréal : Éditions du Jour, 1962.

- Le Grand Roman d'un petit homme. Montréal : Éditions du Jour, 1963.

—. La Rose de pierre. Montréal : Éditions du Jour, 1964. 
—. L'Appelante. Montréal : Éditions du Jour, 1967.

—. Kesten. Montréal : Éditions du Jour, 1968.

—. Mahigan. Montréal : Leméac, 1968.

—. La Mort d'eau. Montréal : Éditions de l'Homme, 1968.

—. N'Tsuk. Montréal : Éditions de l'Homme. 1968.

—. Le Marcheur. Montréal : Leméac, 1968.

—. L'Île introuvable. Montréal : Éditions du Jour, 1968. (2)

-. Tayaout, fils d'Agaguk. Montréal: Éditions de l'Homme, 1969.

- Textes et documents. (Choix des textes, présentation et documention : Rénald Bérubé.) Montréal : Leméac, 1969.

-. Antoine et sa montagne. Montréal : Éditions du Jour, 1969.

—. Le Dernier Havre. Montréal : L’Actuelle, 1970.

- Fredange, suivi de Les Terres neuves. Montréal: Leméac, 1970.

—. La Passe-au-crachin. Montréal : Ferron éditeur, 1972.

—. Le Ru d'lkoué. Montréal : Fides, 1973.

—. Le Haut Pays. Montréal : Ferron éditeur, 1973.

—. OEuvres de chair. Montréal : Stanké, 1975.

—. Agoak, l'héritage d'Agaguk. Montréal : Quinze, 1975.

—. Moi, Pierre Huneau. Montréal : Hurtubise HMH, 1976.

—. La Quête de l'ourse. Montréal: Stanké, 1980.

Thério, Adrien. Jules Fournier, journaliste de combat. Montréal : Fides, 1954.

-. La Soif et le Mirage. Montréal : Le Cercle du Livre de France, 1960. 
-. Flamberge au vent; roman jeunesse. Montréal : Beauchemin, 1961.

-. Mes beaux meurtres. Montréal : Le Cercle du Livre de France, 1961.

—. Mes beaux meurtres. 1961. Montréal : Le Cercle du Livre de France, 1973.

—. Les Brèves Années. Montréal : Fides, 1961.

-. Le Printemps qui pleure. Montréal: Éditions de l'Homme, 1962.

-. Ceux du Chemin-Taché. Montréal: Éditions de l'Homme, 1963.

—. Les Renégats. Montréal : Jumonville, 1964.

-. Le Mors aux flancs. Montréal : Jumonville, 1965.

-. Soliloque en hommage à une femme. Montréal : Le Cercle du Livre de France, 1968.

-. Un païen chez les pingouins. Montréal : Le Cercle du Livre de France, 1970.

—. Les Fous d'amour. Montréal : Jumonville, 1973.

—. La Colère du père. Montréal : Jumonville, 1974.

—. Ignace Bourget, écrivain. Montréal : Jumonville, 1975.

—. La Tête en fête. Montréal : Jumonville, 1975.

—. Des choses à dire (journal littéraire 1973-1974). Montréal : Jumonville, 1975.

—. C'est ici que le monde a commencé. Montréal : Jumonville, 1978.

—. Le Roi d'Aragon. Montréal : Jumonville, 1979.

—. Marie-Ève, Marie-Ève. Montréal : Québec/Amérique, 1983. (2) 
Thério, Adrien, dir. Conteurs canadiens-français. Montréal : Librairie Déom, 1965.

-. L'Humour au Canada français, anthologie. Montréal : Le Cercle du Livre de France, 1968.

- Livres et auteurs québécois 1972. Montréal : Éditions Jumonville, 1972.

Thibaudet, Albert. Histoire de la littérature française de 1789 à nos jours. Paris : Stock, 1936.

Thorburn, Hugh G., ed. Party Politics in Canada. Scarborough: Prentice-Hall, 1963.

Tiger, Lionel. Optimism. The Biology of Hope. New York: Simon and Schuster, 1979.

Tiger, Lionel, et Robin Fox. L'Animal impérial. Paris : Editions du Jour/Robert Laffont, 1973.

Todorov, Tzvetan. Introduction à la littérature fantastique. Paris : Seuil, 1970.

Toffler, Alvin. Le Choc du futur. Paris : Denoël/Gonthier, 1971.

Tolstoi, Leo. Katia. Trad. Le Comte d'Hauterive. Paris : Librairie Plon, 1930.

—. Anna Karénine. Trad. Henri Mongault. Paris: Gallimard, 1948.

-. La Guerre et la Paix. Tomes I et II. Trad. J.-W Bienstock et P. Laurent. Verviers : Gérard \& Co., coll. « Marabout », 1955.

Tolstoy, Leo. War and Peace. Trad. Louise \& Alymer Maude. New York : Simon and Schuster, 1942.

Tougas, Gérard. Les O.N.U.Siens. Paris: Société Commerciale d'Édition et de Librairie, 1951.

—. Liste de référence d'imprimés relatifs à la littérature canadienne-française. Vancouver: University of British Columbia Library, 1958. 
-. La Littérature canadienne-française. Paris : PUF, 1960.

-. Histoire de la littérature canadienne-française. Paris : PUF, 1960. (2)

-. Littérature romande et culture française. Paris: Seghers, 1963.

-. Histoire de la littérature canadienne-française. $2^{\mathrm{e}}$ éd. Paris : PUF, 1964. (2)

—. La Francophonie en péril. Montréal : Le Cercle du Livre de France, 1967.

-. Littérature canadienne-française contemporaine. Toronto: Oxford University Press, 1969.

-. Les Écrivains d'expression française et la France. Paris: Denoël, 1973.

-.Puissance littéraire des États-Unis. Montréal : Éditions l'Âge d'homme, 1979.

—. Destin littéraire du Québec. Montréal: Québec/Amérique, 1982.

Toupin, Paul. Le Mensonge. Montréal : L'Hexagone, 1960.

-. Théâtre : Brutus, Le Mensonge, Chacun son amour. Montréal : Le Cercle du Livre de France, 1961.

- L'Écrivain et son théâtre. Montréal : Le Cercle du Livre de France, 1964.

-. La Nouvelle Inquisition, récit. Montréal: Pierre Tisseyre, 1975.

Tour Fondue, Geneviève de la. Interviews canadiennes. Montréal : Éditions Chantecler, 1952.

La Tourmente, Recueil littéraire des Etudiants de la Faculté des Lettres de l'Université Laval. Saint-Hyacinthe: Yamaska, 1966. 
La Tourmente, Recueil littéraire des Etudiants de la Faculté des Lettres de l'Université Laval. Saint-Hyacinthe: Yamaska, 1967.Tranquille, Henri. Lettres d'un libraire. Tomes I et II. Montréal : Leméac, 1976.

-, et Jean-Jules Richard. Des lettres sur nos lettres - écrivains, éditeurs, critiques, libraires, lecteurs. Montréal : Bergeron, 1984.

Tremblay, Michel, Contes pour buveurs attardés. Montréal : Éditions du Jour, 1966. (2)

—. Les Belles-Sours. Montréal : Holt Rinehart et Winston, 1968.

—. La Cité dans l'œuf. Montréal : Éditions du Jour, 1969.

—. À toi, pour toujours, ta Marie-Lou. Montréal : Leméac, 1971.

—. En pièces détachées. 1970. Montréal : Leméac, 1972.

—. C't'à ton tour, Laura Cadieux. Montréal : Éditions du Jour, 1973.

—. La Grosse Femme d'à côté est enceinte. Montréal : Leméac, 1978.

—. Thérèse et Pierrette à l'école des Saints-Anges. Montréal : Leméac, 1980.

Trevisan, Dalton. The Vampire of Curitiba and Other Stories. Trans. Gregory Rabassa. New York: Alfred A. Knopf, 1972.

Trottier, Pierre. Les Belles au bois dormant. Montréal : L'Hexagone, 1960. (2)

—. Mon Babel. Montréal : Hurtubise HMH, 1963.

Troyat, Henri. Dostoïevski. 1940. Bruxelles : Librairie Arthème Fayard, 1960.

- La Lumière des justes. Sophie ou la fin des combats. Paris : Flammarion, 1963.

—. Tchekhov. Paris : Flammarion, 1984. 
Trudeau, Pierre Elliott. La Grève de l'amiante. Montréal : Éditions Cité libre, 1956.

Trudel, Marcel. L'Influence de Voltaire au Canada. Tomes I et II. Montréal : Fides, 1945.

—. Chiniquy. Trois-Rivières : Éditions du Bien public, 1955.

—. L'Esclavage au Canada français. Montréal : Horizon, 1960.

Turgeon, Louis. La Face humaine analysée. Montréal : Éditions de Mortagne, 1984.

Turgeon, Pierre. Faire sa mort comme faire l'amour. Montréal : Éditions du Jour, 1969.

—.Un, deux, trois. Montréal : Éditions du Jour, 1970.

—. Prochainement sur cet écran. Montréal : Éditions du Jour, 1973.

—. La Première Personne. Montréal : Quinze, 1980.

Turnbull, Jane M.Essential Traits of French-Canadian Poetry. Toronto: Macmillan, 1938.

Twain, Mark. The Adventures of Huckleberry Finn. New York: Harper \& Brothers, 1923.

-. Le Prince et le Pauvre. Trad. Jean Muray. Paris : Hachette, 1953.

$\boldsymbol{U}$

Untermeyer, Louis, ed. The Book of Living Verse. New York: Harcourt Brace, 1945.

\section{$\boldsymbol{V}$}


Vac, Bertrand [Aimé Pelletier]. Louise Genest. Montréal : Le Cercle du Livre de France, 1950.

—. Histoires galantes. Montréal : Le Cercle du Livre de France, 1965.

Vachon, André, éd. Éloquence indienne. Textes choisis, présentés et annotés par André Vachon. Montréal: Fides, coll. « Classiques canadiens », 1968.

Vachon, Louis-Albert. Les Humanités aujourd'hui. Québéc: Presses de l'Université Laval, 1966.

Vadeboncoeur, Pierre. La Ligne du risque; essais. Montréal : Hurtubise HMH, coll. « Constantes », vol. 4, 1963.

—. L'Autorité du peuple. Bourgainville : Éditions de l'Arc, 1965.

—. Un amour libre. Montréal : Hurtubise HMH, 1970.

Valensin, Georges. Adolescence et sexualité. Paris : Éditions de la Table ronde, 1967.

Valéry, Paul. Variété. Paris : Gallimard, 1924.

—. Variété II. Paris : Gallimard, 1930.

—. Regards sur le monde actuel. Paris : Stock, 1931.

—. OEuvres. Paris : Gallimard, coll. "Bibliothèque de la Pléiade», 1957.

Vallières, Pierre. Nègres blancs d'Amérique. Montréal : Parti pris, 1968.

-. White Niggers of America. Trans. Joan Pinkham. Toronto: McClelland \& Stewart, 1971.

Valois, Marcel. Au carrefour des souvenirs. Montréal : Beauchemin, 1965.

Vanasse, André. La Saga des Lagacé. Montréal : Libre Expression, 1980. 
Vandendorpe, Christian, dir. Découvrir le Québec, un guide culturel. Québec : Québec français, 1984.

Van Roey-Roux, Françoise. La Littérature intime du Québec. Montréal : Boréal Express, 1983. (2)

Van Schendel, Michel. Poèmes de l'Amérique étrangère. Montréal : L'Hexagone, 1958.

Van Schendel, Michel, et al. La Poésie et nous. Montréal : L'Hexagone, coll. « Les Voix », 1958.

Van Tieghem, Philippe. Technique du théâtre. Paris : PUF, coll. «Que sais-je?», 1960.

—. Le Romantisme français. PUF, coll. « Que sais-je? », 1963.

Vercors [Jean Bruller]. Les Animaux dénaturés, suivi de La marche à l'étoile. Paris : Albin Michel, 1952.

Verlaine, Paul. Choix de poésies. Préface de Francois Coppée. Paris : Charpentier-Fasquelle, 1939.

—. OEuvres poétiques complètes. Éd. Y.-G. Le Dantec. Paris : Gallimard. coll. « Bibliothèque de la Pléiade », 1948.

Verne, Jules. Voyage au centre de la terre. Paris: J. Hetzel / Hachette, 1966.

Verniolles, M. l'abbé J.Cours élémentaire de rhétorique et d'éloquence. Paris : Delagrave, 1927.

Verstraeten, Pierre, dir. Autour de Jean-Paul Sartre. Littérature et philosophie. Paris : Gallimard, 1981.

Viatte, Auguste. Histoire littéraire de l'Amérique française. Québec: Presses de l'Université Laval, 1954.

Viau, Roger. Au milieu, la montagne. Montréal: Beauchemin, 1951.

-. Contes en noir et en couleur. Montréal : Éditions de l'Arbre, 1948. 
—. La Peinture moderne au Canada français. Québec : Ministère des Affaires culturelles, 1964.

Vigneault, Gilles. Étraves. Montréal : Éditions de l'Arc, 1959. (2)

-. Contes sur la pointe des pieds. Montréal : Éditions de l'Arc, 1960.

—. Avec les vieux mots. Montréal : Éditions de l’Arc, 1964.

—. Balises. Montréal : Éditions de l'Arc, 1965.

- Quand les bateaux s'en vont. Montréal: Éditions de l'Arc, 1965.

- Pour une soirée de chansons. Montréal : Éditions de l'Arc, 1965.

—. Contes du coin de l'œil. Montréal : Éditions de l'Arc, 1966.

Vigneault, Robert. Saint-Denys Garneau à travers «Regards et jeux dans l'espace». Montréal: Presses de l'Université de Montréal, 1973.

Vigneault, Robert, dir. Langue, littérature, culture au Canada français. Ottawa: Cahiers du Centre de Recherche en civilisation canadienne-française, $n^{\circ} 12$, Éditions de l'Université d'Ottawa, 1977.

Vigny, Alfred de. Poésies. Paris : Librairie Gründ, 1937.

—. Servitude et grandeur militaires. Paris : Nelson, 1949.

Viallaneix, Paul. Vigny par lui-même. Paris: Seuil, coll. «Écrivains de toujours », 1964.

Villemaire, Yolande. Meurtres à blanc. Montréal : Guérin, coll. « Le Cadavre exquis », 1974.

—. La Vie en prose. Montréal : Les Herbes rouges, 1980.

Villeneuve, Paul. J'ai mon voyage. Montréal : Éditions du Jour, 1969. 
—.Johnny Bungalow: chronique québécoise, 1937-1963. Montréal : Éditions du Jour, 1974.

Vincens, Simone. Madame Montour et son temps. Montréal : Québec/Amérique, 1979.

Voix des poètes. Montréal : Éditions Variétés, 1945.

Voltaire [François-Marie Arouet]. Le Siècle de Louis XIV. Paris : Firmin Didot Frères, fils et Co., 1872.

-. Romans. Présenté par Roger Peyrefitte. Paris : Librairie Générale Française, 1968.

Voorhies, Felix. Acadian Reminisciences. The True Story of Evangeline. Gretna, Louisiana : 1907.

W

Wade, Mason. Canadian Dualism. La Dualité canadienne. Toronto/Québec : Presses de l'Université Laval, 1960.

-. Les Canadiens français, de 1760 à nos jours. Tome II (19111963). Trad. Adrien Venne. Montréal : Le Cercle du Livre de France, 1963.

Walker, John, ed.The South American Sketches of R.B. Cunninghame Graham.Norman, Oklahoma : University of Oklahoma Press, 1978.

Walker, Kenneth. The Physiology of Sex. Harmondsworth: Penguin, 1949.

Wallace, Irving. The Man. New York.: Fawcett Crest, 1964.

Ward, Barbara. Faith and Freedom. 1954. Garden City, NY: Image, 1958.

Warren, Mark. The Making of a Modern Psychiatrist. Garden City, NY: Doubleday, 1986. 
Warwick, Jack. The Long Journey: Literary Themes of French Canada. Toronto: University of Toronto Press, 1968.

Warwick, Jack. L'Appel du nord dans littérature canadiennefrançaise. Trad. Jean Simard. Montréal : Hurtubise HMH, coll. «Constantes », vol. 30, 1972.

Watt, Homer A., Karl J. Holzknecht, and Raymond Ross. Outlines of Shakespeare's Plays. New York: Barnes and Noble, 1957.

Weber, J.-Paul. Genèse de l'œuvre poétique. Paris : Gallimard, 1960.

Weinmann, Heinz. Du Canada au Québéc: Généalogie d'une histoire. Montréal : L’Hexagone, 1978.

Wellek, René, and Austin Warren. Theory of Literature. New York: Harcourt, Brace \& Co., 1956.

Wells, H.G. The Outline of History. Vols I and II. New York: Garden City Books, 1949.

West, Morris. Un monde transparent. Montréal : Québec/Amérique, 1983.

Whyte, L.L. The Next Development in Man. New York: New American Library, 1950.

Wilhelm, Bernard. Lettres du Canada. Montréal : Éditions Cosmos, 1971.

Willoughby, Westel Woodbury. An Examination of The Nature of the State : A Study in Political Philosophy. New York : Macmillan \& Co., 1896.

Wilson, Edmund. O Canada: An American's Notes on Canadian Culture. New York : Noonday Press, 1966.

Wilson, Sloan. The Man in the Gray Flannel Suit. New York: Pocket Books, 1964.

Woolf, Virginia. To the Lighthouse. New York : The Modern Library, 1927.

Woolf, Virginia. L'Art du roman. Trad. Rose Celli. Paris : Seuil, 1940. 
Wyczynski, Paul. Émile Nelligan: sources et originalité de son œuvre.Ottawa : Éditions de l'Université d'Ottawa, 1960.

-. Émile Nelligan. Montréal : Fides, coll. «Écrivains canadiens d'aujourd'hui », 1967.

- Nelligan et la musique. Ottawa : Éditions de l'Université d'Ottawa, 1971.

-. Bibliographie descriptive et critique d'Émile Nelligan. Ottawa: Éditions de l'Université d'Ottawa, coll. «Bibliographies du Canada français », 1973.

Wyczynski, Paul et al. Archives des lettres canadiennes, tome I: Mouvement littéraire de Québec, 1860. Bilan littéraire de l'année 1960. Ottawa : Éditions de l'Université d'Ottawa, 1961.

—. L'École littéraire de Montréal. Bilan littéraire de l'année 1961. Montréal : Fides, «Archives des lettres canadiennes », t. II, 1963.

-. Le Roman canadien-français. Évolution-TémoignagesBibliographie. Montréal : Fides, coll. "Archives des lettres canadiennes », tome III, 1964.

$\boldsymbol{Y}$

Young, Frank Rudolph. The Secrets of Personal Psychic Power. New York: Paperback Library, 1969.

Young-Bruehl, E. Anna Freud. New York : Summit Books, 1988.

$Z$

Zavattini, Cesare. Les Pauvres sont fous, suivi de Je suis le diable. Trad.

Nino Frank. Paris : Julliard, coll. « Lettres nouvelles », 1965.

Zola, Émile. Germinal. 1885. Paris : Fasquelle, 1955. 